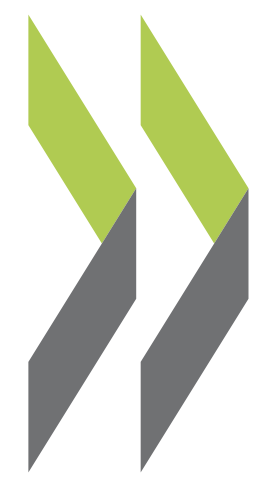

OECD Economics Department Working Papers No. 56

\title{
On Aggregation Methods of Purchasing Power Parities
}

\author{
J. R. Cuthbert, \\ M. Cuthbert
}




\section{OECD \\ DEPARTMENT \\ OF ECONOMICS AND STATISTICS}

\section{WORKING PAPERS}

NO. 56: ON AGGREGATION METHODS OF PURCHASING POWER PARITIES

J. R. Cuthbert and M. Cuthbert

November 1988

0CD菅

需角而

(0) 
GENERAL DISTRIBUTION

\title{
BCONOHICS AND STATISTICS DEPARTHENT
}

\section{VORRING PAPERS}

\begin{abstract}
This series of Working Papers is designed to make available, to a wider readership, selected studies which the Department has prepared for use within OECD. Authorship is generally collective, but main individual authors are named. The Papers are generally available in their original language, English or French, with a summary in the other.

Comment on the Papers is invited, and may be sent to OECD, Department of Economics and Statistics, 2 rue André Pascal, 75775 Paris Cedex 16, France. Additional copies of the Papers on a limited basis can be forwarded on request.
\end{abstract}

ORGANISATION FOR BCONOHIC CO-OPERATION AND DEVELOPMENT

Copyright OECD 1988 16696 
The development of purchasing power parities as converters of national accounts aggregates to comparable volume figures is important for international economic comparisons. This study is primarily concerned with the aggregation of price relativities to basic heading level: that is, the level below which there are no expenditure weights available across all of a given group of countries. Eight possible methods of aggregation to basic heading level are identified and appropriate sumary statistics developed to assist in the subsequent practical investigation of these methods. This is undertaken using price data for 37 basic headings in ten OECD countries.

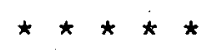

Pour les comparaisons économiques internationales il est important de développer les calculs de parités de pouvoir d'achat. En effet, ces parités permettent de convertir les agrégats de comptabilité nationale et donc de disposer de chiffres en termes réels qui sont comparables de pays à pays. Cette étude porte principalement sur les problèmes d'agrégation des prix relatifs des biens ou services individuels jusqu'au niveau des rubriques de base, c.a.d. Le niveau le plus fin pour lequel une pondération par la dépense est disponible, pour tous les pays comparés. L'étude montre que huit méthodes différentes d'agrégation peuvent être employées et propose des mesures statistiques pour examiner les avantages et inconvénients de chacune de ces méthodes en pratique. Les données sur les prix de 37 rubriques de base dans dix pays de l'OCDE sont utilisées pour tester les différentes méthodes d'agrégation. 
10. 56: ON AGGREGATIOA METHODS OF PURCAASING POWER PARITIES

by

J. R. Cuthbert and M. Cuthbert

This work was carried out during the tenure of an OECD consultancy. ' J.R. Cuthbert is the Chief Statistician of the Scottish office, Edinburgh. $M$. Cuthbert teaches at the Department of Business Organisation, Heriot Watt University, Edinburgh. 
ON AGGREGATION NATHODS OF PORCHASIMG PONER PARIYIES

TABLE OF CONTENTS

Page

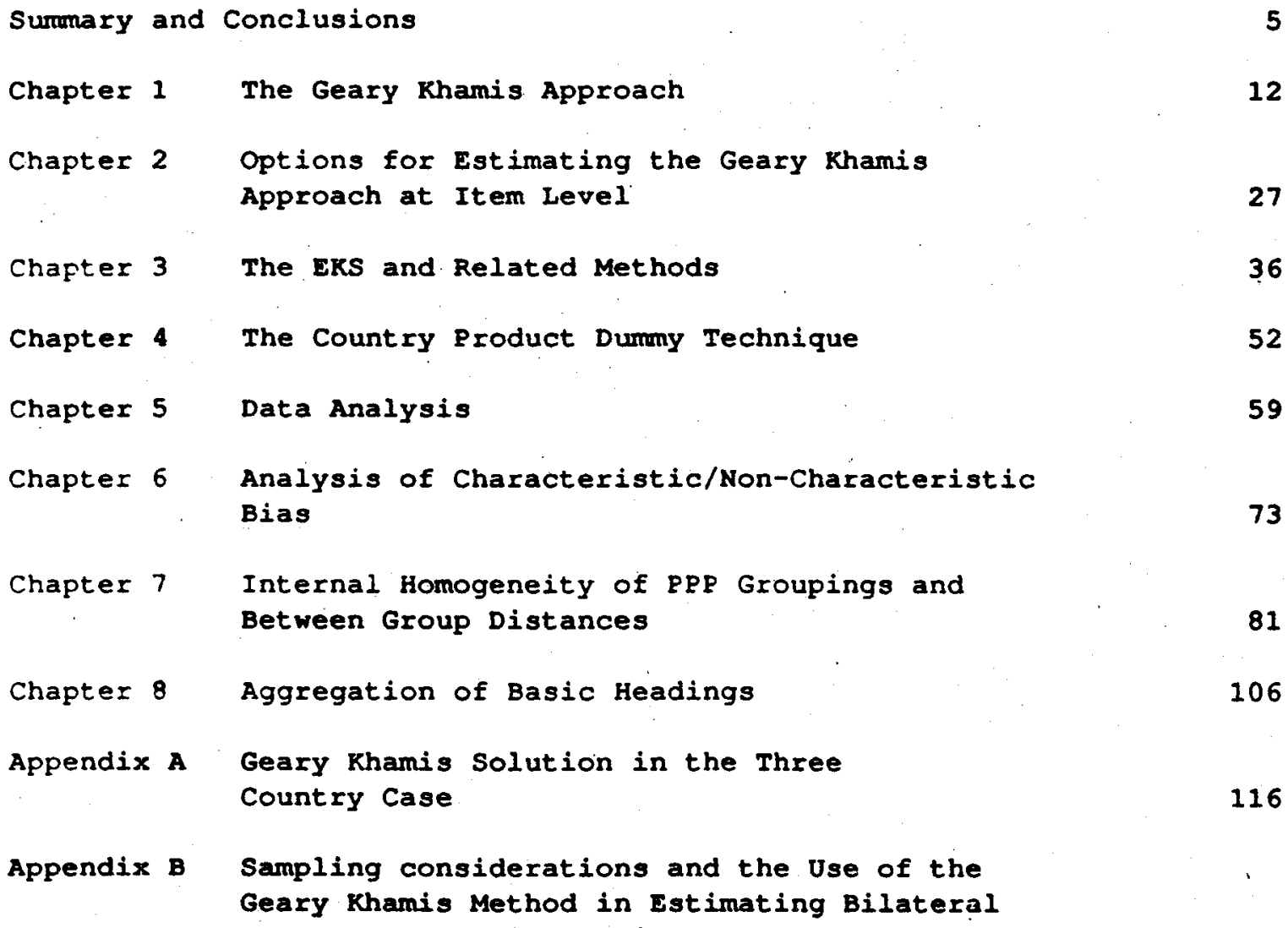


SUMMARY AND CONCLUSIONS.

A major problem in international comparison work is the development of purchasing power parities in their role as convertors of national accounts aggregates from nominal values to comparable real volume figures. This study is primarily concerned with the aggregation of price relativities to basic heading level: here, a basic heading is defined as the lowest level for which expenditure figures are available for a given group of countries. Aggregation to basic heading level must therefore take place in the context of limited information; typically, price data will be available while expenditle or quantity information will be limited or unavailable.

The study contains four main strands:

(i) an introductory discussion of some of the main aggregation methods :- the Geary Khamis method, normally used from basic heading level to GDP level: the fisher / EKS approach and the Country Product Dummy (CPD) method;

(ii) the development of new work on the theory of the three methods. This theoretical work contributes to a general understanding of the workings of these techniques and some of their weaknesses: in addition, it leads to the suggestion of eight possible methods of aggregation to basic heading level for further practical investigation.

(iii) the development of appropriate summary statistics to help in the data analysis. Specifically, there is developed (a) a 
summary statistic to provide a measure of the similarity.

between PPPs and (b) a statistic to measure how multiplicative the structure of aiven set of prices is; that is, how closely the structure of a set of prices approximates to the simple product of item and country. effects.

(iv) an analysis of price and expenditure data for 37 basic headings in 10 OECD countries. The data is aggregated for each basic heading by each of the eight mothods under investigation, and the resulting PPP structures analysed.

In more detail, the contents of the individual chapters are as follows :

In chapter 1, the theory of the Geary Khamis approach $[1,2]$ is introduced and then developed. The Geary Khamis equations are stated and explicit solutions of these equations for the 2, 3, and general n country cases are determined. Important special properties of the this approach are derived. In particular, it is shown that when the structure of prices is multiplicative, the Geary Khamis Purchasing Power Parity solution is independent of the quantities of goods traded.

Typically, in international comparisons, the Geary Khamis, (GK), approach is used to aggregate price parities from basic heading level to GDP level.

Chapter 2 continues the discussion of the GK theory, and 
develops options for extending this approach so that it can be applied in aggregating from individual commodities to basic headings. Three possible approaches are suggested :-

The first is based on developing an appropriate sampling design. This approach is most relovant in the two country case - and is set out in Appendix $B$.

The second is based on assigning imputed quantities, and solving the full Geary Khamis equations. Three methods of imputing quantities are suggested.

The final approach is based on exploitino spocial characteristics of the price structure - in particular, where the price structure is nearly multiplicativo.

Chapter 3 develops the theory of the Fisher index [3], and the EKS approach $[4,5]$ from a statistical viewpoint. By considering a parametric formulation of the PPP estimation problem, alternative estimators of PPPs, based on a regression analysis of the logs of the Fisher indices, are derived. It is shown that the standard EKS approach will normally be sub optimal relative to these alternative approaches. Two versions of the log fisher regression technique are developed - one of which allows explicitly for the possibility of a consistent pricing differential botween characteristic and non characteristic goods: that is, between goods which are in some sense typical and those which are untypical in the country concerned. 
in chapter 4, the thoory behind the Country Product Dummy (CPD) approach $[7,8]$ is considered. It is shown how this technique can be modified to incorporate the possibility of a consistent pricing differential between characteristic and non characteristic goods. It is also shown that, even where such a systematic pricing effect exists, the decision of whether or not to correct for this effect depends on the circumstances of each case.

Chapter 5 contains the necessary proliminaries to the detailed analysis of actual price data described in the later chapters of the report.

The data analysed is described: ( 37 product groupings over ten countries).

The PPFs to be calculated from item level to basic heading level are defined. There are 8 of these, falling into three main families: three in the EKS family; three versions of the GK; and two versions of the CPD.

Further, to assist in the data analysis summary measures are tevelooed: in oarticular. three such statistics have been constructed: (a) a metric, to measure the distance between different PPPS; (b) a measure of the multiplicativity of the price structure;

(c) measures of within group homogeneity and between group distances, for groups of PPPs.

In chapter 6 , there is a detaijed analysis of the question of 
whether a systematic price differential oxists between characteristic and non characteristic goods. Using the modified version of the CPD approach, it is shown that a statistically significant prico differential does exist - and that its size is such as to have a potentially important operational effect. The conclusion is drawn that appropriate techniques should be used in practice, to enable these effects to be detected, and if necessary, corrected for. To do this adequately, would involve having some broad estimates of expenditure or quantities at item level.

Chapter 7 continues the detailed data analysis, by considering the internal homogeneity of the basic PPP families - and the distances between these families. It is shown that, when the price structure is highly multiplicative, the different approaches to calculating PPPs tend to converge, as the preceding theory suggests.

But, unless the price structure is highly multiplicative, the different PPP versions considered can diverge very significantly. It is also shown that, for the data analysed, the CPD family of PPPs tends, in a sense, to occupy an intermediate position between the EKS and the GK families.

The conclusion that emerges is that, unless the price structure is ihighly multiplicative, the choice of the appropriate method of calculating PPPs is by no means clear cut. Three possible approaches are suggested, not necessarily mutually exclusive; 
(a) other things boing oqual, there might be some preference for a CPD approach, as a possible compromiso, given its intermediate position relative to the other approaches.

(b) effort could be devoted to obtaining expenditure or quantity data at item level and then using a GK approach.

(c) effort could be put into collecting better expenditure data, so as to reduce the size of the basic headings. As basic headings become smaller, they are likely to become more multiplicative - and hence the choice of PPP method less critical. There are limits to this approach, however - particularly if using the CPD method, since the CPD method involves fitting a model with a relatively large number of parameters, and so cannot be applied reliably if there are too few items in a given basic heading.

Finally, chapter 8 considers the results of aggregating the basic heading level PPPs over the basic headings studied. Two methods of aggregation, the GK and Gerardi (UCW method), are used at this stage $[9,10]$. Combined with the oight methods used at the first stage, this means that sixteen aggregate PPPs in all are calculated. It is shown that there is a high degree of homogeneity within each of the six groups defined by applying either GK or Gerardi aggregation to one of the three basic PPP families. There is also a fairly high degree of homogeneity among all the GK aggregated indices - and also among all the Gerardi aggregated indices. However, there tend to be consistent differences between GK and 
Gerardi aggregated versions, even of the the same first stage indices. It is shown that these differences relate mainly to underlying US price levels being consistently higher for GK aggregated indices compared with Gerardi indices. 


\section{CHAPTER 1.}

\section{THE GEARY KHAMIS APPROACH}

\section{Introduction.}

1.: The Geary Khamis approach is one of the most commonly used methods of aggregating purchasing power comparisons from basic heading levels to GDP level. In this section the basic equations of the Geary Khamis approach are introduced. Subsequent sections of this chapter explore some of the theoretical aspects of this approach, including the explicit solution in the 2 and 3 country case, and the form of the general solution in the $n$ country case. In the next chapter, some different possible approaches to the problem of extending the GK approach to aggregation from individual item up to main heading lovel are discussed.

The Geary Khamis method determines international prices for commodities simultaneously with country PPPs at GDP level. The theory, as usually stated, proceeds in terms of there being data available on prices and quantities of individual commodities. However, the PPP solution can also be obtained from information on price relativities and expenditures by the trick of defining "pseudo" prices in terms of the price relativities at basic heading level and "pseudo" quantities as the quantity of a good which can be 
bought for one unit of the numeraire currency in the base country.

The general multilateral problem is that of determining a set of PPPs for a group of countries. Without loss of generality or the introduction of any bias to the results, one of the countries in the group is chosen as having the numeraire currency: that is, the currency to be used in the calculations as the unit of account. For each country expenditure data is expressed in national currencies for national account basic headings. In particular, GDP estimates are available:

$G D P=\sum p_{i j} q_{i j}$ $i=1, \ldots, m ; j=0,1, \ldots, n$ where $\quad \begin{aligned} p_{i j} & =\text { price of item } i \text { in country } j \\ a_{i j} & =\text { quantity of item } i \text { in country } j\end{aligned}$

If estimates of international prices, $n_{i}, i=1, \ldots m$, were available, expressed in terms of the numeraire currency, then a volume measure for each country could be defined as

$$
\Sigma \pi_{i} q_{i j}
$$

Note that the quantities of different items cannot simply be added together. For example, lengths of cable and tonnes of wheat cannot be added together. Thus the quantities have to be expressed in a common unit of account; that is, in international prices. 
Following on from this, since

$$
\text { price }=\frac{\text { expenditure }}{\text { volume }}
$$

an average price measure for country j could be derived. This is defined as

$$
\frac{\sum p_{i j} q_{i j}}{\sum n_{i} q_{i j}} \quad j=0,1, \ldots, n
$$

The purchasing power parity between countries $j$ and $k$ is defined as the ratio of the two price measures.

$$
j^{P P P_{k}}=\frac{\sum p_{i j} q_{i j}}{\sum \pi_{j} q_{i j}} / \frac{\sum p_{i k} q_{j k}}{\sum \pi_{j} q_{i k}}
$$

Geary considered that a suitable definition of the international prices of an item was the sum total of expenditures on the item throughout the countries being considered in the exercise, divided by the quantity. Again this requires a means of converting expenditures in national currencies into the numeraire currency. One way of doing this is to use the values $j^{P P P_{0}}$, where country 0 is that of the numeraire currency. Thus the international price $2 f$ commodity i is defined as

$$
\begin{aligned}
& \pi_{i}=\frac{\sum p_{i j} q_{i j} /\left({ }_{j}^{P P P_{0}}\right)}{\sum q_{j j}} \\
& i-1, \ldots, m
\end{aligned}
$$


Equations ( 1 ) and (2) dofine set of international prices $n_{j}$ and the PPPs for each country at GDP level. On noting the identity. for the numeraire country, that,

$$
\sum p_{i 0} q_{i 0}=\sum \pi_{i} q_{i 0}
$$

equation (1) in fact simplifies to

$$
{ }_{j} P P P_{0}=\frac{\sum p_{i j} q_{i j}}{\sum \pi_{i} q_{i j}}
$$

\section{The Geary Khamis Solution in the 2 and 3 Country Cases.}

2.1 In the special cases where only two or three countries are involved, it is a fairly straightforward matter to solve the basic Geary Khamis equations, Equations (1) and (2) above, explicitly. In the two country case, suppose that the countries are denoted by 0 and 1 , and that the currency of country 0 is the numeraire currency. Then the purchasing power parity, ${ }_{1} P P P_{0}$, which is denoted here by $R_{1}$, is given by the formula:

$$
R_{1}=\frac{\sum \frac{p_{i 1} a_{i 0} a_{i 1}}{a_{i 0}+a_{i 1}}}{\sum \frac{p_{i 0} a_{i 0} a_{i 1}}{a_{i 0}+a_{i 1}}}
$$


In the three country case, if the countries are denoted by 0,1 and 2, and country 0 is again taken as providing the numeraire currency, then the PPP, $R_{1}$, is given by

$R_{1}=\frac{\left(\sum \frac{p_{i 1} a_{i 0} a_{i 1}}{\left(a_{i 0}+a_{i 1}+a_{i 2}\right)}\right)\left(\frac{\left(-p_{i 2} a_{i 2}\left(a_{i 0}+a_{i 1}\right)\right.}{\left(a_{i 0}+a_{i 1}+a_{i 2}\right)}\right)+\left(\frac{p_{i 1} a_{i 1} a_{i 2}}{\left(a_{i 0}+a_{i 1}+a_{i 2}\right)}\right)\left(\frac{p_{i 2} a_{i 0} a_{i 2}}{a_{i 0}+a_{i 1}+a_{i 2}}\right)}{\left(\frac{p_{i 0} a_{i 0} a_{i 1}}{a_{i 0}+a_{i 1}+a_{i 2}}\right)\left(\left[\frac{p_{i 2} a_{i 2}\left(a_{i 0}+a_{i 1}\right)}{\left(a_{i 0}+a_{i 1}+a_{i 2}\right)}\right)+\left(\sum \frac{p_{i 0} a_{i 0} a_{i 2}}{a_{i 0}+a_{i 1}+a_{i 2}}\right)\left(\frac{p_{i 2} a_{i 1} a_{i 2}}{a_{i 0}+a_{i 1}+a_{i 2}}\right)\right.}$ --- (4)

with a corresponding expression for $R_{2}$

A derivation of equation (4) is given in Appendix $A$.

2.2 It is instructive to consider the forms of these solutions in the two and three country cases. First of all, equation ( 3 ) shows that the two country PPP is in fact a ratio of an arithmetic average of prices in country 1 to a corresponding average of prices in country 0 . The weights in these arithmetic averages are functions of the quantisies in both countries: and the form of these weights,

$\frac{a_{i 0} a_{i 1}}{\left(a_{i 0}+a_{i 1}\right)}$

is such that the greatest weight will be attached in the price comparisons to items which have relatively large quantities in both countries: conversely, items which have small quantities in either 
country will be given small weight.

The form of the three country solution, as given in equation (4), is rather more complex. $R_{\mathfrak{I}}$ is the ratio of two sums of products of price terms, where the prices are, again, weighted by functions of the quantities. The numerator of equation (4) includes prices in countries 1 and 2 ; while the denominator involves prices in countries 0 and 2. In fact the numerator and denominator of equation (4) are symmetric expressions, in the sense that the two expressions are identical if the subscripts 0 and 1 are switched with each other.

It is also interesting to consider the limiting behaviour of the three country solution, as the quantities in country 2 , the $a_{i 2}$ 's. become either very small or very large.

Suppose, for convenience, that equation (4) is written in the form

$$
R_{1}=\frac{a b+c d}{e f+g h}
$$

Consider, first of all, what happens if $a_{i 2} \rightarrow 0$ for all i.

In this case, $R_{1}$ behaves asymptotically like a/e, which, in turn, converges simply to the two country solution given in equation (3) as would be expected.

Conversely, if $a_{i 2} \longrightarrow-$ for all $i$, then $R_{1}$ behaves asymptotically as $\mathrm{cd} / \mathrm{gh}$, in the notation of equation 5 . It is readily seen that the limiting value of this expression is simply. 
18

$$
R_{1}=\frac{\sum p_{i 1} q_{i 1}}{\sum p_{i 0} q_{i 0}} \cdot \frac{\sum p_{i 2} q_{i 0}}{\sum p_{i 2} q_{i 1}}
$$

or, equivalently,

$$
R_{1}=\frac{\Sigma p_{i 1} q_{i 1}}{\sum p_{i 2} q_{i 1}} / \frac{\Sigma p_{i 0} q_{i 0}}{\sum p_{i 2} q_{i 0}}
$$

The numerator of this expression is a price level for country 1 . defined as the ratio of country 1 expenditures, to a measure of volume for country 1 determined at country 2 prices. The denominator is the corresponding price measure for country 0 . In other words, equation (6), the limiting value for $R_{1}$ as the quantities in country 2 become large, is simply the PPP between country 1 and 0 using country 2's prices as international prices. This, again, is as expected.

3. The General Gary Khamis Solution.

3.1 As noted earlier, Appendix A contains a derivation of equation (4), the explicit Gary Khamis solution in the three country case. The argument in Appendix A proceeds by showing that the country 1 and country 2 PPD's, $R_{1}$ and $R_{2}$, are solutions of the equations:

$$
\sum \frac{p_{i 1} q_{i 1}\left(a_{i 0}+q_{i 2}\right)}{\left(a_{i 0}+q_{i 1}+q_{i 2}\right)} \cdot R_{1}^{-1}-\int \frac{p_{i 2} q_{i 2} q_{i 1} \cdot R_{2}^{-1}}{\left(q_{i 0}+q_{i 1}+q_{i 2}\right)}=\sum \frac{p_{i 0} q_{i 0} q_{i 1}}{\left(a_{i 0}+q_{i 1}+q_{i 2}\right)}
$$


19

$$
-\int \frac{p_{i 1} a_{i 1} q_{i 2} \cdot R_{1}}{\left(a_{i 0}+a_{i 1}+q_{i 2}\right)}+\int \frac{p_{i 2} q_{i 2}\left(a_{i 0}+q_{i 1}\right) \cdot R_{2}^{-1}}{\left(q_{i 0}+q_{i 1}+q_{i 2}\right)}=\sum \frac{p_{i 0} a_{i 0} a_{i 2}}{\left(a_{i 0}+q_{i 1}+q_{i 2}\right)}
$$

It is not difficult to see that a similar argument can be applied in the $(n+1)$ country case, to show that $R_{1}, R_{2}, R_{3}, \ldots, R_{n}$. must be solutions of the $\underline{n}$ equations:

$$
\begin{aligned}
& \sum \frac{p_{i 1} a_{i 1}\left(a_{i 0}+a_{i 2}+\ldots+a_{i n}\right) R_{1}-1}{\left(a_{i 0}+a_{i 1}+\ldots+a_{i n}\right)}-\sum \frac{p_{i 2} a_{i 2} a_{i 1} R_{2}}{\left(a_{i 0}+\ldots+a_{i n}\right)}-\ldots-\sum \frac{p_{i n} a_{i n} a_{i 1} R_{n}^{-1}}{\left(a_{i 0}+\ldots a_{i n}\right)} \\
& \sum \frac{p_{i 0} q_{i 0} q_{i 1}}{\left(a_{i 0}+\ldots+q_{i n}\right)} \\
& -\int \frac{p_{i 1} q_{i 1} q_{i 2} R_{1}}{\left(q_{i 0}+q_{i 1} \ldots+q_{i n}\right)}+\int \frac{p_{i 2} q_{i 2}\left(a_{i 0}+q_{i 1}+q_{i 3} \ldots+q_{i n}\right) R_{2}-1}{\left(a_{i 0}+\ldots \ldots+q_{i n}\right)}-\ldots \frac{p_{i n} q_{i n} q_{i 2} R_{n}}{\left(a_{i 0}+\ldots+q_{i n}\right)} \\
& =\sum \frac{p_{i 0} a_{i 0} a_{i 2}}{\left(a_{i 0}+\ldots+q_{i n}\right)}
\end{aligned}
$$

etc.

$$
\begin{aligned}
& -\sum \frac{p_{i 1} a_{i 1} a_{i n} R_{1}}{\left(a_{i 0}+\ldots+a_{i n}\right)}-\ldots .+\sum \frac{p_{i n} a_{i n}\left(a_{i 0} \ldots+q_{i n-1}\right) R_{n}}{\left(a_{i 0}+\ldots+a_{i n}\right)} \\
& -\sum \frac{p_{i 0} a_{i 0} a_{i n}}{\left(a_{i 0}+\ldots+q_{i n}\right)}
\end{aligned}
$$


In order to simplify the way in which these equations are written, it is convenient to adopt the following special notation - which is used for the remainder of this section only.

Denote,

$$
\sum \frac{p_{i 1} a_{i 1}\left(a_{i 0}+a_{i 2}+\ldots+a_{i n}\right)}{\left(a_{i 0}+\ldots+a_{i n}\right)}
$$

as

$$
p_{1} q_{1}\left(a_{0}+a_{2}+\ldots+q_{n}\right)
$$

and

as

$$
\sum \frac{p_{i 1} a_{i 1} a_{i 2}}{\left(a_{i 0}+\ldots+a_{i n}\right)}
$$

$$
p_{1} q_{1} q_{2} \quad \text {; etc: }
$$

Then, in this special notation, the above equations can be written more simply as :-

$$
\begin{aligned}
& p_{1} q_{1}\left(q_{0}+q_{2}+\ldots+q_{n}\right) R_{1}^{-1}-p_{2} q_{2} q_{1} R_{2}^{-1}-\ldots-p_{n} q_{n} q_{1} R_{n}^{-1}=p_{0} q_{0} q_{1} \\
& -p_{1} q_{1} a_{2} R_{1}^{-1}+p_{2} a_{2}\left(a_{0}+a_{1}+a_{3}+\ldots+q_{n}\right) R_{2}^{-1}-\ldots-p_{n} q_{n} a_{2} R_{n}^{-1}=p_{0} q_{0} q_{2} \\
& -p_{1} q_{1} q_{n} R_{1}^{-1}-p_{2} q_{2} q_{n} R_{2}^{-1}-\ldots+p_{n} q_{n}\left(q_{0}+\ldots+q_{n-1}\right) R_{n}^{-1}=p_{0} q_{0} q_{n}
\end{aligned}
$$


This set of equations can be expressed in matrix form, as follows:

If $A$ is defined to be the $n \times n$ matrix

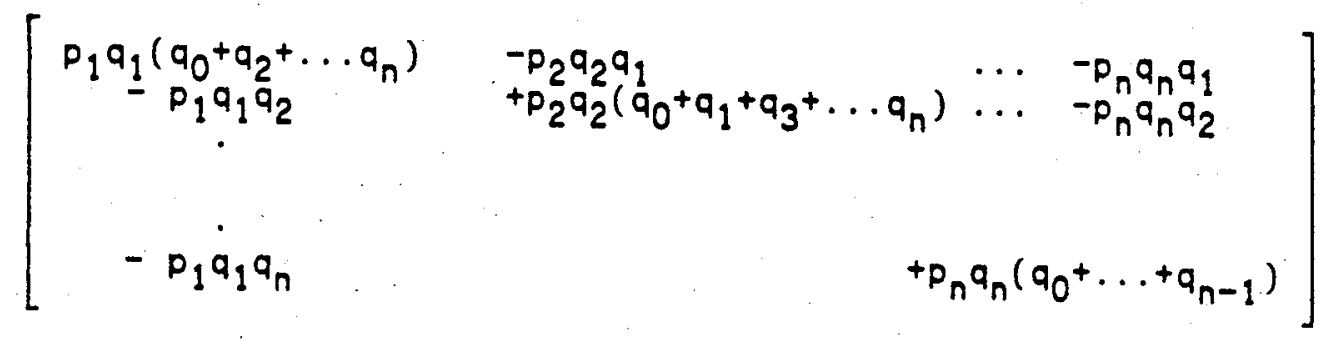

If $R^{-1}$ is defined to be the vector

$$
\left[\begin{array}{c}
R_{1}^{-1} \\
R_{n}^{-l}
\end{array}\right]
$$

and $b$ is defined to be the vector

$$
\left[\begin{array}{c}
p_{0} q_{0} q_{1} \\
p_{0} q_{0} q_{2} \\
p_{0} q_{0} q_{n}
\end{array}\right]
$$

then the vector $R^{-1}$ must satisfy

$$
A R^{-1}=b
$$

and hence, in general,

$$
R^{-1} \quad-A^{-1} \quad b
$$

This is one form of the general Geary Khamis solution in the $(n+1)$ country casé. 
It is possible to express equation ( 7 ) in an alternative form, which is in many ways more informative about the structure of the Geary Khamis' PPPs.

Recalling that, for any non singular vector $A$,

$$
A^{-1}=\frac{1}{|A|} \operatorname{adj}(A)
$$

where $|A|$ is the determinant of $A$, and $\operatorname{adj}(A)$ is the adjunct of $A$, equation ( 7 ) can be written equivalently as

$$
R^{-1}=\frac{\operatorname{adj}(A) \cdot b}{|A|}
$$

It is not difficult to see that the first element in the vector

$$
\operatorname{adj}(A) \cdot b
$$

is, in fact, just the determinant of the matrix obtained by replacing the first column of $A$ by $b$.

Hence, it follows that,

$$
R_{1}^{-1}=\frac{\mid \begin{array}{ll}
p_{0} q_{0} q_{1} & 1 \\
p_{0} & 1 \\
p_{0} q_{0} q_{n} & 1 \\
1 & 1 \\
1
\end{array}}{|A|}
$$

It is also possible to show, although the proof is not given here, that the determinant in the numerator of equation ( 8 ) is equal to the determinant of the matrix obtained by switching the subscripts 0 
and 1 wherover they occur in writing down the matrix $A$. In other words,

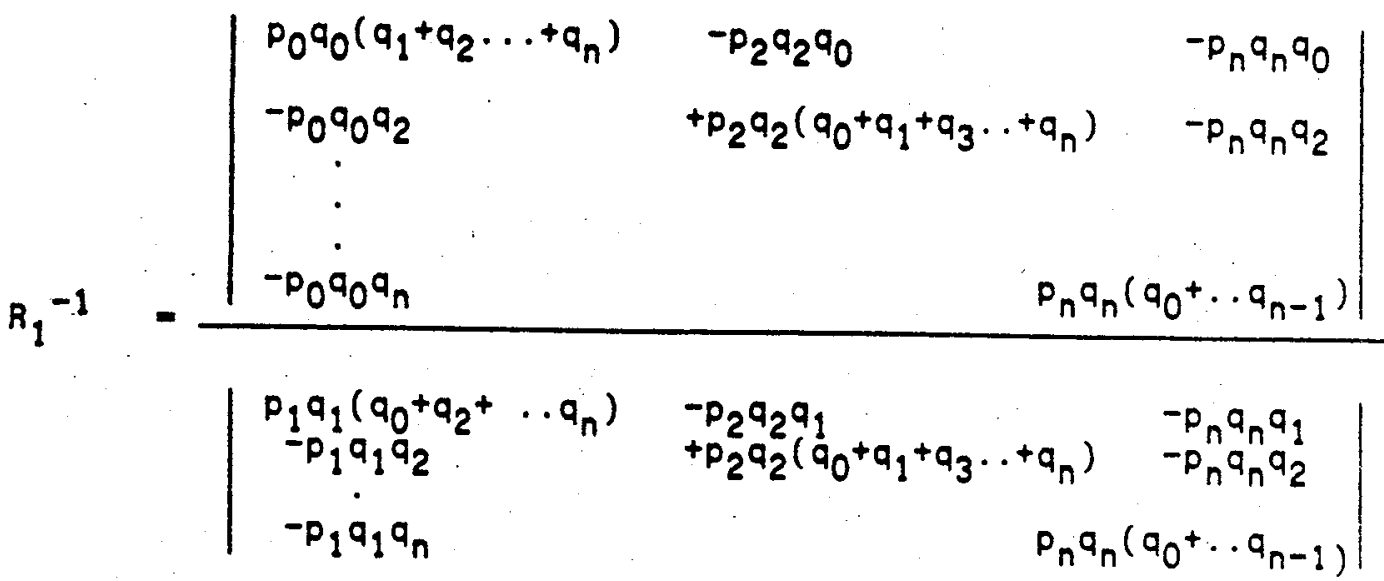

Thus it follows that $R_{1}$ consists of the ratio of sums of products of weighted sums of prices; the numerator ratio involving the prices in country 1 and countries 2 to $n$; the denominator being a similar expression in the prices of country 0 and countries 2 to $n$. The numerator and denominator expressions are symmetric, in the sense that the two expressions are identical on switching country subscripts 0 and 1 throughout. Similar expressions, of course, hold for the other PPPs, $R_{2} \ldots R_{n}$. 


\section{A. Tro Important Spocial Cases.}

4.1 It is useful to conclude this section on the theory of the Geary Khamis solution by considering two important special cases.

a). Exactly Multiplicative Prices.

The orice structure, $P_{i j}$, is defined to be exactly

multiplicative if there exist parameters $a_{i}$ and $\beta_{j}$ such that

$$
p_{i j}=a_{j} \cdot \beta_{j}
$$

In other words, the price of commodity i in country $j$ can be expressed exactly as the product of a commodity price parameter $\left(\alpha_{i}\right)$ and a country price effect $\left(\beta_{j}\right)$. When the price structure is exactly multiplicative, it can be shown that the Geary Khamis international prices are proportional to the parameters $a_{i}$, and the Geary Khamis PPPs, $R_{1}, \ldots, R_{n}$, are simply proportional to the $\beta_{j}$ 's. This follows on noting that:

$$
\frac{\Sigma p_{i j} q_{i j}}{\Sigma a_{i} a_{i j}}=\beta_{j}\left[\frac{\Sigma a_{i} q_{i j}}{\Sigma a_{i} q_{i j}}\right]=\beta_{j}
$$

and that

$$
\frac{\Sigma p_{i j} q_{i j}\left(\beta_{j}\right)^{-1}}{\Sigma q_{i j}}=a_{j}\left[\frac{\Sigma \beta_{j} q_{i j} \beta_{j}^{-1}}{\Sigma q_{j j}}\right]=a_{i}
$$

$$
\begin{aligned}
& \text { so that } \\
& \pi_{i} \\
& \text { and } \\
& R_{j}
\end{aligned}
$$




\begin{abstract}
are solutions of the Geary Khamis equations, taking country
0 as the base country. One important implication of this

result is that, under exact multiplicativity, the Geary

Khamis PPPs are independent of the quantities $q$.
\end{abstract}

b). Proportional Quantities Between Countries.

Suppose that, for two particular countries, say country $A$ and country $B$, the quantities of products are proportional between the two countries. By this is meant that there exists some constant $\tau$, such that $q_{i A}=\tau q_{i B}$ for all $i$

It follows, from the Geary Khamis defining equations, that the Geary Khamis PPP between countries $A$ and $B, A_{B P P}$, has the following expression:

$$
\begin{aligned}
A^{P P P_{B}} & =\frac{\sum p_{i A} q_{i A}}{\sum \pi_{i} q_{i A}} / \frac{\sum p_{i B} q_{i B}}{\sum \pi_{i B} q_{i B}} \\
& =\frac{\sum p_{i A} q_{i A}}{\tau \sum \pi_{i} q_{i B}} / \frac{\sum p_{i B} q_{i B}}{\sum \pi_{i} q_{i B}} \\
& =\frac{1}{\tau} \cdot \frac{\sum p_{i A} q_{i A}}{\sum p_{i B} q_{i B}}
\end{aligned}
$$


In other words, when the quantities of products are proportional botween two countries, the Geary Khamis PPP between these countries does not depend on international prices, or on the prices and quantities in any other countries, but only on the prices and quantities in the two countries in question. 


\section{CHAPTER TWO}

\section{OPTIONS FOR ESTIMATING THE GEARY KHAMIS APPROACH AT ITEM LEVEL.}

\section{Introduction}

1.1 The Geary Khamis approach to calculating PPPs, the theory of which was discussed in the preceding section, has mainly been applied at the stage of aggregation from basic headings up to GDP. It is not difficult to see why this is so: calculation of Geary Khamis PPPs depends on knowledge not just about the prices of commodities, the $p_{i j} s$, but also on tho quantities, the $a_{i j} s$, - or, alternatively, on knowledge of relative prices and expenditures. Basic headings are, by definition, normally the lowest level of aggregation for which quantity or expenditure data are available. Straightforward application of the Geary Khamis approach below basic heading level is, therefore, not normally possible, because of lack of the necessary data.

In principle, however, the Geary Khamis mothod could be used for aggregation from individual items up to basic heading, as woll as for aggregation from basic heading up. It is therefore considered here, whether it is possible to develop techniques of estimating the Geary Khamis method up from individual item lovel, making use of 
such limited information as may bo available about quantities or expenditures in order to do so. This chapter discusses three possible approaches to the problem:-

(a) by devising an appropriate sampling scheme;

(b) by solution of the Geary Khamis equations, using imputed quantities;

(c) by exploring special features of the price structures.

2. The Sampling Approach.

\subsection{Calculation of PPPs at basic heading level involves an} additional problem - that of sampling. There is the problem of choosing those individual items to be priced, as well as the problem of arriving at a suitable method of combining the item prices into a PPP. In certain circumstances, it may be possible to derive a suitable probability sampling scheme for selecting individual items - in such a way that efficient estimates of a desired PPP can be derived as relatively simple expressions of the sampled prices.

This approach is developed in Appendix B, for the two country or binary expression. In Appendix B, it is shown how,

(a) if prior knowledge is available in terms of rough estimates of item level expenditures, and an initial estimate of the inter country purchasing power relativity; and

(b) if it can bo assumed that the price structure within the 
basic heading in question was approximately multiplicative;

then a probability sampling scheme for selecting items can be derived, which has the property that an efficient estimate of the inter country Geary Khamis PPP can be obtained as a relatively simple function of the sampled prices.

This approach is interesting in the binary comparison case. However, in the three country case, or the more general multilateral case, the complexity of the formula for the general Geary Khamis solution, as shown in formulae 4 and 9 in Chapter 1 , is such that there does not appear to be any obvious extension of the sampling approach to these cases. This sampling approach, therefore, must be regarded as a useful suggestion for the binary comparison case, but not one that has implications for multilateral comparisons.

\title{
3. Solving the Geary Khamis Equations Directly Using Imputed Quantities
}

\author{
3.1 Suppose that price data is available for a selection of items: \\ that is, the price data,$p_{j j}$, is known. Then one approach which \\ could be adopted to calculate a Geary Khamis PPP could be to impute, \\ from whatever information is available, a set of notional \\ quantities, $a_{i j}$. This price and notional quantity data could then \\ be used to solve the defining Geary Khamis equations; that is, \\ equations (1) and (2) in Chapter 1.
}

There are number of different ways in which notional quantities 
could be imputed, depending on the available information. Three possible ways are illustrated here.

(a) Suppose that all the information that is available is whether item i is priced in country $j$ or not. In this situation of very limited information, a possible approach would be to define

$$
\begin{array}{ll}
a_{i j}=1 & \text { if item } i \text { is priced in country } j ; \\
=0 & \text { otherwise. }
\end{array}
$$

In fact, after assigning initial q values in this fashion, it might be sensible to normalise the q5, to sum to a constant total within each country. This normalisation step would prevent any individual country being given greater volume weight in the calculation just because more items happened to have been priced in that country.

(b) Alternatively, it might be the case that additional information is available about the individual items, in the sense that it is known for each item, $i$, whether or not that item is "characteristic" or not in country $j$. The definition of characteristic taken here is that suggested by Drechsler, [6]: namely, a product exhibits characteristicity in a country if its specifications are typical for that country. Given information on characteristicity, a possible approach would be to define

$$
\begin{aligned}
a_{i j} & -2 \text { if item } i \text { is characteristic in country } j ; \\
& =1 \text { if } i \text { priced, but not characteristic in } j ; \\
& =0 \text { if } i \text { is not priced in } j .
\end{aligned}
$$


Again, after assigning initial q values in this fashion, a vithin country normalisation would be appropriate, as in mothod (a).

(c) Finally, it might be the case that, in addition to shg characteristicl non characteristic status of individual iqems, da:a is available for broad volume magnitudes of the count $i$ s concerned - probably from prior GDP estimates. If it appears plausiblo to assume, to a first order of approximation, that these same relativities could hold at basic heading level, then the normalised qs, as derived for each country in (b); could be multiplied by overall factors describing the inter country volume relativities.

Of course, the three techniques illustrated above for ascribing notional quantities, $q$, are only throe examples of a large number of possibilities. Other approaches might be much more sensible, depending on the form of whatever prior information is available.

The fact that the techniques are crude is not, in itself, a strong argument against applying them. It may be better to take account, however crudely, of prior information, rather than to discount this information entirely. The important point is that, by imputing notional quantities, versions of the Geary Khamis PPP can bo formally calculated. It is an empirical question how sensitivo the results are to the particular techniques employed for imputing quantities. This question will be addressed in the later chapters which consider the analysis of actual data. 


\section{Exploiting Special. Features of the Price Structure.}

4.1 The third approach to obtaining an approximation to the Geary Khamis PPP at basic heading level is ono which is only feasible in exceptional circumstances, since it involves exploiting special features which the price structure, the $p_{i j} s$, may possess.

It has already been seen, in section 4 of Chapter 1 , that if the price structure, $p_{i j}$, is exactly multiplicative, then the Geary Khamis PPPs are simply functions of the prices alone, and do not depend on the quantities, $q_{j}$. In this case, therefore, the Geary Khamis PPPs could be obtained from knowledge of the $p_{i j} s$ alone.

Of course, exact multiplicativity is unlikely ever to be encountered in the real world. But it is reasonable to hypothesise that, if a price structure was encountered, which was, in some sense, close to being exactly multiplicative, then an approach which breaks down the realised prices into "item offects" and "country effects", could.well give PPPs which are close to the Geary Khamis PPPs.

In fact, one of the standard alternative approaches to estimating PPPs, the Country Product Dummy (CPD) approach, consists exactIy of decomposing prices into item and country effects. The theory of the CPD approach is discussed in Chapter 4.

The hypothesis, therofore, is that when the observed price structure 
is "elose" to multiplicativity, then the CPD approach to PPPS will bo a good approximation to the Geary Khamis PPP. As the CPD depends only on knowledge of prices, and not quantities, this means that an approximation to the Geary Khamis can be derived without bringing in quantity data.

Of course, this discussion leaves unsettled the question of how "closeness" to multiplicativity is to be measured - and how close one has to be before the CPD is a good approximation to the Geary Khamis. These are questions which will be considered in later chapters.

\section{Implications of the Gerschenkron Effect}

It is a well known feature of the GK method, when applied to aggregation up to GDP level that, if one country or a group of countries are dominant in overall volume terms, then the GK international prices will tend to be close to the prices of the dominant country or group. This fact, together with the commonly observed inverse relationship between relative prices and quantities, means that the Geary Khamis approach will tend to give lower aggregate volumes for the dominant country or group, compared to aggregation methods which define international prices as equiweighted averages of country prices. The converse of this is that, in a sense, the aggregate price level for the dominant country or group will be higher under the GK method than under a method based 
on equi - weighted international prices. This is the so called Gerschenkron effect. This feature of the Geary Khamis method has been the root of considerable debate between proponents and opponents of the approach. It is not the purpose here to argue the pros and cons of this aspect of the Geary Khamis method: however it is important to note that the effect exists, and to consider some of the implications.

The question then arises: suppose that the Geary Khamis approach, or a version of it of the kind suggested in this chapter, is being used to aggregate up to basic heading level, and that the standard Geary Khamis method is then being applied again to aggregate up to GDP level. Is there a danger that the Gerschenkron effect will enter into the calculation of the basic heading level Geary Khamis PPPs, and then be compounded in the second stage Geary Khamis aggregation to GDP level, leading to a kind of overall "super" Gerschenkron offect?

It is relevant to note, however, that the Gerschenkron effect cannot arise at the level of first stage aggregation in the following circumstances :-

(a) if either of the first two methods suggested above for imputing quantities is being used: this is because the imputed quantities for each country are scaled to the same total;

(b) if the structure of prices within the basic heading is multiplicative; or almost multiplicative: this is because the 
inverse relationship botween prices and quantities cannot hold when prices are multiplicative.

Therefore, in the context of the "imputed quantities" suggested in section 3 as possible approaches to estimating Geary Khamis parities at basic heading level, the Gerschenkron effect is only potentially a problem when the third possible method is being employed - and only then if the structure of prices within the basic heading is non multiplicative. Whether there is evidence of a compounded Gerschenkron of foct associated with the third imputed quantities method is one of the questions to be considered later on in this report, in the analysis of actual price data. 


\section{CHAPTER THREE}

\section{THE EKS AND RELATED METHODS}

\section{Introduction.}

1.1 In this chapter, the EKS method of aggregating purchasing power comparisons up to a basic heading level is described. It is shown how adopting a parametric formulation of the PPP estimation problem can be used to give insights into the properties of the EKS approach. Finally, some alternative approaches, broadly similar to the EKS approach, but likely to have superior estimating properties, are suggested.

\section{The EXS Method : Description.}

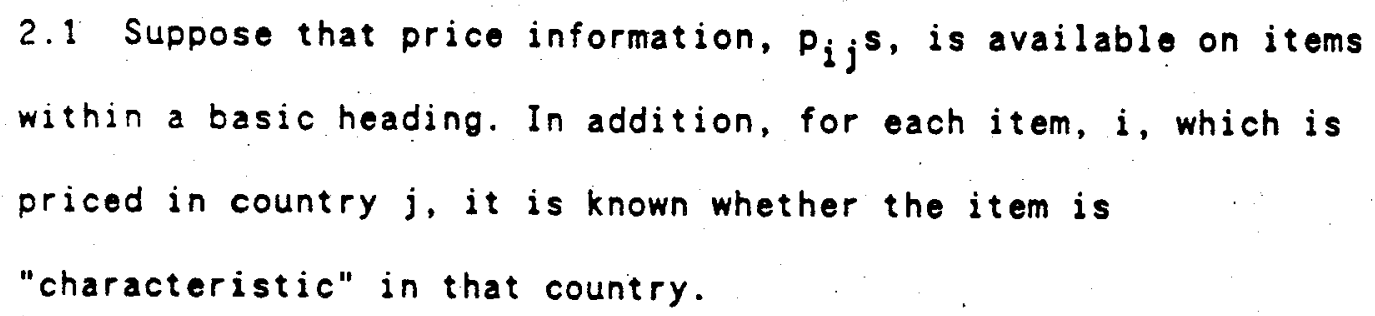


This information on the characteristic status of items is used to define weights, $r_{i j}$, as follows:-

$$
\begin{aligned}
r_{i j} \quad & =1 \text { if item } i \text { is characteristic in } j \\
& - \text { o otherwise }
\end{aligned}
$$

2.2 Given this information, the "Laspeyres" and "Paasche" indices are defined as follows, for any pair of countries $j$ and $k$.

$$
\begin{aligned}
& L_{j k}=\left[\prod_{i}\left(\frac{p_{i j}}{p_{i k}}\right)^{r_{i k}}\right]^{\frac{1}{\Sigma r_{i k}}} \\
& p_{j k}=\left[\left[\left(\frac{p_{i j}}{p_{i k}}\right)^{r_{i j}} \frac{1}{\Sigma r_{i j}}\right.\right.
\end{aligned}
$$

where, in these definitions, only items which are priced in both countries $j$ and $k$ are included in the construction of the indices.

Note that the Laspeyres index, $L$, is therefore defined if there exists at least one item which is priced in both countries, and is characteristic in country $k$. Similarly, the Paasche index, $P$, is only defined if there is at least one item which is priced in both countries, and is characteristic in country $j$.

2.3 When both the Laspeyres and Paasche indices exist, the Fisher index, $F_{j k}$, is defined to be the geometric mean of the Laspeyres and the Paasche: that is; 


$$
\begin{aligned}
F_{j k} & =\left[L_{j k} \cdot P_{j k}\right]^{k} \\
& =\left[\left[\left[\frac{p_{i j}}{p_{i k}}\right]\left[\frac{r_{i k}}{\Sigma r_{i k}}+\frac{r_{i j}}{\Sigma r_{i j}}\right]\right]^{1 / 2}\right.
\end{aligned}
$$

The fisher index is thus invertible, in the sense that,

$$
F_{j k}=\left[F_{k j}\right]^{-1}
$$

but is not, in general, transitive; that is, for countries $j, k$ and $c$

$$
F_{j k} \cdot F_{k c} / F_{j c}
$$

2.4 Suppose that, for a given group of countries, all possible

Fisher indices have been formed, linking pairs of individual countries.

Then,

(a) this matrix will not in general be complete, in the sense that there may be some pairs of countries for which the Fisher index, as defined above, cannot be formed.

(b) The matrix of Fisher indices will not, as noted above, be transitive. 
These problems can be overcome as follows:

Suppose that for country $j$ and $k$, the Fisher index is not directly defined. A value for the Fisher index between $j$ and $k$ can be estimated by taking the geometric mean

$$
\left[\prod_{c}\left[F_{j c} \cdot F_{c k}\right]\right]^{1 / m}
$$

over all countries $c$ where $F_{j c}$ and $F_{c k}$ exist, where $m$ is the cotal number of such countries. By applying this procedure, repeated several times if necessary, the matrix of Fisher indices can usually be completed, but the problem of non transitivity still remains.

2.6 A transitive index, the EKS index, can be obtained by applying the EKS formula to the complete Fisher matrix. The EKS purchasing power relativity between countries $j$ and $k$, and denoted by $E_{j k}$. is defined as

$$
E_{j k}=\left[\prod_{c}\left[F_{j c} \cdot F_{c k}\right]\right]^{1 / n}
$$

where $n$ is the total number of countries. Here, $F_{j j}$ and $F_{k k}$ are taken to be equal to 1 .

The EKS derived PPPs, defined in this way, then have the properties of invertibility and transitivity. 
3. The Properties of the EKS in the Light of a Parametric Approach to the Problem.

3.1 The EKS formulation, as described in the previous section, is an example of the "index number" approach to purchasing power comparisons.

A proponent of this kind of approach might well regard the formulae as being reasonable ways of defining relative price levels, if perfect and complete information were available on the prices of all items. Viewed thus, the formulae stand in thoir own right, independent of consideration of sampling and measurement error.

In the real world, however, consideration of the random elemeitis of the process of estimating PPPs is inescapable: items will normally be sampled, and prices will be subject to random measurement orrors and within country variation.

It is therefore relevant to consider the statistical properties of any given estimator - even if the ultimate rationale of that estimator is based on an "index number" type approach.

One way in which insight can be gained into the statistical properties of an estimator is to formulate the estimation problem in parametric terms: 
3.2 This approach is applied first of all to the Fisher index. defined in the previous section. Suppose that, for countries $j$ and $k$, the price ratios

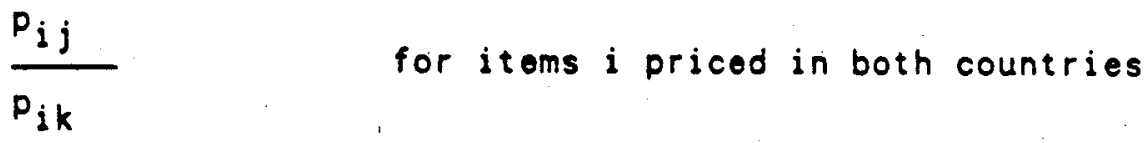

are random variables with the properties that

$$
\log \left[\frac{P_{i j}}{P_{i k}}\right] \text { are independent with mean } \mu_{j k} \text { and variance } 0^{2} \text {. }
$$

Another way of writing this is as follows:-

$$
\log \left[\frac{p_{i j}}{p_{i k}}\right]=\mu_{j k}+E_{j j k} \text {. }
$$

where the $E_{i j k}$ are independent orror terms, with common variance $o^{2}$. This is equivalent to

$$
p_{i j}=\exp \left[\mu_{j k}+E_{i j k}\right] \cdot P_{i k}
$$

In other terms, the parameters, $\exp \left[\mu_{j k}\right]$, determine, in a sense, an average relativity between the prices in country $j$ and country $k$ so motivating this particular choice of parametric model. Assuming that this parametric model holds, the Fisher PPP, $F_{j k}$. between countries $j$ and $k$, (equation 1 ) above, can be written $\log F_{j k}=k \Sigma\left[\frac{r_{i j}}{\Sigma r_{i j}}+\frac{r_{i k}}{\Sigma r_{i k}}\right] \log \left[\frac{p_{i j}}{p_{i k}}\right]$ 


$$
-k \sum\left[\frac{r_{i j}}{\Sigma r_{i j}}+\frac{r_{i k}}{\sum r_{i k}}\right]\left(\mu_{j k}+\epsilon_{i j k}\right)
$$

Hence,

$E\left(\log F_{j k}\right)=k \mu_{j k} \sum\left[\frac{r_{i j}}{\Sigma r_{i j}}+\frac{r_{i k}}{\Sigma r_{i k}}\right]$

$$
\mu_{j k}
$$

Thus, in the statistical sense, $\log F_{j k}$, is an unbiasod ostimator of $\mu_{j k}$. Moreover, it is a straightforward matter to calculate the variance of $\log \left(F_{j k}\right)$. We note that,

$V\left[\log \left(F_{j k}\right)\right]=V\left[k \Sigma\left[\frac{r_{i j}}{\Sigma r_{i j}}+\frac{r_{i k}}{\Sigma r_{i k}}\right]\left(\mu_{j k}+E_{i j k}\right)\right]$

$$
=\frac{0^{2}}{4} \Sigma\left[\frac{r_{i j}}{\Sigma r_{i j}}+\frac{r_{j k}}{\Sigma r_{i k}}\right]^{2}
$$

on using the fact that the $\varepsilon_{i j k}$ are assumed to be independent.

Let $s_{1}$ denote the number of goods which are characteristic in $j$, and priced in $k$;

$s_{2}$ denote the number of goods which are characteristic in $k$, and priced in $j$;

$s_{3}$ denote the number of goods which are characteristic in both $j$ and $k$, 
so that $s_{1}=\sum r_{i j} ; s_{2}-\sum r_{i k} ;$ and $s_{3}-\sum r_{i j} \cdot \sum r_{i k}$

Then, equation 3 for the variance of the log Fisher index can be written as

$V\left[\log \left(F_{j k}\right)\right]=\frac{0^{2}}{4}\left[\frac{1}{s_{1}}+\frac{1}{s_{2}}+\frac{2 s_{3}}{s_{1} \cdot s_{2}}\right]--(4)$

This variance expression therefore becomes smaller, that is, $\log \left(F_{j k}\right)$ becomes a more precise estimator of $\mu_{j k}$, the larger $s_{\mathfrak{l}}$ and $s_{2}$ are - in other words, the more characteristic items are involved in the comparison between country $j$ and country $k$.

The fact that the variances of the $\log$ Fisher indices between different pairs of countries will, in general, be different, means, in effect, that different Fisher indices contain differing amounts of information about the underlying price level comparisons. This has very important theoretical implications for the EKS method - as will be seen later in this chapter.

\subsection{The parametric approach can also be used to explore another} topic of considerable potential importance - namely, the question of characteristic / non characteristic bias in the Fisher index.

It is a well known feature in price comparison work that there tends to be an inverse relationship between the price of a commodity, and the volume of that commodity traded: other things being equal, high volume commodities will tend to be cheaper, relative to low volume commodities. But since, by definition, characteristic goods will 
generally bo high volume goods, and non characteristic goods low. volume, this suggests that there might be a systematic effect on prices, depending on the characteristic/ non characteristic status of an item.

This suggests the following generalisation of the above model, to allow for such an effect; namely, $\log \left[\frac{p_{i j}}{p_{j k}}\right]=\begin{array}{r}\mu_{j k}+a+E_{j j k}, j f i t e m i \text { characteristic in } k, \text { not in } j \\ \mu_{j k}+E_{i j k}, i f \text { item } i \text { characteristic in both } j \text { and } k \\ \mu_{j k}-a+E_{i j k} \text {, if item } i \text { characteristic in } j, \text { not in } k\end{array}$ A systematic characteristic / non characteristic price effect of the kind postulated above would correspond to a positive value of a in the formulation of the model.

Substituting this expression for

$\log \left[\frac{D_{i j}}{p_{j k}}\right]$

into the equation for $\log \left[F_{j k}\right]$, it follows that,

$\log \left[F_{j k}\right]=k \Sigma\left[\frac{r_{i j}}{\Sigma r_{i j}}+\frac{r_{i k}}{\Sigma r_{i k}}\right] \log \left[\frac{p_{i j}}{p_{i k}}\right]$

and hence,

$$
\begin{array}{r}
E\left[\log \left(F_{j k}\right)\right]-\mu_{j k}+\frac{\sigma}{2}\left[\frac{\text { no. of items characteristic in } k \text { but not in } j}{\Sigma r_{i k}}\right. \\
\left.-\frac{\text { no. of items characteristic in } j \text { but not in } k}{\Sigma r_{j j}}\right]
\end{array}
$$




$$
-\mu_{j k}+a / 2\left[\frac{s_{2}-s_{3}}{s_{2}}-\frac{s_{1}-s_{3}}{s_{1}}\right]
$$

in. the notation introduced earlier in this section.

Equation (5) shows how, if there is a systematic characteristic/ non-characteristic effect on prices, then this works through into the $\log F$ isher index in quite a complicated fashion, depending on the relative numbers of goods characteristic in $k$ but not in $j$, and vice-versa.

It is, however, too simplistic to say that the term involving a in equation (5) represents a "bias" to the Fisher index. The term "bias" has connotations of error; there may be circumstances in which it would be desirable to correct for this effect, but, likewise, there will be other circumstances in which it is not appropriate to make any correction, even when the effect exists. This is a point which will be discussed in greater depth in the following chapter.

3.4 The next step is to consider the EKS formula itself, and to show how a parametric formulation of the problem can give additional insight into the characteristics of the formula. In fact, it can easily be shown that a transitive set of PPPs among $n$ countries is formally equivalent to establishing $n$ individual country price levels. 
For example, given a set of transitive PPPs, written as $P_{j k}$, the price level for country 1 can be arbjtrarily taken as 1, and price levels for country $2, \ldots, n$ as $P_{21}, \ldots, P_{n g}$ respectively. Then, any $P_{j k}$ can be defined in terms of these price levels, since,

$$
P_{j k}=\frac{P_{j l}}{P_{k l}}, \quad \text { by transitivity. }
$$

Conversely, a set of $n$ price levels, $P_{1}, P_{2}, \ldots, P_{n}$, obviously defines a transitive set of PPPs, by the relationship,

$$
P_{j k}=P_{j} / P_{k}
$$

Given, therefore, that the existence of a set of $n$ underlying country price levels is implicit in the transitive set of PPPs produced by the EKS formula; it seems natural to adopt the following parametric formulation to describe the steps of obtaining a transitive set of PPPs from a matrix of Fisher indices. Namely,

$\log \left(F_{j k}\right)=\mu_{j}-\mu_{k}+\varepsilon_{j k}, \quad(j=1, n ; k=1, n ; j ; k)$

where the $\mu_{j}$ and the $\mu_{k}$ are the logs of the desired country price levels.

The standard statistical approach to estimating the ( $\mu$ ) parameters 
in a relation like (6) would be by the application of the technique of regression.

If it is assumed that the matrix of Fisher indices

is complete, that is, $F_{j k}$ exists for all comparisons of $j$ and $k$, then it can readily be shown that the regression estimator of

$$
\mu_{j}-\mu_{k}
$$

is simply

$$
\log \left[\prod_{c} F_{j c} \cdot F_{c k}\right]^{1 / n}
$$

Thus the regression estimator is identical with the log of the EKS estimator.

The proof is as follows:-

\section{Proof}

$$
\text { Define } \mu=1 / n \sum_{c=1}^{n}
$$

Then on averaging equation (6), holding $j$ constant, it follows that,

$1 / n \sum_{c} \log F_{j c}-\mu_{j}-\mu+1 / n \sum_{c} E_{j c}$, for all $j$

Thus the regression estimator of $\mu_{j}-\mu$ is simply

$$
\ln \sum \log F_{j c}
$$

Thus the regression estimator of

$$
\mu_{j}-\mu_{k}=1 / n \sum \log F_{j C}-1 / n \sum \log F_{k C}
$$




$$
-\log \left[\prod_{c} \cdot F_{j c} \cdot F_{c k}\right]^{1 / n} \text {. }
$$

which is the desired result.

Starting from a complete matrix of Fisher indices, therefore, and under the stated assumptions on the error term, the EKS and regression approaches yield the same PPP estimates. Since, under the stated assumptions, regression estimates aro optimal, in the sense of being minimum variance unbiased linear, this is an encouraging finding from the EKS viewpoint.

However, if the matrix of Fisher indices, as initially derived before filling in the gaps, is incomplete, a different picture emerges. In this situation, it will normally be possible, unless there are too many gaps in the matrix, to apply the regression techniques directly to the incomplete matrix - and this will again under the stated conditions, give optimal estimates. Further, it can be shown that these estimates will in general differ from the estimates obtained by filling in the gaps, as described in section 2.5, and then applying EKS. The exception is when only one gap exists, where the EKS and regression estimates will still coincide.

Since regression estimates are optimal under the stated conditions, the implication is that this technique of filling in the gaps and then applying EKS will in general givo less precise estimates than the straightforward application of the regression model (6) to the incomplete matrix of $\log$ Fisher indices. 
3.5 The position is, however, in general, oven more complicated than this. It has been shown above that the torms $\log \left[F_{j k}\right]$ will usually have unequal variance, as given by the expression in formula (4) above. Optimal application of regression to estimate the parameters in equation (6), therefore, would take account of this by fitting, not an unweighted regression, but a weighted Generalised Least Squares regression, with weights determined by equation (4). Thus, even when the matrix of Fisher indices is complete, the EKS formula, which is identical to an unweighted regression, is likely to be sub optimal relative to a weighted regression of the $\log$ Fisher indices. In these circumstances, the EKS estimator will still be unbiased, but will have sub optimal precision.

3.6 It is appropriate to summarise what has been a complicated argument :-

(a) when the matrix of first step Fisher links is complete, or almost complete; then the EKS approach is identical to an unweighted regression of the $\log$ Fisher indices.

(b) where the matrix of first step Fisher links is incomplete, the method of filling in gaps and applying EKS will not in general be equivalent to an unweighted regression of the log Fisher values. So if the assumptions for an unweighted regression hold, the EKS will. be an unbiased, but sub optimal estimator. 
(c) In any ovent, because the $\log$ Fisher variances are in general unequal, (equation 4), it will generally be appropriate to apply a weighted log Fisher regression.

Points (b) and (c) both suggest that the techniques of estimating PPPs by applying a weighted log Fisher regression is likely to give results which are close to, but more precise than, the straightforward EKS.

In addition, the weighted log fisher regression model can be specified either in the straightforward form of equation (6), or, in a form which allows for the possiblo existence of characteristic/ non characteristic bias, utilising the expression for the bias term in equation (5) above. The regression model allowing for bias would be

$\log F_{j k}=\mu_{j}-\mu_{k}+a / 2\left[\frac{s_{2}-s_{3}}{s_{2}}-\frac{s_{1}-s_{3}}{s_{1}}\right]+E_{j k}$ where $s_{1}, s_{2}$, and $s_{3}$ are defined in terms of the numbers of items characteristic in countries $j$ and $k$, as in section 3.2 above.

3.7 Ono final cautionary remark should be made. Consider two direct Fisher indices, $F_{j k}$ and $F_{j c}$ say, both involving country $j$. It is possible, indeed it is likely, that some of the items appearing in 
the numerator of these indices (priced in country j), are the same in both indices. In this case, there will be correlation between these two indices. Thus, in applying regression to estimato the parameters in equations (6) or (7) allowance should strictly be made not just for unequal error variances, but for potential correlation between the errors. This is a problem which applies not just to the log Fisher regression methods, but also to the EKS itself, given the equivalence between the EKS and the log Fisher regression under given circumstances. This suggests the desirability of considering other methods which get round the error correlation problem. One such method is considered in the next chapter. 


\section{THE COUNTRY PRODUCT DUMMY TECHNIOUE.}

\section{Introduction.}

1.1 The Country Product Dummy (CPD) approach is the third of the standard PPP techniques discussed. The next section introduces the technique. Following that, there is a description of how the technique can be generalised to allow for characteristic / non characteristic product bias. The theoretical question of when characteristic / non characteristic bias ought to be corrected for is also discussed.

\section{The CPD Technique.}

2.1. The CPD is a parametric technique, which depends only on knowledge of price information, $p_{j} s$, without any information on quantities, or the characteristic/non characteristic classification of items. For reference, see Kravis et al; [7,8] and Hill, [11].

Suppose that there are $n$ countries, and $m$ items, and that the price of item $i$ in country $j$ is $p_{i j}$. It is not necessary that every item be priced in every country. 
The basic assumption of the technique is that $\log \mathrm{p}_{i j}$ can be expressed in the form

$$
\log p_{i j}=\alpha_{i}+\beta_{j}+E_{i j}
$$

where $a_{i}$ is a price effect parameter for item $i$;

and $\beta_{j}$ is a country offect parameter for country $j$.

Under the assumption that the errors $E$ are uncorrelated, with common variance $0^{2}$, the parameters are estimated by the application of standard, unweighted regression. To avoid parameter redundancy, a single constraint has to be imposed on the parameters: without loss of generality, this could be taken to be the condition that $\beta_{1}=0$. This would have the effect of expressing the price effect terms, the a parameters, in the currency of country 1.

Once the $\beta$ parameters have been estimated, the PPP as determined by the CPD method between any two countries, $j$ and $k$ say, is given by $C_{j k}=\exp \left\{\beta_{j}-\beta_{k}\right\}$

These CPD derived PPPs are thus clearly invertible and transitive.

The CPD technique has major attractions:

* it is simple, and straightforward to apply;

* being a parametric approach, it has a good underlying rationale;

* Unlike the EKS and $\log F$ isher regression techniques, there is 
no a priori reason to suppose that correlation between the errors in the regression equations is likely to be a problem.

However, the CPD approach also has limitations. In particular:-

(a) implicit in the approach is the assumption that the price structure being analysed is reasonably approximated by the product of item and country price effects: i.e., that the prices are basically multiplicative. This may not be a reasonable assumption in particular cases.

(b) the model fitted is relatively parameter intensive. That is, it involves $(n+m-1)$ price or country effect parameters plus one variance parameter. Unless at least $(n+m)$ price observations are available, the model cannot be fitted at all: and even where more than $(n+m)$ prices are available, precision may be poor if the number of observed prices is close to $(n+m)$.

(c) The approach makes no use of either available quantity information, or of any information which may be available on the characteristic / non characteristic classification of items. In fact, this statement is not quite true : versions of the technique have been developed which apply overall quantity weights, per item, in estimating the basic equations. But this involves weighting all countries similarly for a given item - and so represents only a very partial use of quantity data. 
3. Extension of the CPD Technique to allow for Characteristic I Non Characteristic Bias.

3.1 As noted in the preceding section, the standard CPD technique makes no allowance for characteristic / non characteristic bias. It is not difficult, however, to soe how the basic CPD model could be extended to allow for the possibility of a differential price between characteristic and non characteristic products, if information on the characteristic / non characteristic classification of items is available. The required adjustment to the basic CPD equation is

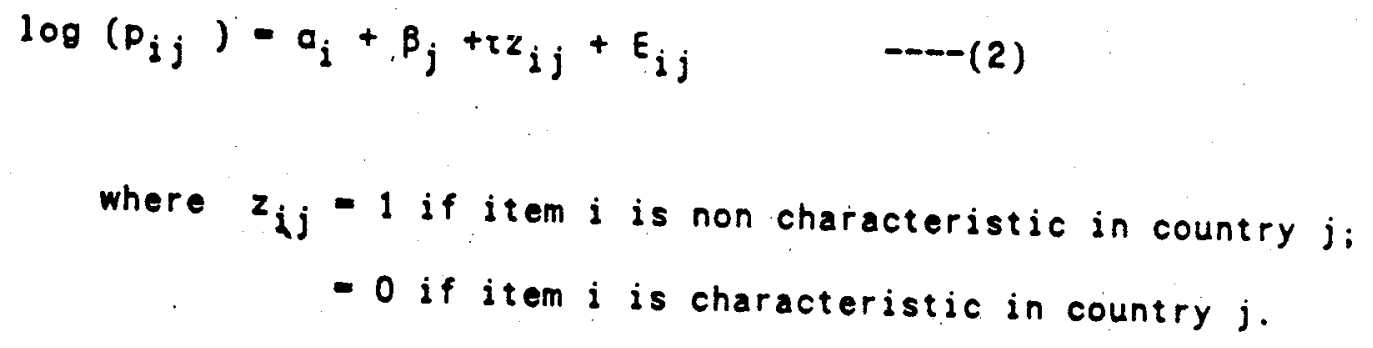

If a characteristic / non characteristic pricing differential exists, as postulated in an earlier chapter, then this would show up as a positive coefficient of $z$ in this equation.

There are no technical difficulties about estimating the coefficients in equation (2) by standard regression - although occasionally, in practice, circumstances may occur when the $t$ parameter is not identified: for example, if all the items in country $j$ are non characteristic, and no items are non 
characteristic in other countries, then the r parameter would be confounded with the $\beta_{j}$ country parameter.

Two models have thus been developed - the log Fisher regression with bias torm, and the CPD with non characteristic dummy, which could be applied to real life data to test whether significant non characteristic bias exists in practice. Which model should be preferred?

As noted above, there is a potential problem of error correlation in the log Fisher regression; this is liable to distort tests of statistical significance. Because of this, the detailed analysis of non characteristic bias reported in a later chapter is based on the CPD approach.

The CPD model with non characteristic dummy offers a convenient framework for detecting the existence of a differential price effect for non characteristic items. However, the question still remains of whether, in calculating the final inter country PPPs any correction should in principle be made for non characteristic bias. This is not a simple question to answer - indeed, each case probatly has to be considered on its own merits. This is illustrated by considering two hypothetical examples.

\section{Example 1.}

Consider two countries, $j$ and $k$, with five items priced in each country. Suppose that all items are characteristic in country $j$, but four are non characteristic in country $k$. In country $k$, however, these 
non characteristic items are of minor importance, accounting for only $10 x$ of the total volume of trade in that basic heading.

\section{Example 2.}

Suppose that the situation is the same as in example 1, except that now the four non characteristic items each account for $15 \%$ of trade in country $k$, that is $60 \%$ of trade in all.

If there is a significant non characteristic price differential, how should this be allowed for in these two cases?

It is fairly clear that, in example 1 , the effect of the non characteristic price differential should be removed, or largely removed, in calculating country k's price level. $90 \%$ of the trade in country $k$ is in the characteristic product - so the average price level in country $k$ will be largely determined by the price of that product. It would give distorted estimate of the average level of prices actually paid in country $k$ to give equal weight to four prices including the non characteristic price effect, and one price excluding it. Yet this is what the standard CPD regression would do.

On the other hand, in the case of example 2, $60 \%$ of the volume traded in the country includes the non characteristic differential. So the average price of goods actually traded will be substantially influenced by the non characteristic effect. In this case application of the CPD model without the non characteristic dummy would probably give an estimated country effect for country $k$ which would be closer to the true average price. 
The optimal answer to the problem would presumably involve running the CPD model with the non characteristic dummy, and then, for each country, adding to the estimated country effect a fraction of the estimated non characteristic coefficient - that fraction depending on a separate assessment of what proportion of trade in the country is accounted for by non characteristic products. 


\section{CHAPTER FIVE}

\section{DATA ANALYSIS}

\section{Data Analysis : Preliminaries.}

1.1 For those OECD countries not within the EEC, price and expenditure data were collated by the OECD. In the first instance, this data was collected by individual member government statistical departments. In all, price and expenditure data were analysed for the following ten countries; Austria, Finland. Norway, Sweden, Australia, New Zealand, Japan, Canada, United States and Turkey, numbered in the analysis, 1 to 10 respectively.

\section{Price Data}

Price information is collected at individual item level. Each country in the group supplied information on the specification of the commodity, for example, name of product and how packaged; together with its price, and detail on whether the good was characteristic or not. In general, several items would be priced within each basic heading. For the purposes of this study, the price collection methods are taken as given. 


\section{Expenditure Data}

Briefly, expenditure data was collected by the OECD, at Gross

Domestic Product lovel, for each of the countries in the study.

Expenditure figures are in national currencies (millions). Sub divisions of expenditure data were also provided, both at a fairly agrogate lovel, such as Consumer Expenditure, and also at basic heading level. The latter is more important for the current study. Basic heading level is defined as the smallest grouping for which individual country expenditure data is available. For this study, the price data for 37 product groupings, falling into 34 basic headings, were examined. The following is a list of the products studied:

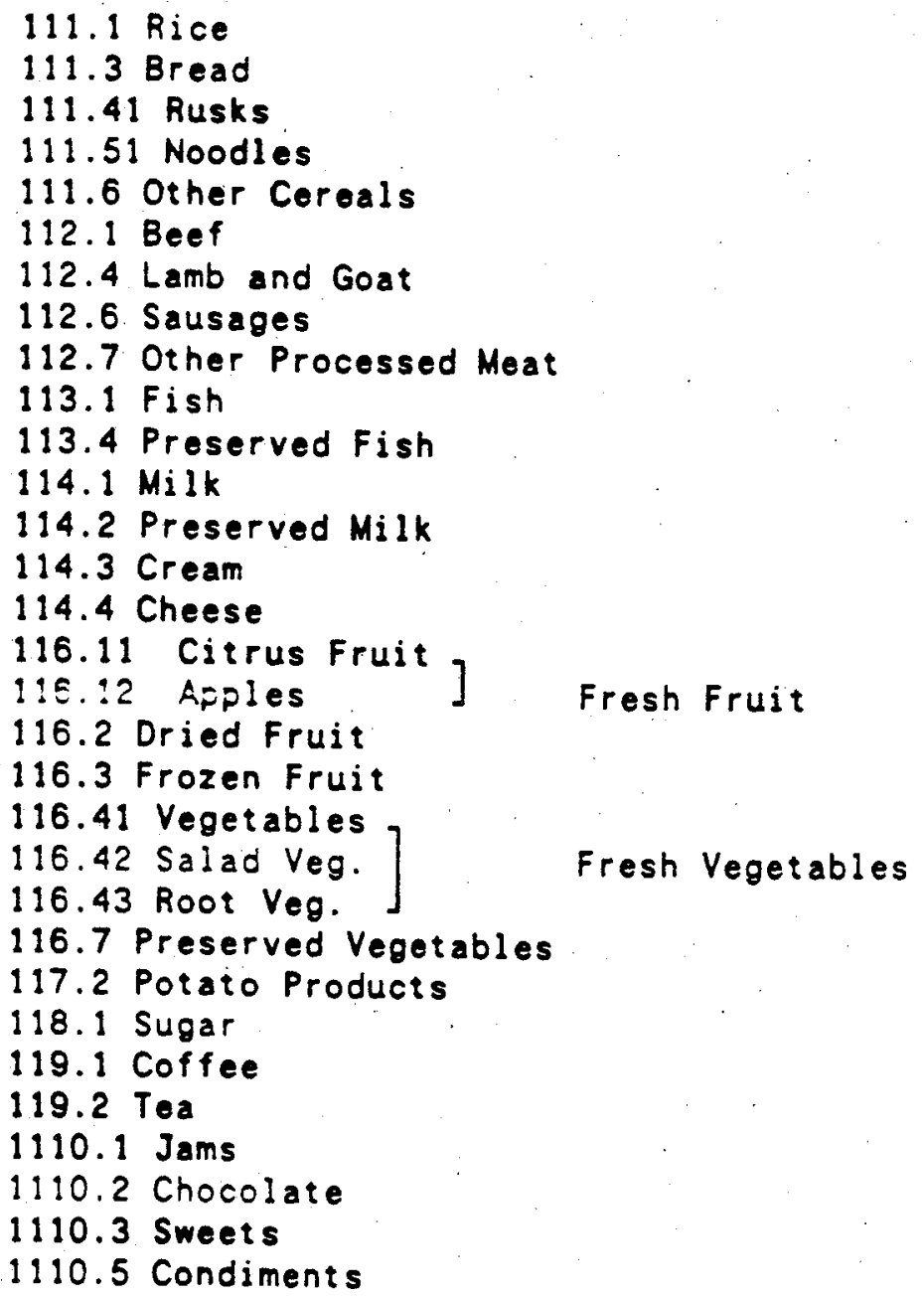


131.1 Alcohol

131.2 Wine

131.3 Beer

131.4 Aperatifs

141.1 Cigarettes

\section{Outline of the PPPs Calculated for this Study.}

2.1 For each of the 37 product groupings selected for detailed study, 8 different methods were applied for aggregating the item level price data up to a PPP for each basic heading. The methods employed fall into three main groups, as follows :-

\section{(a) The Geary Khamis Group.}

Three methods of calculating Geary Khamis indices were used, each involving imputing quantities, as described in Chapter 1 , and then solving the resulting full Geary Khamis equations. The three techniques differ in the methods used for imputing quantities : the procedures adopted are those outlined in Chapter 1. The resulting PPPs have been denoted GK1, GK2 and GK3.

GK1 : this involved imputing the quantities $q_{j j}$ as

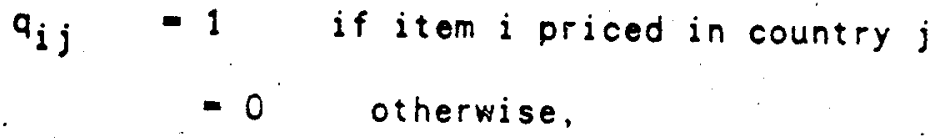


As for GKI, the resulting $q$ 's are then scaled to the same total within oach country.

GK3 : as for GK2, but country totals are scaled to a prior estimate of the overall GDP volume relativities between the countries.

The volume relativities assumed were :-

$\begin{array}{ll}\text { Austria : } & 1.76 \\ \text { Finland : } & 1.18 \\ \text { Norway: } & 1.18 \\ \text { Sweden: } & 2.94 \\ \text { Australia: } & 3.53 \\ \text { New Zealand: } & .59 \\ \text { Japan: } & 22.9 \\ \text { Canada: } & 5.89 \\ \text { United States: } & 58.82 \\ \text { Turkey: } & 1.18\end{array}$

These percentages were the approximate shares of each country in the toial GDP of the 10 countries determined from Purchasing Power Parities and Real Expenditures, 1985, as published by OECD.

(b) The EKS Group

The three methods used were :-

E : the standard EKS approach. 
F1 : the log Fisher regression approach, without bias term; the regression was weighted by the inverse of the square root of the theoretical log Fisher variance, to correct for the problem of heteroscedasticity.

F2 : the 100 Fisher regression with bias term to allow for a possible characteristic / non characteristic price differential: again, this regression is weighted to correct for heteroscedasticity.

See Chapter 3 for a description of the underlying theory for these approaches.

(c) The CPD Group.

Cl : CPD regression without bias term;

C2 : CPD regression with bias term;

See Chapter 4 for a discussion of the relevant theory.

As noted above, each of these 8 methods for calculating PPPs was applied for each of the 37 product groupings selected for detailed study. In fact, in a few cases it was not technically possible to calculate the versions of the $\log$ Fisher and CPD PPPs involving bias terms - for example, because all of the items priced were characteristic in every country. 


\section{The Results.}

Table 5.1 gives examples of the PPPs obtained by these different methods for a number of basic headings. In each case the PPPs are relative to the Unitod States (Country 9): that is, for example for preserved fish the price relative of Austria to the US using the EKS method is 9.6 Austrian schillings to the US dollar.

4. Summary Statistics Used in the Analysis.

4.1 Before embarking on the description of the data analyses, in the subsequent chapters, it is necessary to develop some summary and descriptive statistics, which will be used as tools in the data, analyses.

\section{(a) A Measure of the Difference between the PPPs.}

The first requirement is to have a simple and convenient means to assess how close one PPP is to another. Suppose, for example, tha:, 8 different PPPs are calculated for a particular basic heading, using the methods outlined in the previous section. It is then natural to ask questions like - is the FI index or the F2 index closer to the EKS index? - and so on.

To answer this kind of question, a measure of the distance betweer two PPPs is required. But since each PPP consists of a set of 9 
TABLE 5.1 EXAMPLES OF PPPS AT BASIC HEADING LEVELS

All PPPs in this table are shown relative to the United states

\section{A. PRESERVED FISH}

\begin{tabular}{|c|c|c|c|c|c|c|c|c|c|}
\hline $\begin{array}{l}\text { Sountry } \\
\text { lethod }\end{array}$ & Aus & Fin & Nor & Swe & $\begin{array}{l}\text { Aust } \\
\text { ralia }\end{array}$ & NZ & Jap & Can & Turkey \\
\hline $\begin{array}{l}\text { EKS } \\
\text { LOG F with bias } \\
\text { LOG F w'out bias } \\
\text { GK1 } \\
\text { GK2 } \\
\text { GK3 } \\
\text { CPD with bias } \\
\text { CPDw'out bias }\end{array}$ & $\begin{array}{r}9.60 \\
8.82 \\
9.71 \\
12.32 \\
11.76 \\
10.92 \\
9.83 \\
11.70\end{array}$ & $\begin{array}{l}10.16 \\
9.65 \\
10.00 \\
11.27 \\
11.63 \\
10.64 \\
10.20 \\
10.63\end{array}$ & $\begin{array}{l}11.28 \\
11.33 \\
11.38 \\
11.45 \\
11.65 \\
10.44 \\
11.48 \\
11.49\end{array}$ & $\begin{array}{r}9.69 \\
8.77 \\
9.76 \\
11.49 \\
11.58 \\
10.69 \\
10.54 \\
10.40\end{array}$ & $\begin{array}{l}0.88 \\
0.90 \\
0.80 \\
0.91 \\
0.92 \\
1.03 \\
0.93 \\
0.88\end{array}$ & $\begin{array}{l}1.26 \\
1.23 \\
1.24 \\
1.30 \\
1.30 \\
1.26 \\
1.22 \\
1.24\end{array}$ & $\begin{array}{l}312.10 \\
302.62 \\
313.01 \\
343.26 \\
330.98 \\
326.34 \\
309.90 \\
329.27\end{array}$ & $\begin{array}{l}1.13 \\
1.10 \\
1.15 \\
1.37 \\
1.26 \\
1.20 \\
1.19 \\
1.27\end{array}$ & $\begin{array}{l}328.30 \\
325.46 \\
332.67 \\
341.53 \\
345.51 \\
294.98 \\
336.30 \\
350.45\end{array}$ \\
\hline
\end{tabular}

B. CHEESE

\begin{tabular}{|c|c|c|c|c|c|c|c|c|c|}
\hline $\begin{array}{l}\text { Country } \\
\text { Mothod }\end{array}$ & Aus & Fin & Nor & Swe & $\begin{array}{l}\text { Aust } \\
\text { ralia }\end{array}$ & $\mathrm{NZ}$ & Jap & Can & Turkey \\
\hline $\begin{array}{l}\text { EKS } \\
\text { LOG F with bias } \\
\text { LOG F w'out bias } \\
\text { GKI } \\
\text { GK2 } \\
\text { GK3 } \\
\text { CPD with bias } \\
\text { CPDw'out bias }\end{array}$ & $\begin{array}{l}15.91 \\
16.28 \\
15.80 \\
16.12 \\
16.41 \\
14.88 \\
17.19 \\
15.85\end{array}$ & $\begin{array}{l}5.01 \\
5.16 \\
5.06 \\
4.56 \\
4.68 \\
3.56 \\
5.28 \\
4.79\end{array}$ & $\begin{array}{l}7.42 \\
7.67 \\
7.52 \\
7.12 \\
7.13 \\
5.91 \\
8.06 \\
7.45\end{array}$ & $\begin{array}{l}8.65 \\
8.70 \\
8.68 \\
8.98 \\
8.66 \\
7.28 \\
9.36 \\
9.07\end{array}$ & $\begin{array}{l}0.72 \\
0.73 \\
0.71 \\
0.70 \\
0.70 \\
0.68 \\
0.73 \\
0.66\end{array}$ & $\begin{array}{l}1.14 \\
1.20 \\
1.16 \\
1.25 \\
1.26 \\
1.17 \\
1.29 \\
1.16\end{array}$ & $\begin{array}{l}236.67 \\
234.06 \\
237.79 \\
341.13 \\
334.46 \\
265.29 \\
249.48 \\
263.68\end{array}$ & $\begin{array}{l}1.31 \\
1.37 \\
1.33 \\
1.31 \\
1.33 \\
1.42 \\
1.44 \\
1.24\end{array}$ & $\begin{array}{l}411.34 \\
424.83 \\
416.49 \\
411.62 \\
411.07 \\
363.28 \\
446.06 \\
407.96\end{array}$ \\
\hline
\end{tabular}

c. JAM

\begin{tabular}{|c|c|c|c|c|c|c|c|c|c|}
\hline $\begin{array}{l}\text { Country } \\
\text { Method }\end{array}$ & Aus & in & Nor & Swe & $\begin{array}{l}\text { Aust } \\
\text { ralia }\end{array}$ & $\mathrm{NZ}$ & Jap & Can & Turkey \\
\hline $\begin{array}{l}\text { EKS } \\
\text { LOG } F \text { with bias } \\
\text { LOG } F \text { w'out bias } \\
\text { GK1 } \\
\text { GK2 } \\
\text { GK3 } \\
\text { CPD with bias } \\
\text { CPDw'out bias }\end{array}$ & $\begin{array}{l}15.99 \\
15.70 \\
16.02 \\
16.24 \\
15.93 \\
16.22 \\
15.48 \\
16.30\end{array}$ & $\begin{array}{l}7.60 \\
7.59 \\
7.59 \\
7.40 \\
7.40 \\
7.60 \\
7.44 \\
7.44\end{array}$ & $\begin{array}{l}12.08 \\
12.01 \\
11.95 \\
11.33 \\
11.34 \\
11.54 \\
11.37 \\
11.28\end{array}$ & $\begin{array}{l}7.56 \\
7.62 \\
7.59 \\
7.56 \\
7.56 \\
7.70 \\
7.63 \\
7.57\end{array}$ & $\begin{array}{ll}6 & 0.75 \\
2 & 0.75 \\
9 & 0.75 \\
6 & 0.73 \\
6 & 0.73 \\
0 & 0.75 \\
3 & 0.74 \\
7 & 0.74\end{array}$ & $\begin{array}{l}1.06 \\
1.07 \\
1.06 \\
1.03 \\
1.03 \\
1.05 \\
1.05 \\
1.03\end{array}$ & $\begin{array}{l}345.29 \\
346.88 \\
344.92 \\
335.66 \\
336.63 \\
343.96 \\
341.96 \\
335.87\end{array}$ & $\begin{array}{l}1.47 \\
1.47 \\
1.47 \\
1.40 \\
1.40 \\
1.40 \\
1.41 \\
1.41\end{array}$ & $\begin{array}{l}296.48 \\
295.99 \\
295.99 \\
288.65 \\
288.65 \\
296.33 \\
290.13 \\
290.13\end{array}$ \\
\hline
\end{tabular}


price lovels relative to a base country. (or, equivalently, of the set of 45 possible inter country comparisons), it is not obvious how such a distance measure between PPPs should be defined.

The following argument suggests a possible approach. Consider two PPPs - denoted $F$ and $G$ say. For each PPP, construct the vector consisting of all 45 possible inter country comparisons : (there are 45 comparisons between 10 countries). F and $G$ will be identical PPPs if the two vectors are the same - or equivalently, if the vector obtained by dividing each term in the F vector by the corresponding term in the $G$ vector is a vector of ones. This suggests that a measure of the distance between $F$ and $G \mathrm{might}$ be based on how great the dispersion is between the terms in the vector $F / G$

A standard measure of the dispersion of a set of numbers is the sample variance. Thus an initial distance measure might be taken as the variance of $F / G$.

Note: here the sample variance of a vector $\left(x_{1}, \ldots x_{k}\right)$ is defined as

$$
\frac{1}{(k-1)} \sum\left(x_{i}-\bar{x}\right)^{2}
$$

However, a little thought indicates that this measure of distance is deficient, in that the variance of $(F / G)$ is not in general equal to the variance of $(G / F)$; and clearly it is desirable in defining a distance measure that the distance from $F$ to $G$ should be the same as the distance from $G$ to F. 
A simple modification to the definition gets round the problem namely, taking the variance of $\log (F / G)$.

This follows since

$$
\log (F / G)=-\log (G / F)
$$

and hence

$$
\operatorname{var}[\log (F / G)]-\operatorname{var}[\log (G / F)]
$$

Thus the distanco measure $D$ between $F$ and $G$ is defined as

$$
D(F, G)=\operatorname{var}[\log (F / G)]
$$

or equivalently,

$$
D(F, G)=\operatorname{var}[\log F-\log G]
$$

It would be possible to define other distance measures between PPPs which fulfill a similar function - however, the distance measure defined above is certainly adequate for the purpose intended.

It is important to have a feel for the magnitude of the differences between PPPs implied by different values of the measure. Such a fee! can be supplied by the following houristic argument.

Roughly speaking, about $95 x$ of a given set of observations are likely to fall within a range of $\pm 2 \mathrm{~J}$ (sample variance) of the mear of the observations. This suggests that, for two PPPs, $F$ and $G$, about $95 \%$ of the terms in the vector $\log (F / G)$ will fall within a 
range of $\pm 2 J[D(F, G)]$.

Or, in other words, about $95 x$ of the terms in the vector $F / G$ can be oxpected to fall in the range

$$
[\exp [-2 J D], \exp [+2 \sqrt{ }]] .
$$

The right hand limit of the approximate $95 x$ confidence interval lies, in percentage terms, at $[\exp (2 \sqrt{D})-1] * 100 x$ above G. For example, suppose that, for particular PPP voctors $F$ and $G$, the corresponding $D$ value is 0.01 , then the above approximate $95 \%$ confidence interval for the terms in $F / G$ is

$$
[\exp \{-2 \sqrt{ }(0.01)\}, \exp \{+2 \mathrm{~J}(0.01)\}]
$$

that is,

$$
.819 \leq \frac{F}{\bar{G}} \leq 1.22
$$

with approximately $85 x$ confidence.

Expressing this another way, approximately $95 \%$ of the terms in $F$ will be expected to lie in the interval

$$
.819 G \leq F \leq 1.22 G
$$

In other words, the right hand bound of the confidence interval is $22 \times$ above $G$. 
Fig 5.1 Plot of $\{\operatorname{Exp}(2 \sqrt{D})-1\} \times 100$ as a function of $D$

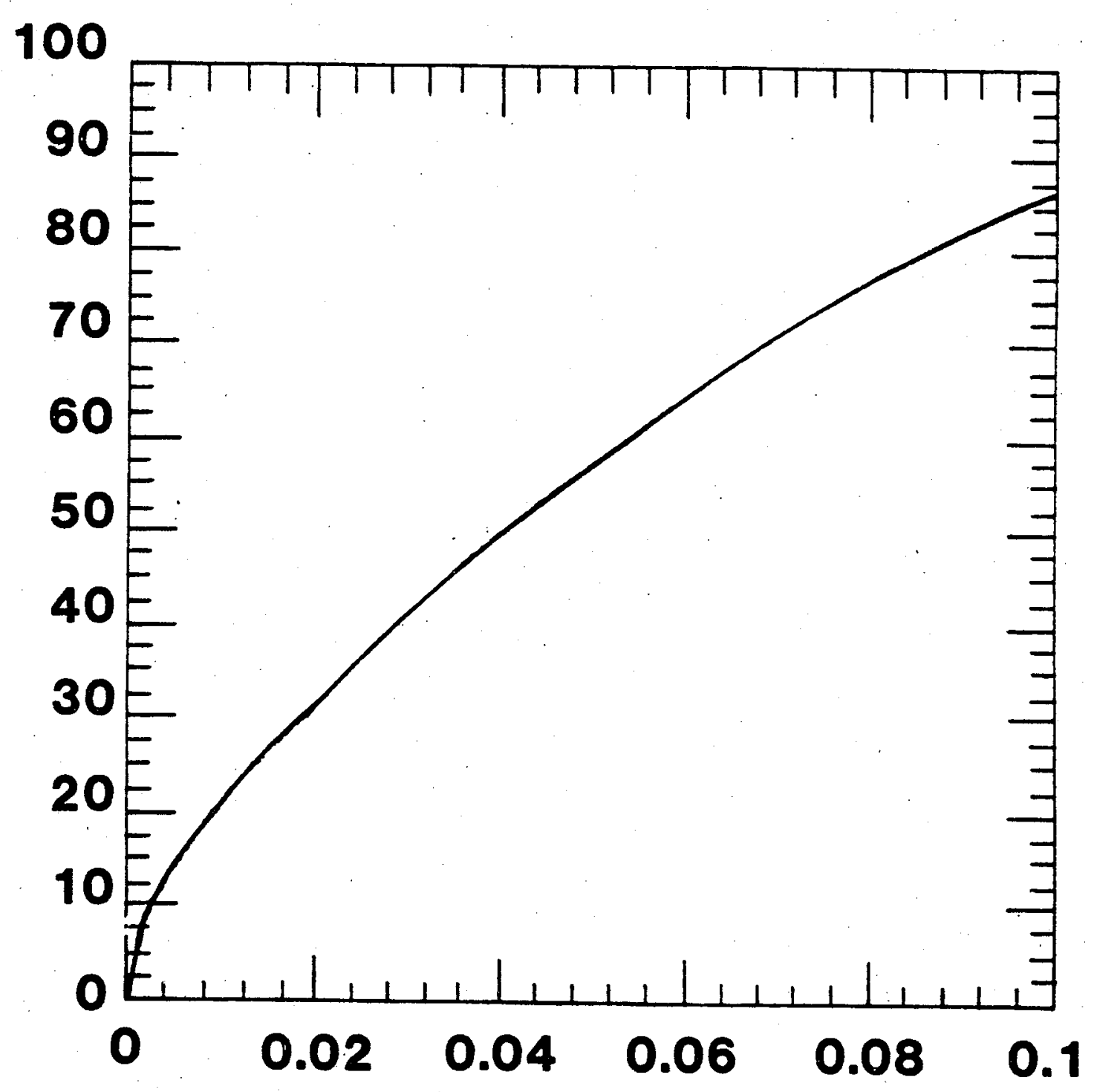

Distance D 
Figure 5.1 plots $[\exp \{2 J 0\}-1]=100$ as anction of $D$.

From the chart, it can be seen that, for a distance $D$ of .05 between the PPPs, approximately 95\% of inter country comparisons between the different PPPs are likely to lie within $60 \%$ of each other. Putting this another way, for a $D$ value of .05 , it might be expected that 2 or 3 inter country comparisons out of the 45 possible for 10 countries, would differ by $60 x$ or more, between the different versions of the PPPs. This is certainly not very close. It can be seen that, roughly speaking, for inter country comparisons to differ by less than 10x, D values of .003 or smaller are required.

(b) A Measure of the Degree of Multiplicativity for a Set of Prices. It was hypothesised, in Chapter 1 , that the closer the set of prices $\left(p_{i j}\right)$ corresponds to being multiplicative, then the less would the Geary Khamis PPP depend on the particular quantities $\left(q_{j}\right)$, and the closer the Geary Khamis PPP would converge to what is, in effect, the CPD PPP. This begs the question, however, of how closeness to multiplicativity is to be defined, for a given set of prices.

Consideration of the CPD regression model suggests a natural measure of closeness to multiplicativity. If the price structure is exactly multiplicative, then there will be an exact fit in the CPD regression, and the coefficient $R^{2}$, ( the coefficient of multiple correlation for that regression) will be 1 . This suggests taking the $R^{2}$ value from the CPD regression as the measure of closeness to 
multiplicativity.

$R^{2}$ itself, however, suffers from one potential drawback. In a CPD regression with $n$ countries, and $m$ items, an apparently, very good fit ( high $R^{2}$ ) will tend to be observed, if there are too few price observations in fitting the regression. That is, if the number of observed prices is not much greater than $m+n$. To attempt to get round the problem of spuriously good $f i t$, when observations are too few, a better measure of multipicativity is $R^{2}$ adjusted for degrees of freedom, conventionally denoted by $\bar{R}^{2}$. Formally, if a regression is being fitted involving $r$ observations and $s$ parameters: and if the total sum of squares of the dependent variable about its mean is denoted TSS, and the regression residual sum of squares is denoted RSS, then

$\bar{R}^{2}$ is defined as

$$
\bar{R}^{2} \quad-1-\left[\frac{R S S}{r-s}\right]^{\prime}\left[\frac{T S S}{r-1}\right]
$$

Like $R^{2}, \bar{R}^{2}$ from the basic CPD regression will equal 1 if the price structure is exactly multiplicative. The closeness of $\bar{R}^{2}$ to 1 can be taken as a reasonable measure of how multiplicative the price structure is.

$\bar{R}^{2}$ cannot be used as an absolute measure of multiplicativity, $\div 0$ compare price structures between different sets. of countries, since it will be dependent, for example, on the absolute price levels in the different countries - which in turn are dependent on the 
particular currancies in use in the different countries. But for a

suxed of of countries, $\bar{R}^{2}$, is satisfactory means of comparing relative closeness to multiplicativity, for different sets of prices.

\section{(c). Internal Homogeneity of a Family of PPPs.}

As noted above, the 8 PPPs which have been calculated fall into three basic families - the Geary Khamis family, the EKS family, and the CPD family. It is useful to have a summary statistic to describe how internally homogeneous each family is. For a given basic heading. the internal homogeneity of a particular family.of PPPs is taken to be the largest distance between any two PPPs in the family, using the $D$ measure of distance defined at (a) above.

\section{(d). Closeness of Different PPP Families.}

Similarly, for two different families of PPPs, it is useful to have a summary statistic measuring how close the families are to each other. A measure of the closeness of two families is taken to be the smallest distance, in terms of the $D$ measure, between any two PPPS in the different families. 


\section{Introduction}

1.1 In previous chapters, it was noted that there may be a consistent price differential in the prices of non characteristic goods; that is, a characteristic / non characteristic bias.

In the discussion of the CPD approach in Chapter 4, it was suggested that the CPD regression model, with non characteristic dummy, would be an appropriate model to investigate this phenomenom. This chapter reports on the results of applying the CPD model to the price data described in the previous chapter for the purposes of studying the characteristic / non characteristic pricing differential. Two main questions are considered:

(a) Is there statistically significant evidence that a differentia: pricing effect exists, of the kind hypothesised?

(b) If so, is the magnitude of the effect such that it has a potentially important operational effect: that is, is it liable to make any real difference to calculated PPPs?

1.2 Table 6.1 shows the following information for the 33 out of the 
37 basic headings for which it was possible to estimate the CPD model with non characteristic dummy.

(a) the coefficient of the non characteristic dummy estimated from the regression. It will be recalled that a positive coefficient corresponds to a differential price effect of the direction hypothesised.

(b) the "t" values associated with the coefficient.

(c) the values of $[\exp ($ dummy coefficient) -1$] * 100$ : this is the estimated percentage effect on the price of an item through being non characteristic.

(d) the distance $D$, as defined in Chapter 5, between the CPD PPPS, calculated with and without the non characteristic dummy variable in the regression.

1.3 It will be seen, from the first two columns of the table, that, out of the 33 product groupings, the coefficient of the non characteristic dummy variable is positive in 26 cases, negative in 7. On the basis of the " $t$ " statistic, five of the coefficients are significantly different from 0 at the $5 \%$ level-and in each of these cases the coefficient is positive. These five commodities are cheese, preserved vegetables, condiments, alcohol and beef. The disproportionate number of positive coefficients, both overall, and among the individually significant items, suggests that there may well be an effect at work of the form hypothesised - although the reader may well not find tho evidence yet conclusive. However, a more refined analysis of the data shows that this conclusion can indeed be strengthened. 
TABLE 6.1

CHARACTERISTICINON CHARACTERISTIC BIAS

\begin{tabular}{|c|c|c|c|c|}
\hline ITEM & $\begin{array}{l}\text { COEFFICIENT } \\
\text { OF NON CHAR } \\
\text { DUMMY }\end{array}$ & $\stackrel{t}{\text { VALUE }}$ & $\begin{array}{l}\text { X EFFECT } \\
\text { ON ITEM } \\
\text { PRICE }\end{array}$ & $\begin{array}{l}\text { D MEASURE } \\
\text { BETW. CPD } \\
\text { WITH \& WOUT } \\
\text { BIAS }\end{array}$ \\
\hline $\begin{array}{l}\text { RICE } \\
\text { BREAD } \\
\text { OTHER CEREALS } \\
\text { LAMB } \\
\text { SAUSAGES } \\
\text { PRES MEAT } \\
\text { FISH } \\
\text { PRES FISH } \\
\text { CHEESE } \\
\text { CITRUS FRUIT } \\
\text { APPLES } \\
\text { DRIED FRUIT } \\
\text { FROZ FRUIT } \\
\text { VEGETABLES } \\
\text { SALAD VEG } \\
\text { ROOT VEG } \\
\text { PRES VEG } \\
\text { COFFEE } \\
\text { TEA } \\
\text { JAM } \\
\text { CHOCOLATE } \\
\text { SWEETS } \\
\text { CONDIMENTS } \\
\text { ALCOHOL } \\
\text { WINE } \\
\text { BEER } \\
\text { RUSKS } \\
\text { NOODLES } \\
\text { BEEF } \\
\text { CREAM } \\
\text { SOFT DRINKS } \\
\text { APERITIFS } \\
\text { CIGARETTES }\end{array}$ & $\begin{array}{r}.127 \\
.064 \\
.017 \\
.088 \\
-.107 \\
.068 \\
.061 \\
.303 \\
.282 \\
.572 \\
.088 \\
.195 \\
.144 \\
-.025 \\
-.117 \\
.485 \\
.257 \\
-.247 \\
.089 \\
.18 \\
-.014 \\
.104 \\
.562 \\
.323 \\
-.318 \\
.184 \\
.142 \\
.034 \\
.403 \\
-. .376 \\
.062 \\
.149 \\
.148\end{array}$ & $\begin{array}{c}.44 \\
.42 \\
.11 \\
.73 \\
-.9 \\
.3 \\
.43 \\
1.59 \\
3.59 \\
1.33 \\
.21 \\
.78 \\
1.14 \\
-.11 \\
-.28 \\
1.77 \\
2.1 \\
-1.02 \\
.59 \\
2.41 \\
-.07 \\
.51 \\
2.27 \\
2.49 \\
-1 \\
.75 \\
.81 \\
.16 \\
3.57 \\
-1.18 \\
.25 \\
.5 \\
1.05\end{array}$ & $\begin{array}{r}13.5417 \\
6.6092 \\
1.7145 \\
9.1988 \\
-10.1474 \\
7.0365 \\
6.2899 \\
35.3915 \\
32.5779 \\
77.1807 \\
9.1988 \\
21.5311 \\
15.4884 \\
-2.469 \\
-11.0415 \\
62.4175 \\
29.3045 \\
-21.8859 \\
9.308 \\
19.7217 \\
-1.3902 \\
10.96 \\
75.4177 \\
38.1265 \\
-27.2397 \\
20.2016 \\
15.2577 \\
3.4585 \\
49.6307 \\
-31.3398 \\
6.3692 \\
16.0673 \\
15.9513\end{array}$ & $\begin{array}{l}.0005 \\
.0006 \\
0 . \\
.0013 \\
.0005 \\
.0007 \\
.0005 \\
.0074 \\
.007 \\
.0037 \\
0 \\
.0056 \\
.0011 \\
0 \\
.0002 \\
.0075 \\
.0047 \\
.004 \\
.0005 \\
.0007 \\
0 \\
.0011 \\
.0112 \\
.0161 \\
.001 \\
.0132 \\
.0017 \\
.0001 \\
.0161 \\
.0085 \\
.0006 \\
.0019 \\
.0036\end{array}$ \\
\hline
\end{tabular}


For all of the regression results recorded in the table, a probability value (P) can be associated with the observed statistic, as follows:

Let $T$ be the value of the "q" statistic actually observed, and let $z$ be a random variable with the appropriate "t" distribution possessed by $T$, under the null hypothesis that the coefficient of the non characteristic dummy is actually zero.

Then define

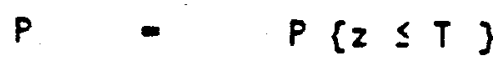

In other words, $P$ is the probability of obtaining a value of the "t" statistic $\leq$ the value actually observed, under the null hypothesis that the coefficient of the non characteristic dummy is actually zero.

Under this hypothesis, the $33 \mathrm{P}$ values associated with Table 6.1 would be equivalent to 33 independent observations on the uniform distribution over the interval $[0,1]$. It is appropriate, therefore, to apply the Kolmogorov Smirnov test to this set of $P$ values, to see whether they could indeed reasonably be regarded as being drawn from this particular distribution. Figure 6.1 shows the comparison of the two distributions. It will be seen that the empirical distribution is shifted uniformly to the right compared with the theoretical; the value of the Kolmogorov Smirnov statistic is indeed significant, at higher than the $0.3 \%$ level. Viewed thus, therefore, there is strong evidence of the existence of a positive differential effoct on the prices of non characteristic items. 
Fig 6.1 Empirical and Fitted Cumulative Distribution Functions

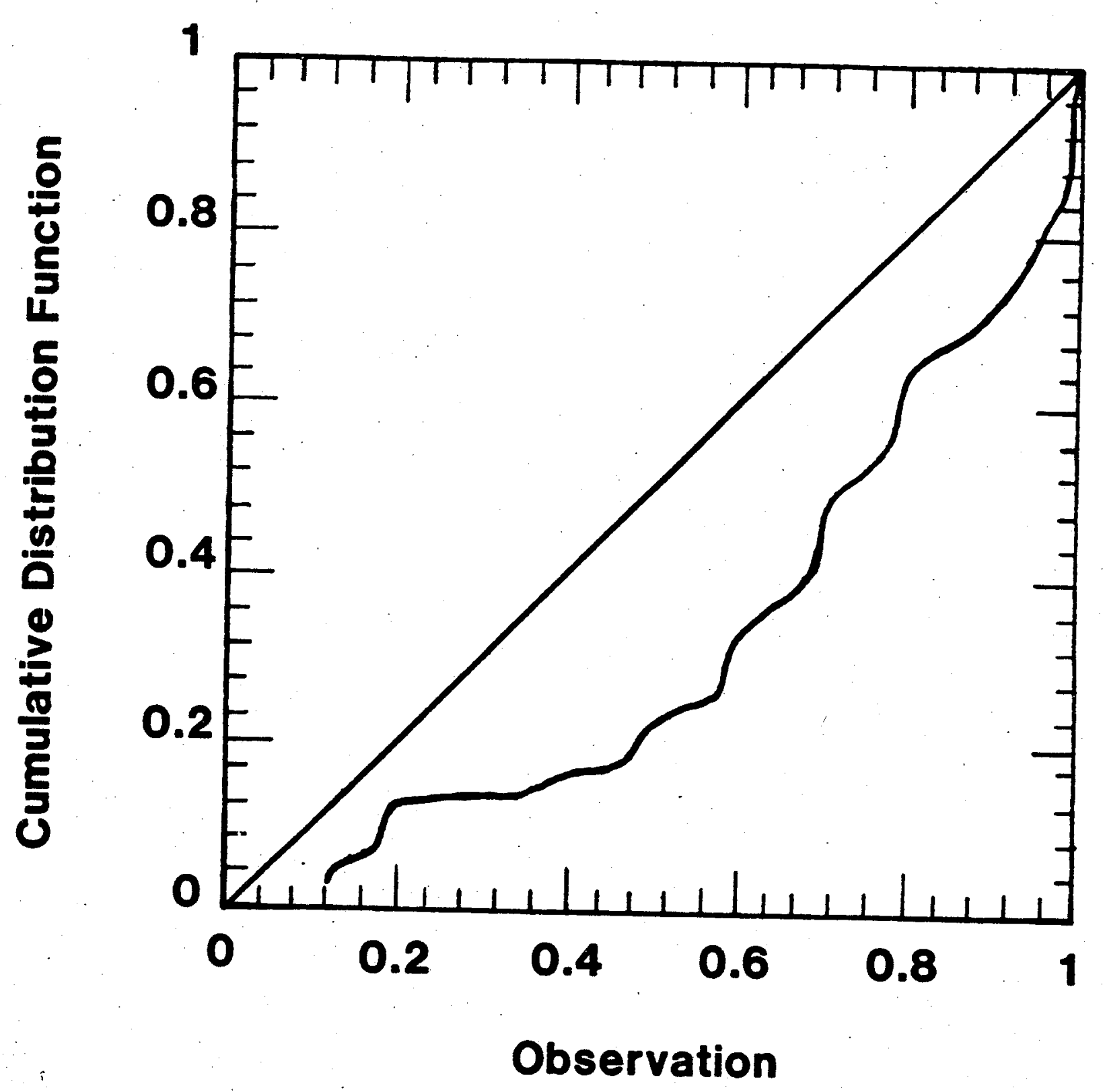


1.4 Having established that there is strong evidence for the existence of characteristic / non characteristic bias - the next question is - does it potentially make an important difference to the PPP comparisons? Column 3 in Table 6.1 shows the estimated effect on individual prices of being characteristic as a multiplicative factor. The largest effects, (for condiments, and citrus fruits) are indeed large - of the order of $75 \%$. Most of the effects are much smaller - typically around $10 \%$ on individual prices. Nevertheless, this is large enough to be of potential concern.

\subsection{Column 4 of Table 6.1 illustrates what is perhaps a more} relevant measure of the size of this effect. This is the distance, in terms of the distance measure $D$, between the CPD PPPs calculated with and without the non characteristic dummy. It will be noted that the large coefficients in column 1 do not always correspond to large D values: this, in fact, is not unexpected and can arise if there are, proportionately, only a small number of non characteristic to characteristic products in the basic heading.

The largest $D$ values occur for condiments, alcohol, beef and beer, where the $D$ value is greater than .01 in each case. For $D$ values of this magnitude, it would be anticipated ( see Fig.5.1 in Chapter 5) that some inter country PPP comparisons would be affected by $20 \%$ or more - and this is indeed the case. For example for condiments, the estimated Turkey / Austria PPP for the C2 index, that is the CPD with bias, is 14.8 , but the CPD without bias, $\mathrm{Cl}$, is only 11.4 , - a 
difference of 30x. In fact, three out of the five condiments priced in Austria are non characteristic - so it is not surprising that correcting for non characteristic bias naturally lowers the Austrian price level relative to other countries.

Similarly, for beer, there is an effect approaching $20 \%$ on some of the inter country comparisons involving Austria (five out of the seven beers priced in Austria are non characteristic); and over $15 \%$ on some of the comparisons involving Japan, (three out of five beers priced in Japan are non characteristic).

These examples illustrate that the effect of differential prices for non characteristic items can indeed be of potentially major importance for particular basic headings. For most of the basic headings considered, however, the apparent effect is much smaller: that is the $D$ values observed would typically imply differences of a few percentage points in inter country PPPs.

1.6 To sumarize therefore:-

(a) There is evidence of a significant positive differential effect on the prices of non characteristic items.

(b) The magnitude of this is such that, for some basic headings, it could potentially have a vory serious effect in distorting inter. country PPP comparisons. 
Tho problem of non characteristic bias is shown here to be one that has to be taken very seriously. It is relovant, however, to recall the theoretical discussion at the ond of Chapter 4. In particular. each case really has to be considered on its merits: there are no a priori grounds for regarding either of the CPD PPPs as boing intrinsically superior to the other. 


\section{CHAPTER SEVEN}

INTERNAL HOMOGENEITY OF PPP GROUPINGS AND BETWEEN GROUP DISTANCES.

1. Introduction.

1.I This chapter continues the detailed analysis of the data for 37 product groupings, looking at the internal homogeneity of the three basic PPP groupings, and the inter group distances. It will be recalled that the necessary concepts for this analysis, for example, inter PPP distances etc., were defined in Chapter 5.

2. The Internal Homogeneity of the Geary Khamis Family.

2.1 When the theory of the Geary Khamis method was discussed in Chapter 1, it was noted that, where the price structure is exactly multiplicative, then the Geary Khamis PPP is independent of the quantities. This suggests that, in real life, as the price structure becomes more multiplicative, the different versions of the Geary Khamis defined in Chapter 2, which differ only in their imputed quantities, should come closer together. In other words, as $\bar{R}^{2}$, the measure of price structure mulitplicativity defined in chapter 5 , 
increases. the internal homogeneity of the Geary Khamis grouping should increase.

Figure 7.1 shows $\bar{R}^{2}$ on the horizontal axis plotted against the measure of internal homogeneity for the Geary. Khamis group, defined in Chapter 5. Recall that internal homogeneity is measured by the largest within group distance: so the smaller this measure is, the greater the degree of internal homogeneity.

Examination of Figure 7.1 suggests that there is a relationship of the form suggested - but that it is fairly weak. All basic headings where $\bar{R}^{2}$ is $>.99$ have a homogeneity measure of .01 or less: and below an $\bar{R}^{2}$ value of .99 , there is, apart from one notable outlier, discussed in more detail below, the suggestion of a downward slope to the upper bound of the scatter of plotted points. On the other hand, the maximum observed value of the homogeneity measure rapidly becomes very large as $\bar{R}^{2}$ falls below .99 . Thus, it is clear that, for the bulk of the basic headings in the sample, the degree of price multiplicativity $\left(\bar{R}^{2}\right)$ is not in itself such as to place any very stringent bound on the expected homogeneity of the Geary Khamis family.

Further examination of the marked outlier towards the top right of Figure 7.1 is of interest. This product grouping is, in fact, noodles: and within this group, there are only four items which are priced within the ten countries considered. For three countries, Australia, Canada and Turkey, only one item is priced in each country. The large value of the Geary Khamis internal homogeneity 
Fig 7.1 GK Internal Homogeneity versus $R$ (BAR) Squared

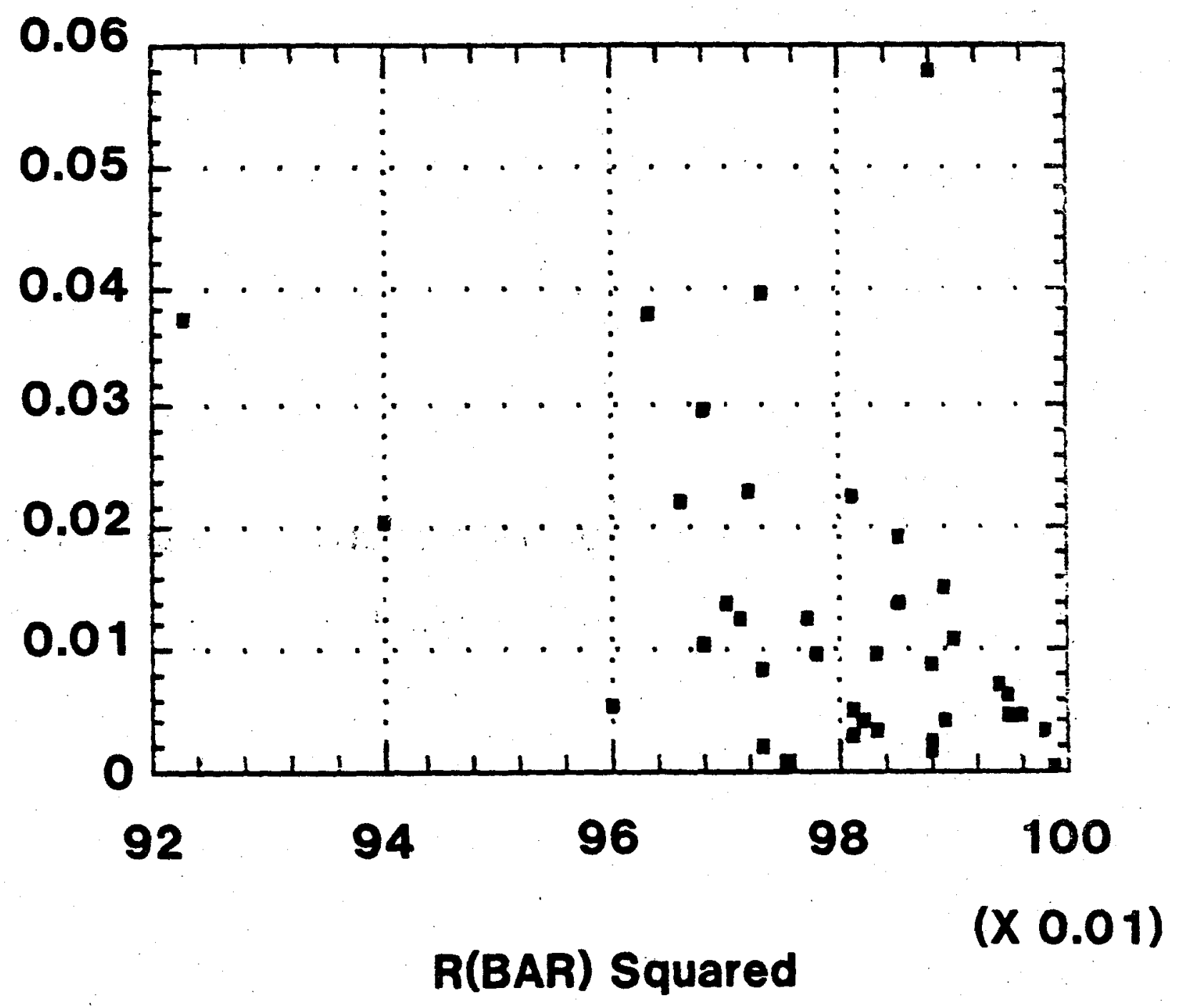


measure for this group is largely accounted for by the Turkey / Canada price comparison which has a value of 117.7 for GK1 and 196.7 for GK3 - a difference of 67x. This large difference arises because of two contributory factors :-

(a) First of all, the price structure for items 4 and 5 is very non multiplicative between Japan and the USA:

JAPAN

601

250
USA

Largely because of this, the international price of item 5 is much higher under GK3 (which attaches relatively more weight to the USA) than under GK1. The GK1 and GK3 international prices of item 5 are 12.85 and 18.33 respectively, in Austrian schillings.

(b) The second factor at work is that only one item is priced in each of Turkey and Canada: item 1 in Turkey, item 5 in Canada. So if Turkey is denoted by the suffix $T$ and Canada by the suffix $C$, it follows that

$$
\begin{aligned}
G K T C & =\frac{\sum p_{i T} q_{i T}}{\sum \pi_{i} q_{j T}} / \frac{\sum p_{i C} q_{i C}}{\sum \pi_{i} q_{i C}} \\
& =\frac{p_{1 T} q_{1 T}}{\pi_{1} q_{1 T}} / \frac{p_{5 C} q_{5 C}}{\pi_{5} q_{5 C}}
\end{aligned}
$$




$$
\frac{p_{1 T}}{p_{5 C}} \cdot \frac{\pi_{5}}{\pi_{1}}
$$

Thus the change in the Turkey / Canada comparison between the GK! and GK3 versions depends on the change in the ratio $\pi_{5} / \pi_{1}$ from GK 1 estimated prices to GK3 estimated prices - and this is in fact very large mainly due to the instability of $\pi_{5}$ already noted at (a).

Study of the noodles outlier, therofore, suggests two important points.

(i) Despite an apparently high $\bar{R}^{2}$ (.988 in this $\left.\operatorname{cas} \theta\right)$, the struciure of international prices may be very non multiplicative - and this can have a significant offect on the Geary Khamis methods proposed.

(ii) When small numbers of items are priced in individual countries, then the Geary Khamis PPPs between individual countries can reduce to ratios of individual prices: thus the averaging effects of adding prices are lost, and the resulting price comparisons can be fairly unstable.

The overall conclusion of this section are, therefore, fairly sobering for the Geary Khamis methods considered. In particular, (a) unless the price structure involved is very multiplicative the 
different Geary Khamis methods can be sensitive to the choice of imputed quantities:

(b) there is a suspicion that the Geary Khamis methods may tend to be fairly unstable in cases where only a small number of items are priced in particular countries.

3. Distance between Geary Khamis and CPD Families: Relationship with $\overrightarrow{R^{2}}$.

3.1 The same theoretical argument that suggested that the internal homogeneity of the Geary Khamis would increase as $\bar{R}^{2}$ tends to 1 , also suggests that the distance between the Geary Khamis and CPD families is likely to decrease with increasing multiplicativity. Fig 7.2 examines this, plotting $\bar{R}^{2}$ on the horizontal axis against the Geary Khamis / CPD distance on the vertical: For very high values of $\bar{R}^{2}$, the Geary Khamis and CPD families are indeed very close together. As is the case for the Geary Khamis internal distance, however, the GK /CPD distance can rapidly become quite large when $\bar{R}^{2}$ falls below about .99 .

The main outlier in Figure 7.2, with a GK / CPD distance of about .04 , is processed meat. The characteristics of this basic heading are described in more detail below. 
Fig 7.2 GK / CPD Distance versus $R(B A R)$ Squared

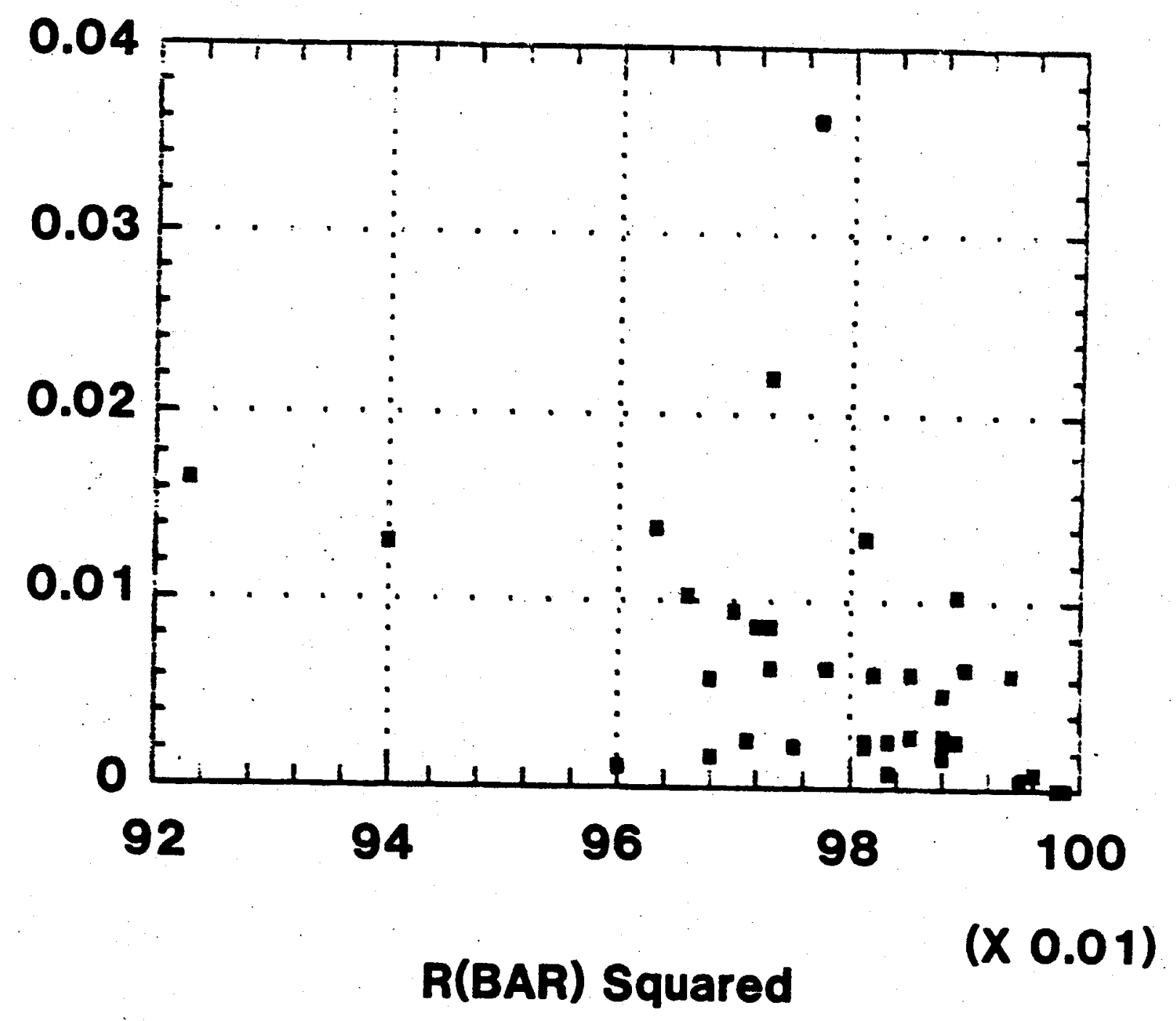


4. Internal Homogeneity of the EKS Family.

4.1 It will be rocallod that the term "EKS" has been used to denote the group of three PPPs consisting of the EKS itself, the $\log$ Fisher regression with bias term, and the log fisher without bias. This section examines the internal homogeneity of this family.

4.2 With one exception, Dried Fruit, the EKS family is very internally homogeneous for the 37 product groupings considered. For dried fruit, 4 out of the 6 items priced in the USA are non characteristic - and the US in fact forms only two Fisher links. the effect is that the estimation of the bias coefficient in the "log Fisher with bias" regression for the US is confounded with the estimate of the US price offect, leading to imprecise estimates and accounting for the very large internal homogeneity measure of 1.5 for the EKS family. For this reason, dried fruit has been excluded from the further analysis of the EKS family.

4.3 Apart from Dried Fruit, the largest internal distance within the EKS family occurs for Sweets $(.0056)$ and Beer $(.005)$ : in tast, for most other basic headings, the EKS internal distances are considerably smaller than this. Figure 7.3 shows a three dimensional plot of the maximum EKS internal distance (vertical axis) against the number of Fisher links found at the first stage in calculating the EKS, and the percentage of prices which relate to non characteristic products. It can be seen that, when the number of first stage Fisher links is close to its theoretical maximum, (45), 
Fig 7.3

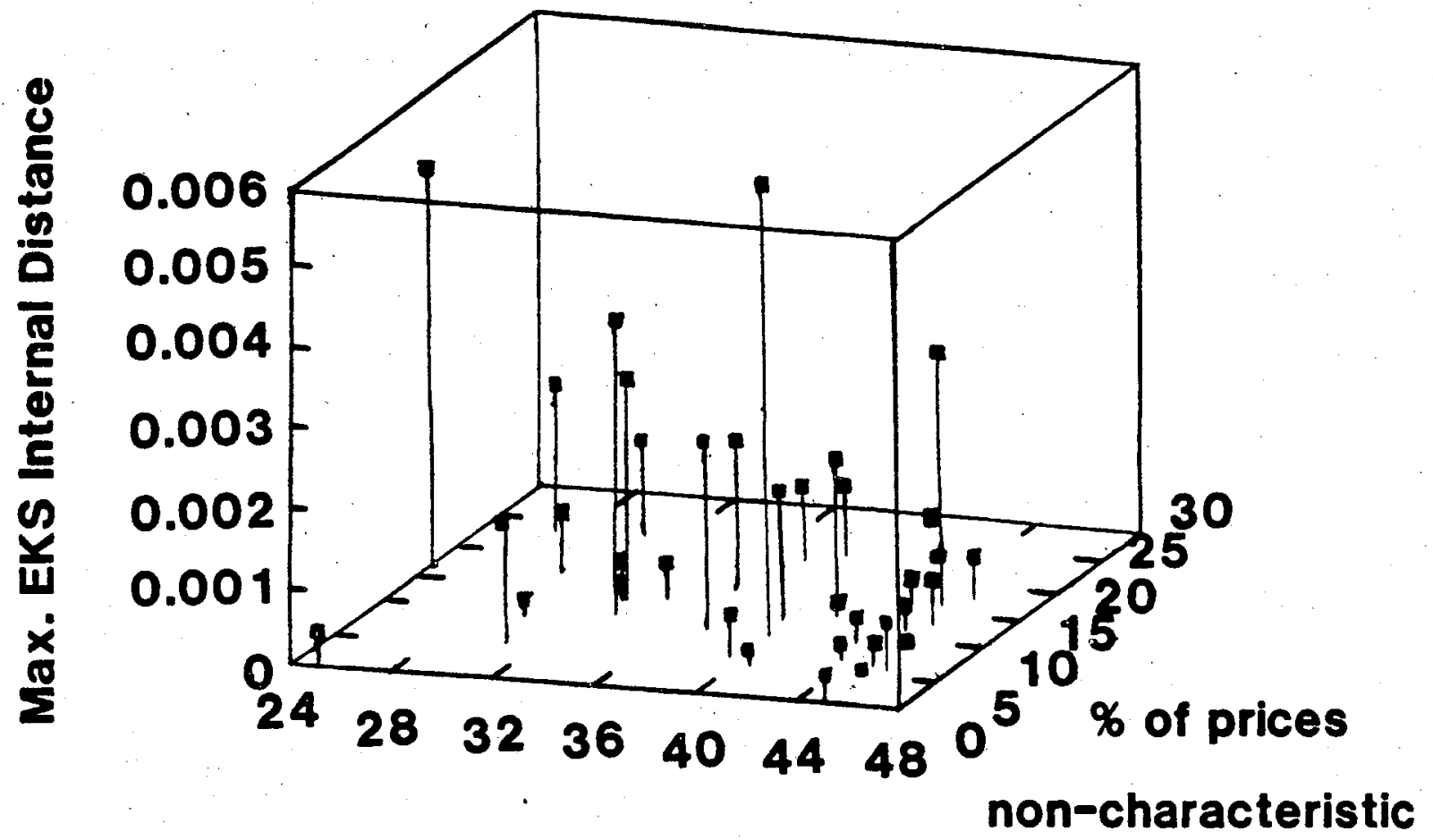
No. of Fisher Links 
and where there is a low percentage of non characteristic prices, then the maximum internal distance within the EKS family tends to be very small indeed.

4.4 It should be noted, however, that, despite the high degree of internal homogeneity within the EKS family, some of the distances observed are still large enough to be operationally important. Thus a distance measure of .005. (which was the largest internal distance observed within the EKS family, apart from the dried fruit anomoly) corresponds to an approximate range of $+1-15 x$ on inter country price comparisons. This is certainly large enough to be of some concern in practice.

5. Distance between EKS and Other Families: Relation with $\bar{R}^{2}$.

5.1 If the price structuro is exactly multiplicative, then the EKS purchasing power parities will coincide with the GK and CPD PPPs. It is therefore appropriate to examine whether there is evidence of convergence between the EKS PPPs and those derived by the other methods, as $\bar{R}^{2}$ increases. Figure 7.4 shows the EKS /CPD distance plotted against $\vec{R}^{2}$ : and Figure 7.5 shows the corresponding plot for the EKS / GK distance.

5.2 Examination of Figure 7.4 suggests that there is some relationship, albeit fairly weak, for the EKS /CPD distance: all basic headings with a value of $\bar{R}^{2}$ greater than .99 have an EKS / CPD 
Fig 7.4 EKS / CPD Distance versus R(BAR) Squared

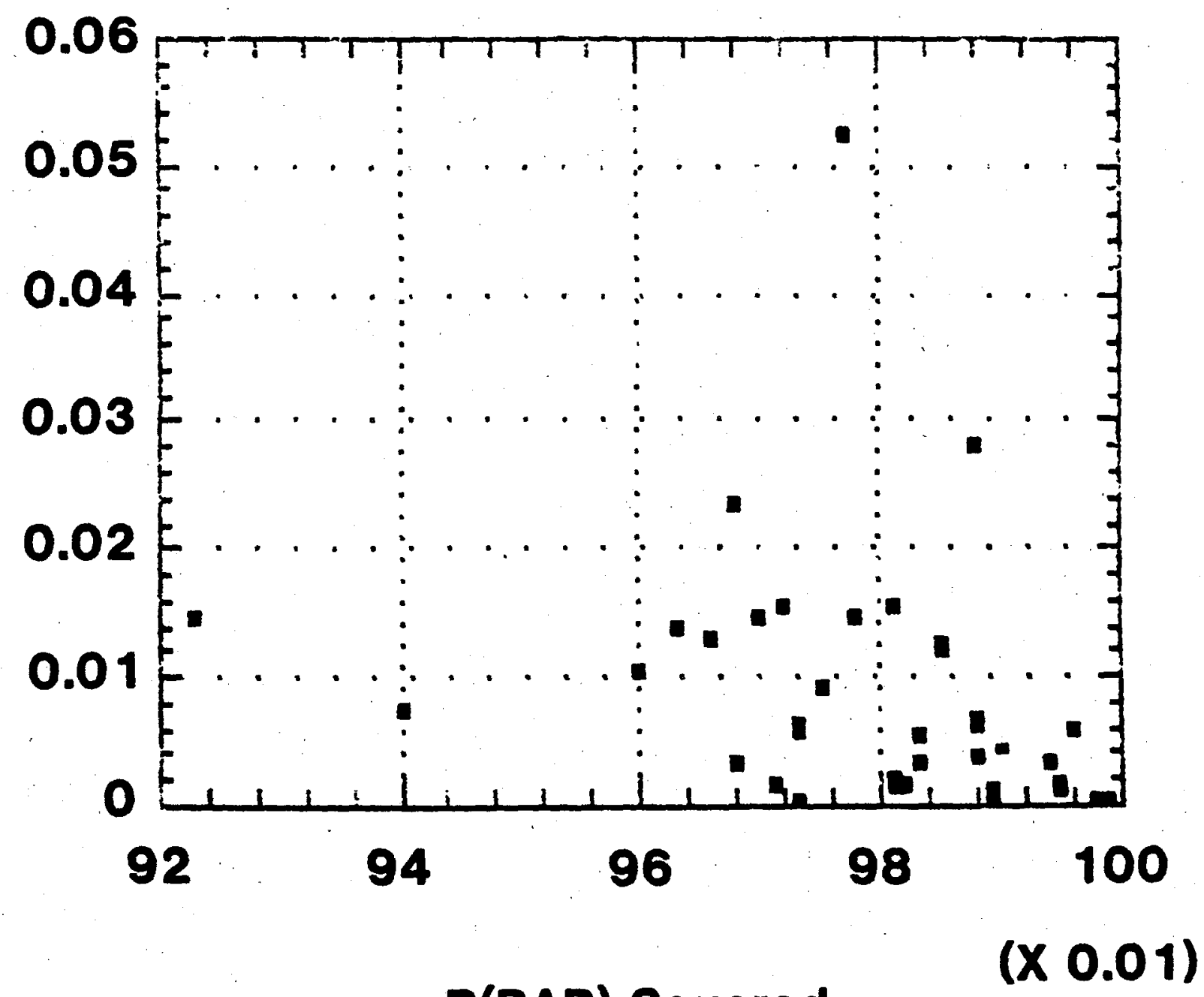


Fig 7.5 EKS / GK Distance versus $R(B A R)$ Squared

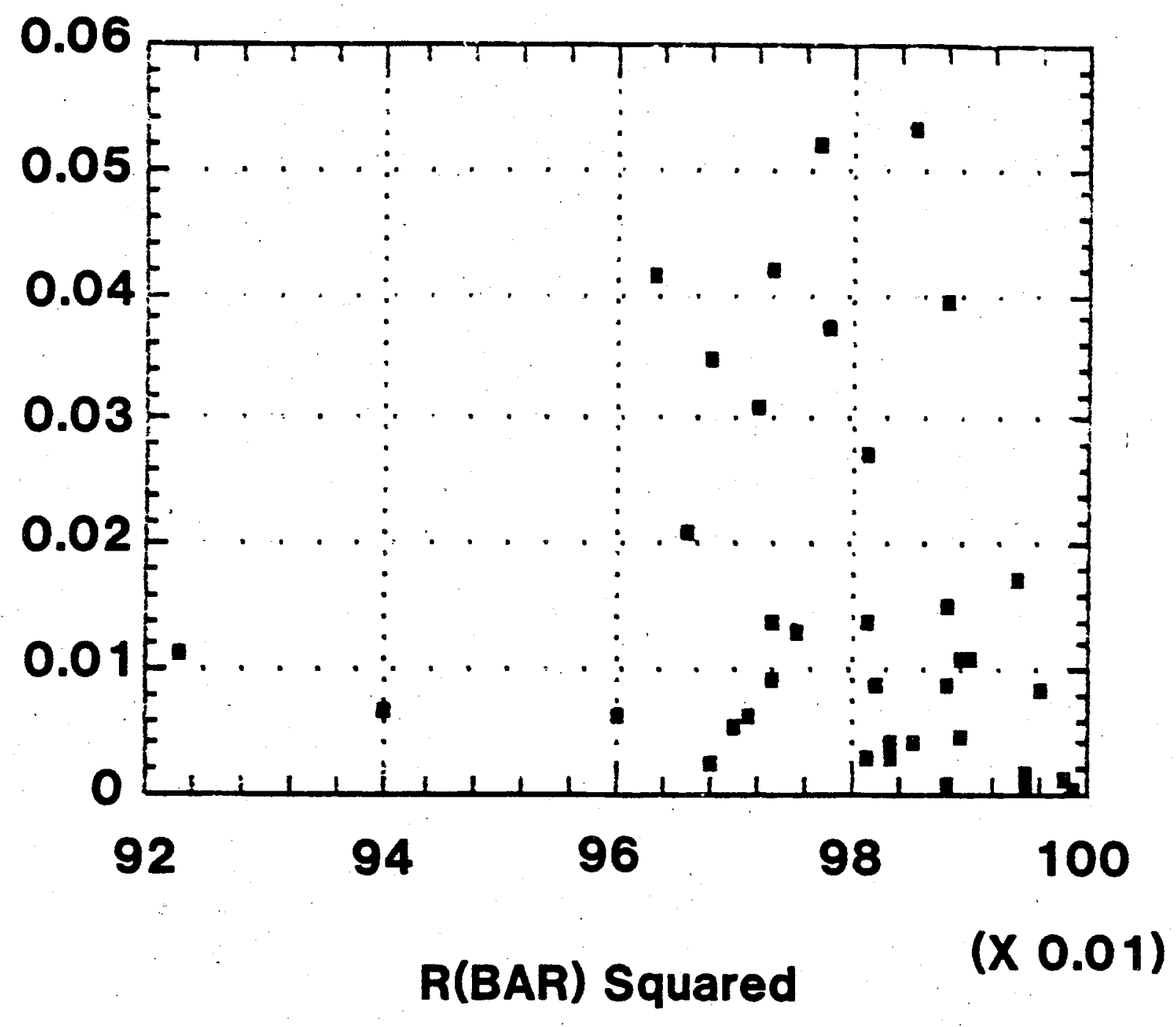


distance of less than .01 . For $\bar{R}^{2}$ values of less than .99 , the maximum observed value of the EKS / CPD distance increases quite rapidly. The main outlier in this plot, with an EKS / CPD distance of greater than .05 , is again, processed meat.

5.3 Figure 7.5, on the EKS /GK distance, suggests that any relationship is much weaker than for the other distance comparisons considered above. With the overall greater dispersion of points in Figure 4 there are less well defined outliers - the largest values of the EKS /GK distance, however, which aro both larger than .05 , occur for processed meat and beef.

5.4 It is of interest that processed meat shows up as an outlier in each of Figures $7.2,7.4$ and 7.5 : in other words, for processed meat there is a large distance betweon each of the three basic PPP families. More detailed analysis of the price data for the processed meat basic heading shows that it has the following features:

(a) $23 \%$ of the observed prices for processed meat are non characteristic: this is the second largest percentage of any basic heading. However, the estimated bias coefficient from the CPD regression, at .068 , is not particularly large.

(b) In the first stage of the EKS procedure, only 27 direct Fisher links can be formed. This is the third smallest number of any of the basic headings considered.

(c) Three countries (Finland, Turkey and Canada) have only one item 
priced in each of them: and in fact, the distribution of the number of priced items over countries is the second most skewed of all the basic headings considered.

The above factors suggest that the observed price structure for processed meat is particularly ill conditioned: it is littlo surprise, therefore, that it emerges as a consistent outlier.

6. Further Examination of Distances between the Basic PPP Groupings.

6.1 This section continues analysis of the distances between the basic PPP groupings: the main question considered is - is there any consistent pattern or relationship among the inter group distances.

Figures $7.6,7.7$, and 7.8 illustrate respectively:

Figure 7.6 : the EKS /CPD distance plotted against the EKS / GK distance;

Figure 7.7 : the GK / CPD distance plotted against the EKS / GK distance;

Figure 7.8 : the GK / CPD distance plotted against the EKS / CPD.

6.2 Drawn in on each plot are the $45^{\circ}$ lines, to help assess which distances tend to be the smaller.

It is clear from examination of the plots that 
Fig 7.6 EKS / CPD Distance

\section{versus EKS / GK Distance}

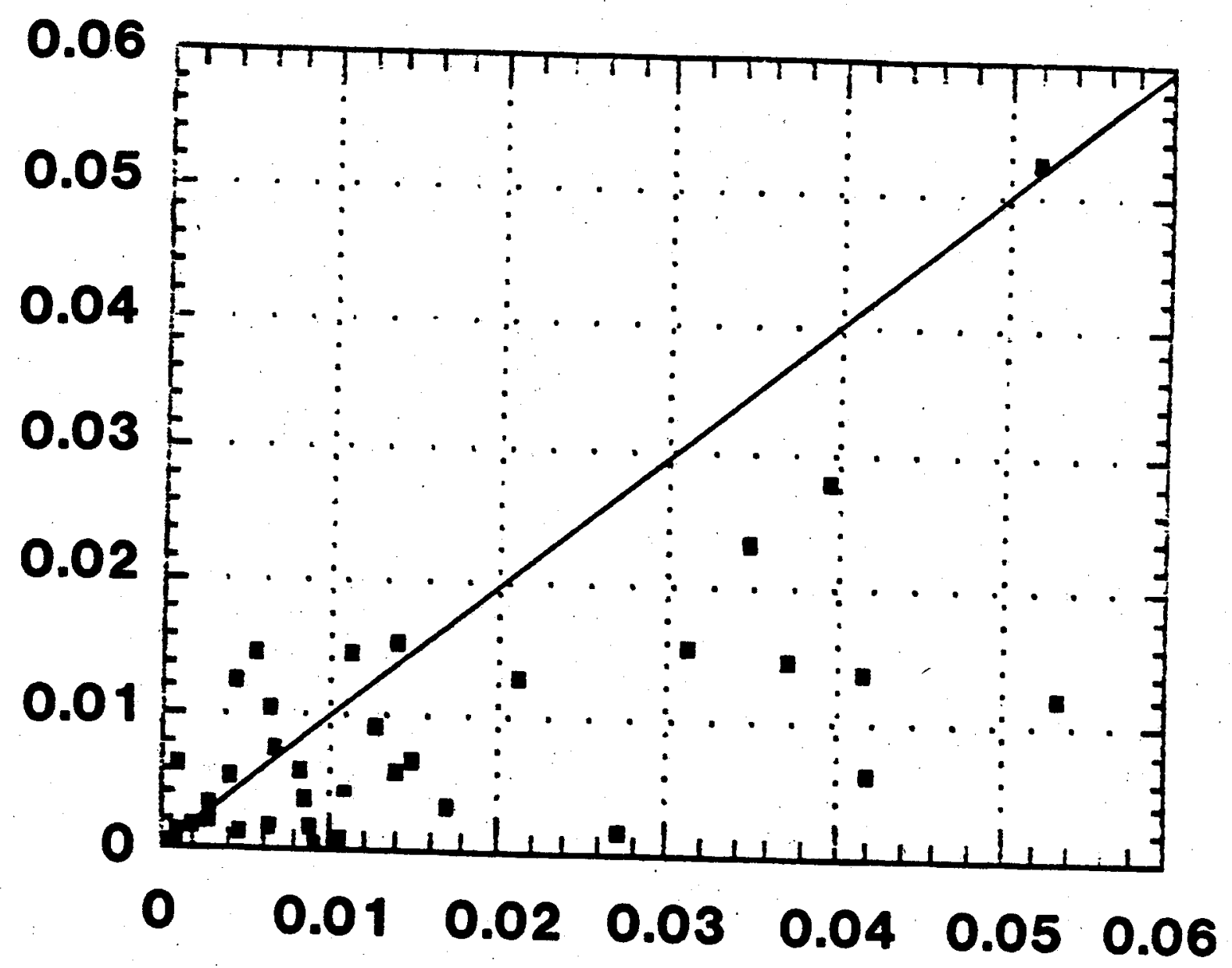

EKS / GK Distance 
Fig 7.7 GK / CPD Distance versus EKS / GK Distance

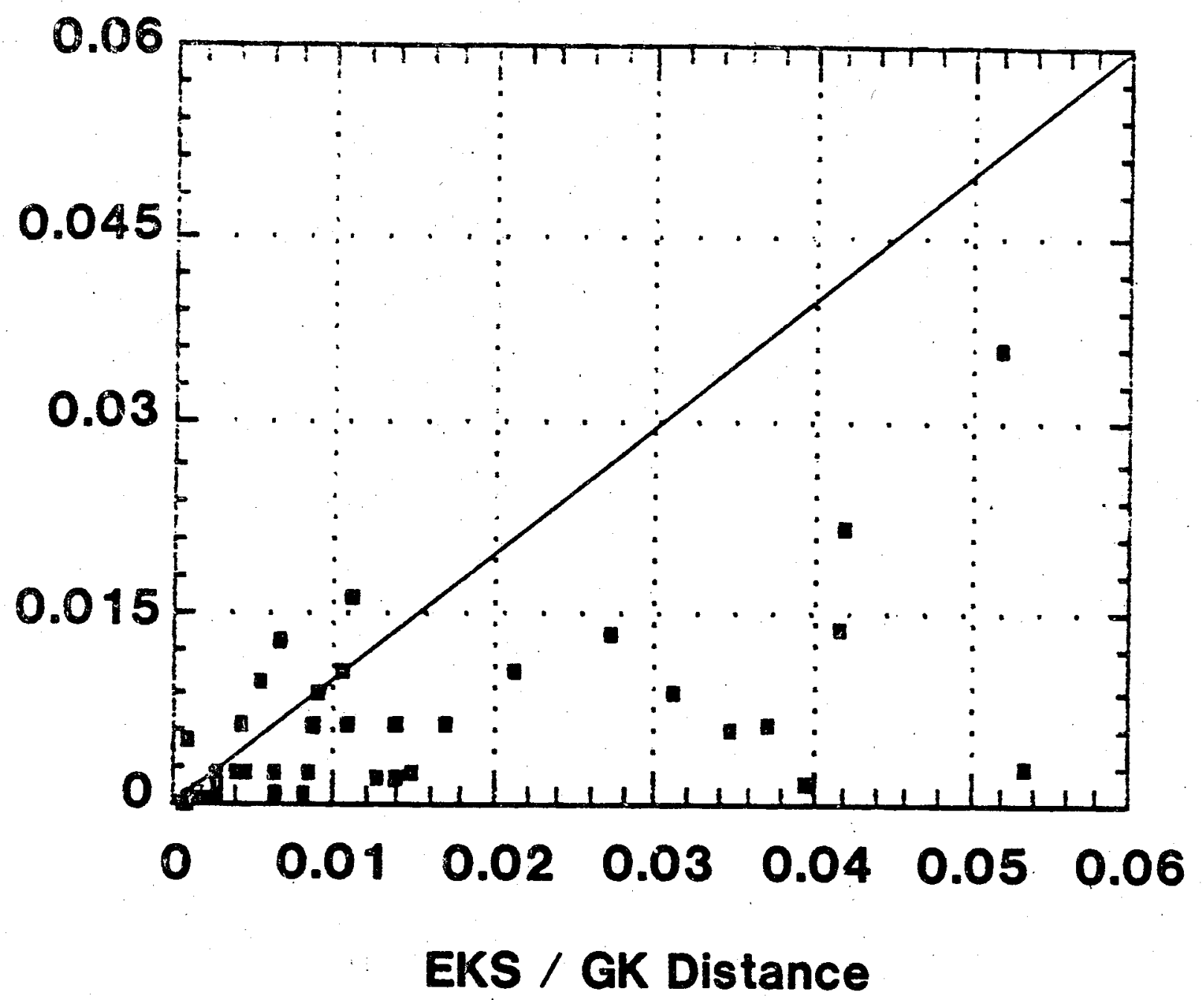


Fig 7.8 GK / CPD Distance

EKS / CPD Distance

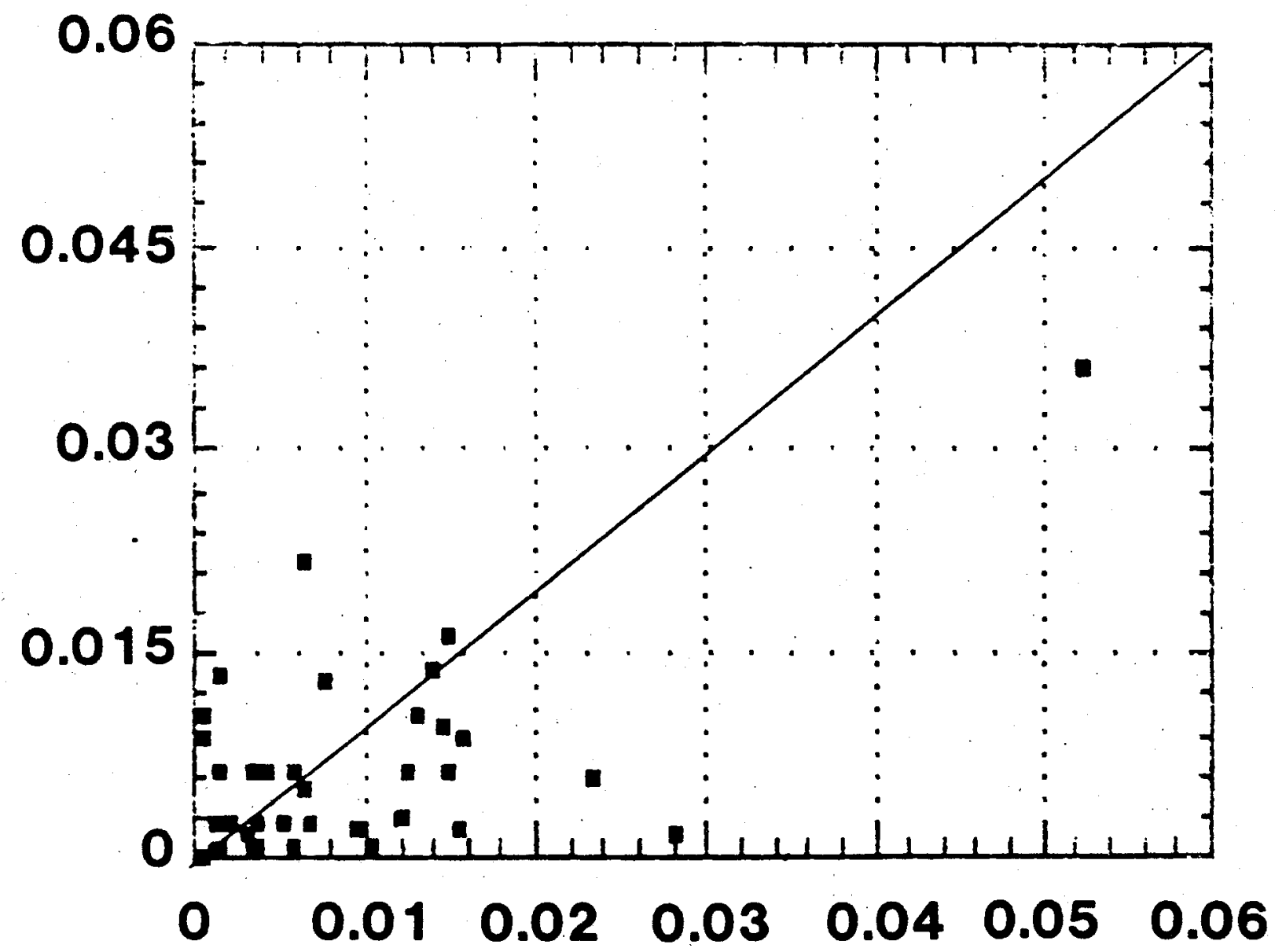

EKS / CPD Distance 
(a) for most basic hoadings, the EKS / CPD distance is smaller than the EKS / GK distance : (Figure 7.6)

(b) similarly, for most basic headings, the GK / CPD distance is smailer than the EKS / GK distances : (Figure 7.7)

(c) the striking factor about Figure 7.8 is that both of the GK/ CPD and EKS / CPD distances tend to be fairly small. For 20 out of the 37 product groupings, both distances are less than 01 : and for all but 4 of the groups, both distances are less than .02 . There is little or nothing to suggest that the CPD tends to be consistently closer to either the EKS or the GK. In fact, in 25 out of the 37 basic headings, the CPD is closer to the GK than to the EKS. This is weak evidence: however, taken together with the pattern of outliers in Fig 7.8, there is a slight suggestion that the CPD may tend to be closer to the GK than to the EKS.

6.3 To summarise the information in Figs $7.6,7.7$ and 7.8 : from the point of view of the Geary Khamis, the distance from the GK to the CPD tends to be smaller than the distance from the GK to the EKS. Conversely, from the point of view of the EKS, the distance from the EKS to the CPD tends to be smaller than the distance from the EKS to the GK. We could illustrate this state of affairs in $a$ heuristic diagram as follows, by saying that the CPD tends to lie, in distance terms, somewhere between the EKS and the GK: 
Furthermore, there is a weak suggestion that the CPD may tend to lie closer to the GK than to the EKS.

Of course, this kind of heuristic diagram is not to be interpreted too literally : but it provides a useful way of summarising the information in Figures 7.7 and 7.8 .

\section{Precision of CPD Estimates.}

7.1 Since the CPD technique involves fitting a regression equation, the standard properties of regression provide a direct estimate of the precision with which the CPD coefficients are estimated - in terms of the estimated standard errors of the regression coefficients. This is a bonus in the CPD approach: no such estimates of precision are readily available for the EKS or GK approaches.

7.2 In fatting the CPD regressions for the 37 product groupings studied, country 1 (Austria) was arbitrarily taken as the base country. This means that the estimated country coefficients from the 
Fig 7.9

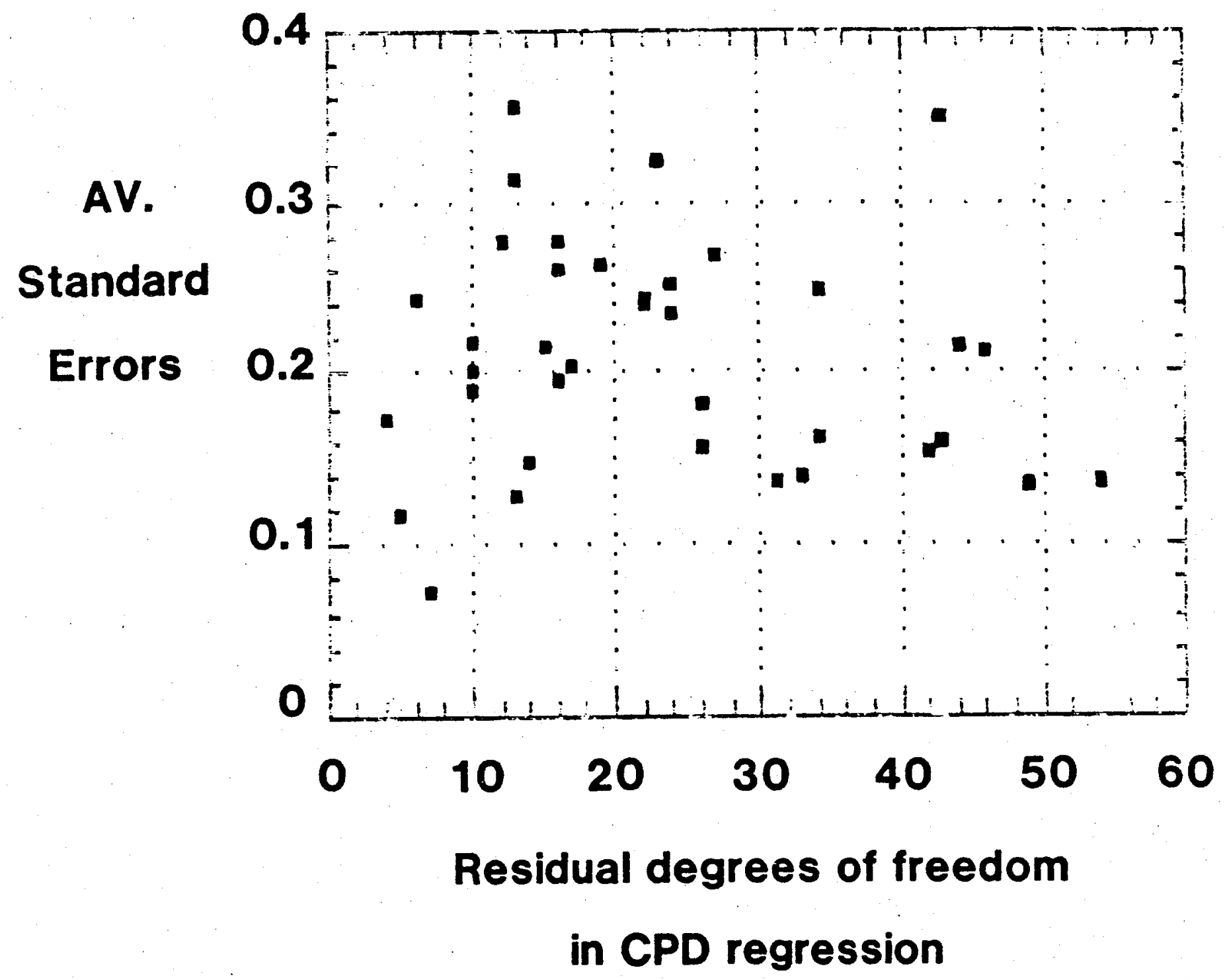


CPD regression represent the logs of the purchasing power relativities to Austria. In order to provide a convenient summary measure, the average of the standard errors of the 9 country coefficients was calculated within each basic heading.

7.3 Figure 7.9 shows the average product grouping standard errors, plotted against the residual degrees of freedom from the CPD regression. The version of the CPD regression model without a non characteristic dummy was used in this analysis. Since the number of coefficients estimated in this regression is

1 constant

plus 9 country offects

plus ( number of items - 1) item effects, the residual number of degrees of freedom is equal to (number of observed prices) - (number of items) - 9.

7.4 Two factors are of potential interest in Figure 9.

(a) The first is the size of the average standard errors: only one standard error is smaller than 0.1 , and most are around 0.2 . A 95\% confidence interval for a given log price relativity is approximately $+1-2$ standard errors: Hence, for a given price relativity for which the standard error of the coefficient was 0.2 , the half width of a $95 \%$ confidence interval around the rice relativity $p$ would be given by a multiplicative factor of $\exp \{2 * 0.2\}-1.5$; that is, the confidence interval would be given by the range 


$$
\{p / 1.5, p * 1.5\}
$$

This suggests that the CPD technique, on the data studied, will typically give very imprecise estimates of purchasing power relativities. This is sobering - but is not, in itself, a criticism of the CPD technique, relative to the EKS or GK, since corresponding estimates of precision for the EKS and GK methods are not readily available. There is therefore no reason to suppose that the CPD is any less precise than the EKS or GK approachos. Indeed, since, as has been noted earlier, the CPD tends to occupy a central position between the EKS and the GK, thero may be some circumstantial grounds to suggest that the CPD may be more precise than the other techniques.

(b) The second interesting feature in Figure 7.9 is the suggestion that the vertical spread of averago standard orrors is greater towards the left of the diagram - that is, where the residual degrees of freedom in the regression are small. This is as one would expect - since there will be greater imprecision in estimating the standard error, the smaller the number of residual degrees of freedom. This feature points to a difficulty with the CPD approach, If the number of observed prices is only slightly greater than the number of countries plus items. In this situation, there is a danger of getting a severely misleading impression of the precision of the CPD estimates. 


\section{Conclusions}

8.1 Finally, what conclusions can be drawn from the data analysis presented in this and the previous chapter?

(a) First of all, on the question of characteristic/ non characteristic bias, the conclusions are fairly positive. Significant evidence has been found that this kind of bias exists and of a magnitude which could have an important bearing on real. Iife Ppp comparisons. No uniform a-priori rule can be laid down as to whether this effect should be corrected for in any specific instance : this really depends on how large a proportion of total trade within the country is accounted for by non characteristic products.

The implication, therefore, is that, unless there is to be a risk of significant distortion arising from this cause, effort has to be put into more refined estimates of commodity volumes below basic heading level : and a technique of calculating PPPs should be employed which would enable the size of the potential bias to be assessed, and any appropriate adjustment made, if necessary.

This points to the use of the CPD with non characteristics dummy, or the Log Fisher with dummy. In addition, with refined enough quantity data, the Geary Khamis method will automatically make the appropriate adjustment.

(b) More generally, the choice between different PPP methods is by no means clear cut. Where the price structure is very 
multiplicative, there does tend to be a general convergence between the different measures considered. In this happy circumstance it is unlikely to make much difference which measure is chosen. But for this to hold, the degree of multiplicativity, as measured by $\bar{R}^{2}$ from the CPD regression, has to be very high indeed. Unless the price structure is very multiplicative, there can be large differences between the PPPs assessed by different methods, both within the Geary Khamis family, and between the different families. In the absence of any objective reasons for preferring one particular approach to another, this points to a major problem of choice.

(c) What can be done about this?

There are perhaps three possible approaches, not necessarily mutually exclusive:

(i) as has been noted earlier, the CPD approach tends to produce a PPP which lies "between" the EKS and Geary Khamis families. This may suggest a preference for the CPD as a reasonable compromise approach.

(ii) alternatively, effort could bo put into deriving more realistic quantity data within basic headings. In practice, this is unlikely to be a feasible option, for cost and other reasons. But if fairly accurate quantity data could bo derived, the theoretical arguments for the Geary Khamis approach might suggest adopting the Geary Khamis,

(iii) A third approach would involve putting effort into deriving more refined quantity or expenditure data - but this time directed 
at roducing the size of the basic headings, that is., splitting them down into smaller aggregates, rather than attempting to obtain quantities at individual itom lovel.

As basic headings become smaller, there is a good chance that the internal price structure may become more multiplicative - so making the choice of method less critical. There are, however, limits to this approach - and these relate only partly to cost and data availability. As the number of items in the basic heading gets smaller, the number of price observations upon which to base estimates of the required parametors is therefore also reduced. This could lead to imprecision in parameter estimates. In particular, since the CPD approach involyes the simultsaepis estimation of a relatively large number of parameters, (equal to the number of countries plus the number of items), this might be a mora serious problem for the CPD approach compared to the other techniques. 


\section{CHAPTER EIGHT}

\section{AGGREGATION OF BASIC HEADINGS}

\section{Introduction}

1.1 The final stage in the analysis was to aggregate the PPPs derived at product group level over the 37 product groups. Two methods were used in this aggregation - the Geary Khamis and the Gerardi (UCW) method. Both of these methods were applied to each of the eight PPPs calculated at product group level - yielding, therefore, sixteen different ways of calculating the final PPP at the aggregate level. These sixteen methods are denoted by numbers, as follows :-

$1:$ GK

2 :Gerardi

$3:$ GK

4 :Gerardi

$5:$ GK

6 :Gerardi

$7:$ GK

8 :Gerardi aggregation of EKS

aggregation of EKS

aggregation of (log Fisher with bias) aggregation of (log fisher with bias)

aggregation of ( $\log$ Fisher without bias) aggregation of ( $\log$ Fisher without bias)

aggregation of GKI

aggregation of GK1 
9 : GK

aggregation of GK2

10: Gerardi

aggregation of GK2

11: GK

aggregation of GK3

$12:$ Gerardi

aggregation of GK3

13: GK

aggregation of CPD with bias

$14:$ Gerardi

aggregation of CPD with bias

15: GK

aggregation of CPD without bias

$16:$ Gerardi

aggregation of CPD without bias

In the fow cases where it was not possible to ealeulite the tog

Fisher or CPD with bias, the corresponding indices without bias were.

used. For Dried Fruit, where the log Fisher with blas ogit be

calculated but is suspect, because of an identiffabllfty problem, the without bias version was also used.

Note that in the above numbering, odd numbered methods felor to GK aggregation: even numbered to Gerardi.

\section{The Results}

2.1 Table 8.1 shows the complete set of resuliting ppopagregate level for the 16 methods outlined above. For each PPP, all 45 posstiblo 
TABLE 8.1 PURCHASING POWER PARITIES, AGGREGATE LEVEL AMONC 10 COLNTPIES

\begin{tabular}{|c|c|c|c|c|c|c|c|c|}
\hline $\begin{array}{l}\text { AGGREGATION } \\
\text { SECOND STAGE } \\
\text { FIRST STAGE }\end{array}$ & EKS & GER'DI & $\begin{array}{l}\text { LOG F } \\
\text { (with }\end{array}$ & $\begin{array}{l}\text { LOOF } F \\
\text { bias) }\end{array}$ & $\begin{array}{l}\text { LOG F } \\
\text { (wisho }\end{array}$ & $\begin{array}{l}\operatorname{LOG} F \\
\text { (bias) }\end{array}$ & GK1 & GER'DI \\
\hline 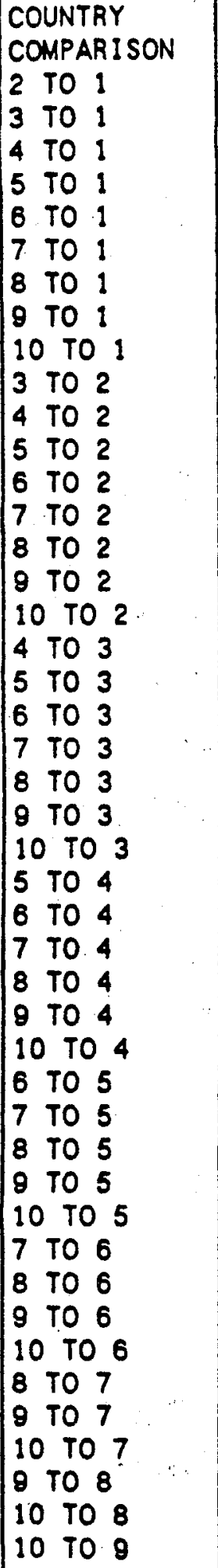 & $\begin{array}{l}.4738 \\
.7084 \\
.6665 \\
.0659 \\
.0831 \\
18.75 \\
.0856 \\
.0626 \\
10.80 \\
1.495 \\
1.407 \\
.1390 \\
.1754 \\
39.58 \\
.1807 \\
.1321 \\
22.79 \\
.9408 \\
.0930 \\
.1174 \\
26.47 \\
.1208 \\
.0883 \\
15.24 \\
.0988 \\
.1247 \\
28.14 \\
.1284 \\
.0939 \\
10.20 \\
1.262 \\
284.7 \\
1.300 \\
.9500 \\
163.9 \\
225.6 \\
1.030 \\
.7528 \\
129.9 \\
.0046 \\
.0033 \\
.5759 \\
.7310 \\
126.2 \\
172.6\end{array}$ & $\begin{array}{l}.4730 \\
.7228 \\
.6626 \\
.0663 \\
.0818 \\
18.45 \\
.0814 \\
.0581 \\
10.94 \\
1.528 \\
1.401 \\
.1402 \\
.1730 \\
39.00 \\
.1720 \\
.1228 \\
23.12 \\
.8166 \\
.0917 \\
.1132 \\
25.52 \\
.1126 \\
.0803 \\
15.13 \\
.1000 \\
.1235 \\
27.84 \\
.1228 \\
.0877 \\
16.51 \\
1.234 \\
278.2 \\
1.227 \\
.8764 \\
165.0 \\
225.4 \\
.0944 \\
.7100 \\
133.7 \\
.0044 \\
.0031 \\
.5930 \\
.7140 \\
134.4 \\
188.2\end{array}$ & $\begin{array}{l}.4770 \\
.7224 \\
.6742 \\
.0657 \\
.0828 \\
18.77 \\
.0863 \\
.0626 \\
10.89 \\
1.514 \\
1.413 \\
.1377 \\
.1735 \\
39.36 \\
.1810 \\
.1313 \\
22.84 \\
.9334 \\
.0909 \\
.1146 \\
25.99 \\
.1195 \\
.0867 \\
15.08 \\
.0974 \\
.1227 \\
27.85 \\
.1280 \\
.0929 \\
16.16 \\
1.260 \\
285.8 \\
1.314 \\
.8535 \\
165.8 \\
226.8 \\
1.043 \\
.7568 \\
131.6 \\
.0046 \\
.0033 \\
.5803 \\
.7256 \\
126.2 \\
173.8\end{array}$ & $\begin{array}{l}.4742 \\
.7329 \\
.6682 \\
.0859 \\
.0813 \\
18.37 \\
.0819 \\
.0581 \\
10.95 \\
1.546 \\
1.409 \\
.1390 \\
.1715 \\
38.75 \\
.1727 \\
.1225 \\
23.10 \\
.8117 \\
.0899 \\
.1110 \\
25.07 \\
.1117 \\
.0792 \\
14.85 \\
.0987 \\
.1217 \\
27.50 \\
.1226 \\
.0869 \\
16.39 \\
1.234 \\
278.7 \\
1.242 \\
.8811 \\
166.2 \\
225.9 \\
1.007 \\
.7143 \\
134.7 \\
.0045 \\
.0032 \\
.5962 \\
.7082 \\
135.8 \\
188.6\end{array}$ & $\begin{array}{l}.4721 \\
.7075 \\
.8630 \\
.0854 \\
.0822 \\
18.61 \\
.0853 \\
.0620 \\
10.73 \\
1.499 \\
1.404 \\
.1384 \\
.1742 \\
39.43 \\
.1806 \\
.1314 \\
22.72 \\
.9370 \\
.0924 \\
.1162 \\
26.31 \\
.1205 \\
.0877 \\
15.16 \\
.0986 \\
.1240 \\
28.08 \\
.1286 \\
.0936 \\
16.18 \\
1.26 \\
284.8 \\
1.305 \\
.9493 \\
164.1 \\
226.4 \\
1.037 \\
.7545 \\
130.4 \\
.0046 \\
.0033 \\
.5762 \\
.7276 \\
125.8 \\
172.0\end{array}$ & $\begin{array}{l}.4705 \\
.7212 \\
.6585 \\
.0658 \\
.0809 \\
18.32 \\
.0812 \\
.0577 \\
10.83 \\
1.533 \\
1.399 \\
.1399 \\
.1720 \\
38.93 \\
.1723 \\
.1226 \\
23.01 \\
.9130 \\
.0913 \\
.1122 \\
25.40 \\
.1124 \\
.0800 \\
15.01 \\
.0999 \\
.1229 \\
27.82 \\
.1231 \\
.0876 \\
16.44 \\
1.230 \\
278.3 \\
1.232 \\
.8767 \\
164.5 \\
226.3 \\
1.002 \\
.7129 \\
133.8 \\
.0043 \\
.0032 \\
.5911 \\
.7116 \\
133.6 \\
187.7\end{array}$ & $\begin{array}{l}.4501 \\
.6738 \\
.6357 \\
.0632 \\
.0771 \\
18.92 \\
.0816 \\
.0599 \\
10.06 \\
1.497 \\
1.412 \\
.1404 \\
.1714 \\
42.04 \\
.1813 \\
.1331 \\
22.35 \\
.0435 \\
.0938 \\
.1144 \\
28.08 \\
.1211 \\
.0889 \\
14.93 \\
.0894 \\
.1213 \\
29.76 \\
.1284 \\
.0942 \\
15.82 \\
1.221 \\
299.5 \\
1.292 \\
.9483 \\
159.2 \\
245.3 \\
1.058 \\
.7767 \\
130.4 \\
.0043 \\
.0032 \\
.5316 \\
.7341 \\
123.2 \\
167.9\end{array}$ & 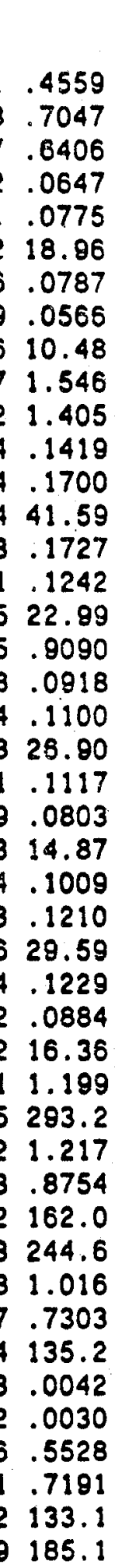 \\
\hline
\end{tabular}


TABLE 8.1 PURChasing POWER PARITIES, NGGREGATE LFVEL ARRNG 10 COUNTPIES

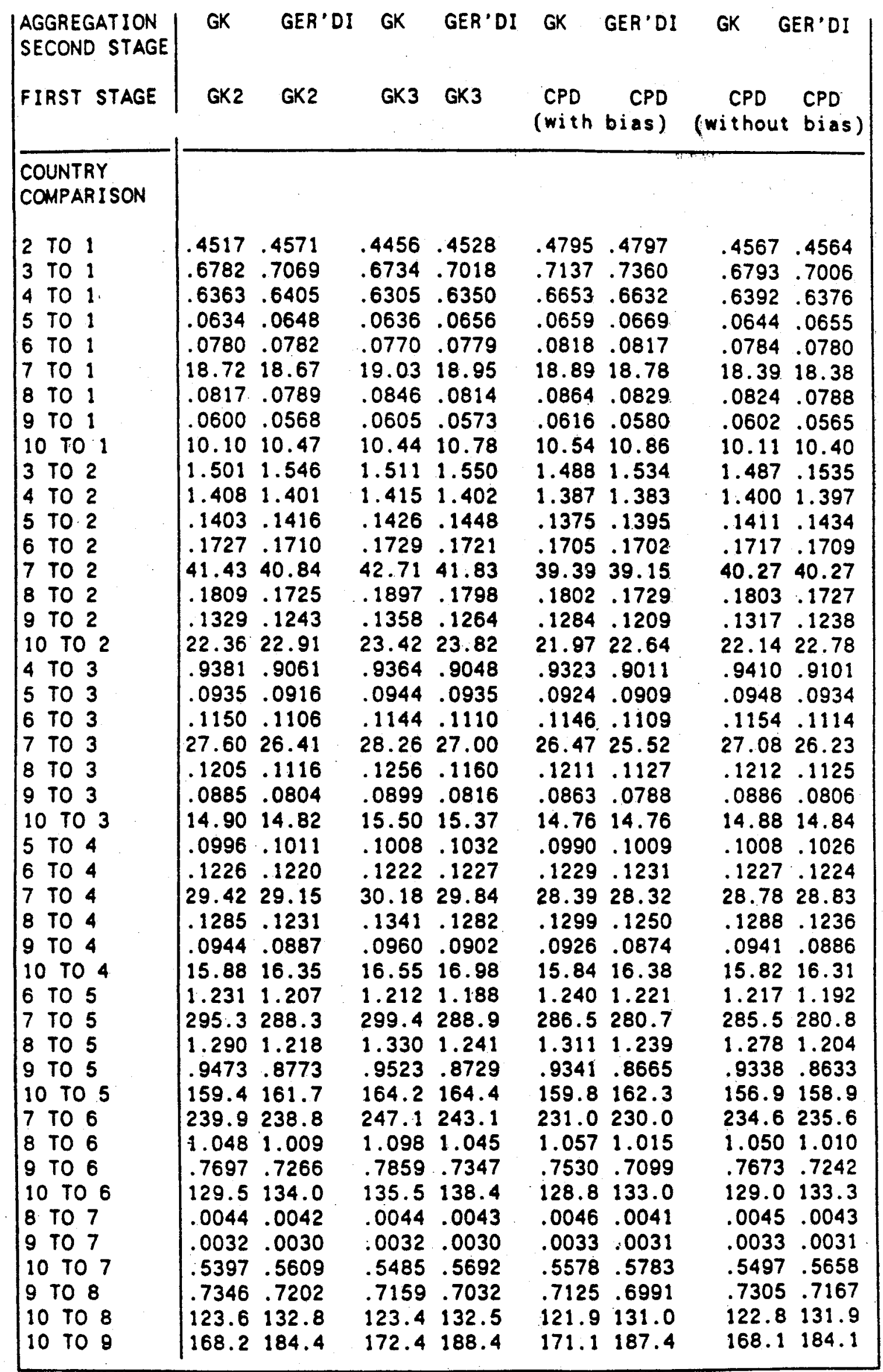


inter country comparisons among the 10 countries are shown.

Visual inspection of Table 8.1 suggests that there is a fairly high degree of uniformity among the different PPPs. But for a more informative analysis, it is useful to consider the inter PPP distance measure, $D$, defined earlier. Table 8.2 shows the complete $16 \times 16$ matrix of the distances, $D$, between every possible pair of. PPPS. For ease of reference, the GK PPPS are grouped together first of all, followed by the Gerardis: also, lines have been drawn on Table 8.2 to indicate the main PPP groupings.

2.2 The main points to be noted from Table 8.2 are as follows:-

(a) First of all, consider the group defined by PPPs numbered 1, 3 and 5: that is, the group consisting of GK aggregates of the EKS family. The within group distances for this group form the top left hand $3 \times 3$ block of the matrix in Table 8.2. It can be seen that this group is, in fact, very internally homogeneous, with a maximum distance within the group of .0001 . Examination of the other diagonal blocks of the matrix shows that a high degree of internal homogeneity is also a feature of the other groups which are defined by a common method of aggregation of the basic PPP families: the GK - GK, GK - CPD, Gerardi - EKS, Gerardi - GK, and Gerardi CPD groups.

(b) It is also noticeable that there is a fair degree of internal 


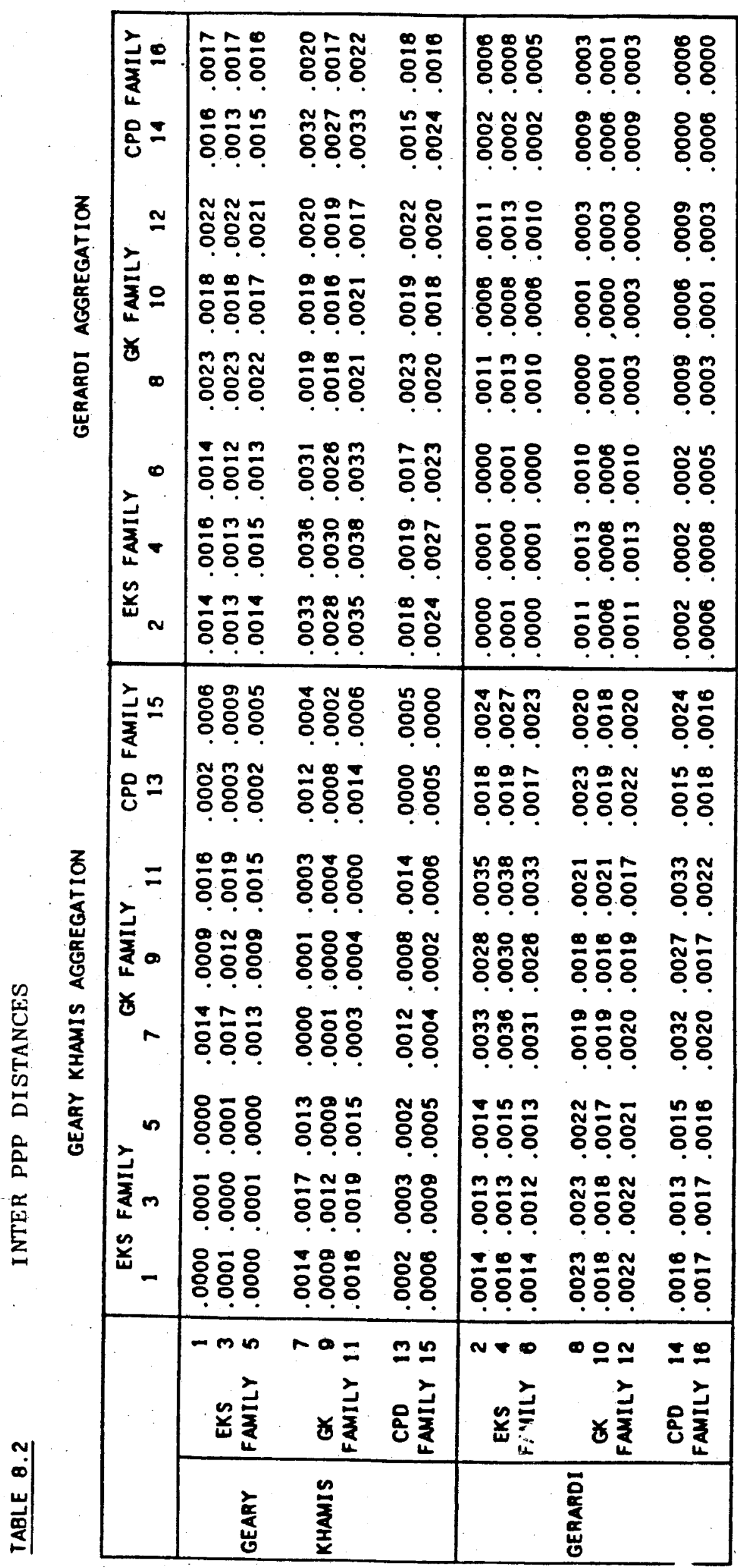


homogeneity within the $8 \times 8$ block of PPPs defined by GK aggregation: the top left $8 \times 8$ block in the matrix. Within this block, the largest internal distance is .0019 , between PPPs numbered 3 and 11 , and most of the distances within this group are a good deal smaller than this. .

Similarly, there is also a high degree of homogeneity within the Gerardi group, which is shown in the bottom Right hand $8 \times 8$ block in the matrix. In fact, within the Gerardi block, the largest internal distance is .0013 , between PpPs numbered 8 and 4 , and also between PPPs 12 and 4 .

(c) One of the most interesting features in Table 8.2, however, is the relatively high distances between the GK and Gerardi groupings. These inter group distances are those occuring in the top right or bottom left $8 \times 8$ block of the table. The smallest of these is .0012 . In other words, the GK aggregates are uniformly fairly distant from the Gerardi aggregates.

Examination of Tablo 8.1 suggests at least one of the main factors accounting for this feature. From inspection, it appears that the major differences between the GK and Gerardi aggregates of a particular PPP tend to occur in country comparisons involving the US. In each of rows $8,16,23,29,34,38,41$, and 43 , the US is in the numerator of the inter country comparison, and the price ratio is higher in the GK aggregated version compared with the corresponding Gerardi aggregated version. The opposite is true for row 45; there the US is in the denominator of the comparisons. This 
pattern is consistent with the underlying US price lovel being higher in the GK aggregate method than for the corresponding Gerardi aggregate method.

This consistent difference between the price levels for the US in the GK and Gerardi aggregation methods is not unexpected. The Gerardi method computes international prices as the unweighted geometric average of basic heading prices. On the other hand, the GK approach computes interriational prices essentially as a weighted average, where the weights defined are the quantities in the individual countries. Since the US has by far the largest volumes of the 10 countries, it is not unexpected that the largest difference between the GK and the Gerardi approach shows up primarily for the US. In other words, this observed pattern is consistent with the Gerschenkron effect.

2.3 In chapter 2 , section 5 , the question was raised as to whether the combined effect of applying the Geary Khamis approach in aggregating first to basic heading lovel and then to GDP lovel might lead to a compounded Gerschenkron effect - with a consequent over estimation of the price level of the dominant country or group. It was noted that this could not happen with the GK1 and GK2 methods for imputing quantities - since, under both these methods the imputed quantities are scaled to the same totals for all countries. In the context of the present data analysis, therefore, the compounded Gerschenkron effect could only ariso when the GK3 method is usod in the first stage of aggregation, combined with the Geary Khamis method in the second. 
Examination of the aggregate PPPs considered in this chapter is not entirely conclusive on this point. In Table 8.2 , the largest distances. $D$, occur between the PPP derived from combining the GK3 with the Geary Khamis (PPP number 11) and the PPPs obtained by combining the EKS family with the Gerardi, and the CPD (with bias) and the Gerardi. This is consistent with the existence of a compounded Gerschenkron effect. However, both the GK1 - GK and GK2 - GK PPPs, also have relatively large distances from the EKS and CPD families combined with the Gerardi. Thus, the evidence for the existence of a compounded Gerschenkron effect is still equivocal.

Direct examination of Table 8.1 is also relevant. On considering the price relativities in the Table botween the US (country 9), and each of the other countries, it can be seen that for four of these countries the GK3 - GK price relativity is higher than for all of the other aggregation methods. The countries for which this is true aro 2 (Finland), 3 (Norway), 4 (Sweden), and 6 (New Zealand) - all small countries in overall torms. This suggests that a compounded GK effect might indeed be at work.

In summary, it would not be appropriate to reach any firm conclusion, given the rather inconclusive nature of the ovidence: nevertheless, the evidence does tend to suggest that a compounded Gerschenkron offect could be a possibility if the GK3 method of aggregating up to basic heading. level is combined with Geary Khamis aggregation up to GDP level. 
2.4 It is appropriate to conclude with the following cautionary remark. The emphasis of this report is on problems and techniques arising in aggregating purchasing power parities up to basic heading level. This final chapter has involved moving from basic heading level to a higher level of aggregation. However, the discussion in this chapter is intended to throw more light on the techniques used in aggregating up to basic heading level - it is not intended as an account of aggregation beyond basic headings. In particular, the two higher aggregation techniques used, the Geary Khamis and Gerardi (UCW) methods, have been selected merely as two useful illustrative examples of the kind of techniques which can be applied in aggregating at higher level. It would not be appropriate to draw any conclusions, from the discussion in this chapter, on the relative merits of different aggregation techniques up to GDP level. 
116

APPENDIX A

GLARY KHAMIS SOLUTION IN THE THREE COUNTRY CASE.

Let the three countries be designated 0,1 , and 2 . Further, with no loss of generality, let us choose country 0 as the country with the numeraire currency and which is also the base country. Thus,

$$
R_{0}=1
$$

where $A_{j}$ is the ratio of prices in the numerator country to the base country 0 .

$$
\begin{aligned}
\pi_{i} & =\frac{\sum p_{i j} R_{j}^{-1} q_{i j}}{\Sigma q_{i j}} \\
& =\frac{\left[p_{i 0} q_{i 0}+p_{i 1} q_{i j} R_{i}^{-1}+p_{i 2} q_{i 2} R^{-1}\right]}{\left(a_{i 0}+q_{i 1}+q_{j 2}\right)} \\
R_{j} & =\frac{\sum p_{j j} q_{j j}}{\sum \pi_{j} q_{i j}}
\end{aligned}
$$

Therefore.

$$
\begin{aligned}
R_{1}^{-1} & =\frac{\left[\sum \pi_{i} q_{i 1}\right]}{\left(\sum p_{i 1} q_{i 1}\right)} \\
& =\frac{1}{\left(\sum p_{i 1} a_{i 1}\right)}\left[\sum \frac{p_{i 0} a_{i 0} a_{i 1}+p_{i 1} a_{i 1}{ }^{2} R_{1}{ }^{-1}+p_{i 2} a_{i 1} a_{i 2} R_{2}-1}{\left(a_{i 0}+q_{i 1}+q_{i 2}\right)}\right]
\end{aligned}
$$


Thus,

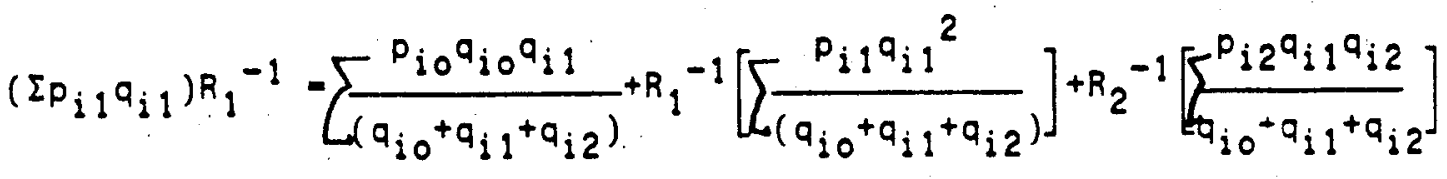

That is,

$$
\begin{aligned}
{\left[\int \frac{p_{i 1} a_{i 1}\left(a_{i 0}+a_{i 1}+a_{i 2}\right)-p_{i 1} a_{i 1}{ }^{2}}{a_{i 0}+a_{i 1}+a_{i 2}}\right] R_{1}-1 } & -\left[\sum \frac{p_{i 2} a_{i 1} a_{i 2}}{a_{i 0}+a_{i 1}+a_{i 2}}\right] R_{2}{ }^{-1} \\
& -\sum \frac{p_{i 0} a_{i 0} a_{i 1}}{a_{i 0}+a_{i 1}+a_{i 2}}
\end{aligned}
$$

That is,

$$
\begin{aligned}
{\left[\sum \frac{p_{i 1} a_{i 1}\left(a_{i 0}+a_{i 2}\right)}{a_{i 0}+a_{i 1}+a_{i 2}}\right] R_{1}^{-1}-\left[\sum \frac{p_{i 2} a_{i 1} a_{i 2}}{a_{i 0}+a_{i 1}+a_{i 2}}\right] R_{2}^{-1} } \\
=\sum \frac{p_{i 0} a_{i 0} a_{i 1}}{a_{i 0}+a_{i 1}+a_{i 2}}
\end{aligned}
$$

Similarly,

$$
-\left[\sum \frac{p_{i 1} a_{i 1} a_{i 2}}{a_{i 0}+a_{i 1}+a_{i 2}}\right] R_{1}^{-1}+\left[\sum \frac{p_{i 2} a_{i 2}\left(a_{i 0}+a_{i 1}\right)}{a_{i 0}+a_{i 1}+a_{i 2}}\right] R_{2}-1=\sum_{p_{i 0} a_{i 0} a_{i 2}}^{a_{i 0}+a_{i 1}+a_{i 2}}--(d)
$$


113

Thus,

$$
\begin{aligned}
& R_{i}^{-1}\left[\sum \frac{p_{i 1} a_{i 1}\left(a_{i 0}+a_{i 2}\right)}{a_{i 0}+a_{i 1}+a_{i 2}}-\frac{\left(\sum \frac{p_{i 1} a_{i 1} a_{i 2}}{a_{i 0}+a_{i 1}+a_{i 2}}\right)\left(\sum \frac{p_{i 2} a_{i 1} a_{i 2}}{a_{i 0}+a_{i 1}+a_{i 2}}\right)}{\sum \frac{p_{i 2} a_{i 2}\left(a_{i 0}+a_{i 1}\right)}{a_{i 0}+a_{i 1}+a_{i 2}}}\right] \\
& \sum \frac{p_{i 0} a_{i 0} a_{i 1}}{a_{i 0}+a_{i 1}+a_{i 2}}+\frac{\left(\frac{p_{i 0} a_{i 0} a_{i 2}}{a_{i 0}+a_{i 1}+a_{i 2}}\right)\left(\sum \frac{p_{i 2} a_{i 1} a_{i 2}}{a_{i 0}+a_{i 1}+a_{i 2}}\right)}{\sum \frac{p_{i 2} a_{i 2}\left(a_{i 0}+a_{i 1}\right)}{a_{i 0}+a_{i 1}+a_{i 2}}}
\end{aligned}
$$

Thus,

$$
\begin{aligned}
& R_{1}=\frac{\left(\left\langle\frac{p_{i 1} a_{i 1}\left(a_{i 0}+a_{i 2}\right)}{a_{i 0}+a_{i 1}+a_{i 2}}\right)\left(\frac{p_{i 2} a_{i 2}\left(a_{i 0}+a_{i 1}\right)}{a_{i 0}+a_{i 1}+a_{i 2}}\right)-\left(\frac{p_{i 1} a_{i 1} a_{i 2}}{a_{i 0}+a_{i 1}+a_{i 2}}\right)\left(\left\langle\frac{p_{i 2} a_{i 1} a_{i 2}}{a_{i 0}+a_{i 1}+a_{i 2}}\right)\right.\right.}{\left(\sum \frac{p_{i 0} a_{i 0} a_{i 1}}{a_{i 0}+a_{i 1}+a_{i 2}}\right)\left(\frac{p_{i 2} a_{i 2}\left(a_{i 0}+a_{i 1}\right)}{a_{i 0}+a_{i 1}+a_{i 2}}\right)+\left(\sum \frac{p_{i 0} a_{i 0} a_{i 2}}{a_{i 0}+a_{i 1}+a_{i 2}}\right)\left(\sum \frac{p_{i 2} a_{i 1} a_{i 2}}{a_{i 0}+a_{i 1}+a_{i 2}}\right)} \\
& \frac{\left(\frac{p_{i 1} a_{i 0} a_{i 1}}{a_{i 0}+a_{i 1}+a_{i 2}}\right)\left(\sum \frac{p_{i 2} a_{i 2}\left(a_{i 0}+a_{i 1}\right)}{a_{i 0}+a_{i 1}+a_{i 2}}\right)+\left(\sum \frac{p_{i 1} a_{i 1} a_{i 2}}{a_{i 0}+a_{i 1}+a_{i 2}}\right)\left(\sum \frac{p_{i 2} a_{i 0} a_{i 2}}{a_{i 0}+a_{i 1}+a_{i 2}}\right)}{\left(\frac{p_{i 0} a_{i 0} a_{i 1}}{a_{i 0}+a_{i 1}+a_{i 2}}\right)\left(\sqrt{p_{i 2} a_{i 2}\left(a_{i 0}+a_{i 1}\right)} \frac{a_{i 0}+a_{i 1}+a_{i 2}}{a^{2}}\right)+\left(\int \frac{p_{i 0} a_{i 0} a_{i 2}}{a_{i 0}+a_{i 1}+a_{i 2}}\right)\left(\sum \frac{p_{i 2} a_{i 1} a_{i 2}}{a_{i 0}+a_{i 1}+a_{i 2}}\right)}
\end{aligned}
$$


APPENDIX B

SAMPLING CONSIDERATIONS AND THE USE OF THE GEARY KHAMIS METHOD IN ESTIMATING BILATERAL PURCHASING POWER PARITIES AT. THE BASIC HEADING LEVEL.

1. This appendix considers the implications of applying sampling theory to the problem of estimating price relativities by the Geary Khamis method at the basic heading lovel in the bilateral case and suggests:

(a) how individual commodities should be sampled within basic headings;

(b) an alternative to existing methods for combining the selected price ratios to determine basic heading price relativities.

There are resource and time constraints to the numbers of items which can be selected for pricing within any one basic heading. The method of choosing the items to represent a basic heading and the manner of combining the prices of these items to estimate a price relativity between two countries are interdependent.

2. Suppose there are two countries, 0 and 1 , and that within the basic heading being considered there are $n$ commodities; the prices and quantities of commodity $i$ are denoted by $p_{j 0}$ and $a_{j o}$ in country 0 and $p_{i j}$ and $q_{i}$ in country 1 . The Geary Khamis purchasing power parity ${ }_{P P P}$, of country 1 relative to country 0 , is denoted $R_{9}$, and the international prices determined simultaneously with $R_{1}$ are denoted $\pi_{i}$. Without loss of generality, country 0 's currency is taken as the numeraire currency in which international prices are denominated.

It has been soen that

$$
R_{1}=\frac{\sum \frac{p_{i 1} a_{i 0} a_{i 1}}{a_{i 0}+a_{i 1}}}{\sum \frac{p_{i 0} a_{i 0} a_{i 1}}{a_{i 0}+a_{i 1}}}
$$


3. The sampling problems associated with the estimation of the expression for $R_{1}$ are now considered. When the collection of information is restricted to sample of commodities, the following problems have to be considered:

(a) how should tho sample bo drawn?

(b) what estimator should be used to determine the expression for $R_{1}$ ?

It is assumed hero, to begin with, that the quantities $a_{j 0}$ and $a_{i l}$ of the items in both countries are known. The unknowns, which are observed for the sample of commodities, are the prices $p_{j 0}$ and $p_{i j}$. In formulating the problem, country 1 has been taken arbitrarily as the numerator counery and country 0 as the denominator. But the ordering of the two countries is arbitrary: and it seems a reasonable first condition to impose on the technique to be derived that it should satisfy the country reversal test; that is, the resulting price relativities should be independent of which country is used as the base country. Thus, if we want to find $P^{P P P},{ }_{1}$ then we require the sampling and estimating techniques to be such that we have the same rules for drawing the samplo of items as we would have in ostimating, ${ }^{P P P} 0$. Further, we require that the estimate of PPP, should be the reciprocal of ${ }_{1} P P_{0}$. If this criterion is acceptod, then it has implications for the approach to estimating the expression for $R_{1}$, which is in the form of a ratio.

Now, if $t$ is an unbiased estimator of a quantity $r$; that is,

$$
E[t]=\tau
$$

then, in general, it will not be true that $1 / t$ is unbiased for $1 / x$. That is,

$$
E\left[t^{-1}\right] \neq 1 / \tau
$$

This suggests that if we look for an estimator which is an unbiased estimator of the ratio in the expression for $R_{1}$, we will be breaking the principle of country reversal - since the reciprocal of the estimator will not bo unbiased for the reciprocal of the expression.

This in turn suggests that rather than looking for an unbiased estimator of the ratio, we should look for a technique which will give, in some sense, equally good estimates of the numerator and denominator in the oxpression. In other words, in order to socure the country reversal principle, we should consider the problem of estimating tho expressions:

$$
\sum \frac{q_{i 0} q_{i 1} p_{i 1}}{q_{i 0}+q_{i 1}} \text { and } \sum \frac{a_{i 0} q_{i 1} p_{i 0}}{q_{i 0}+q_{i 1}}
$$

soparately.

4. Consider then, the problem of estimating the quantity 


$$
\sum \frac{a_{i 0} a_{i 1} p_{i j}}{a_{i 0}+a_{i 1}}
$$

For simplicity, consider first of all the case in which wo draw a sample of a single commodity, selecting commodity i with probability $\tau_{j}$, and, having established the prico of the commodity $p_{i l}$, we take as the estimate of [2] the quantity $w_{i} p_{i l}$, whore the $w_{i}$ aro weights to be determined.

How should the probabilities, ${ }^{q} i$ and the weights $w_{i}$ be determined to give a "good" estimate of [2]?

The problem can be approached as follows:

$$
E[w p]=\sum w_{i} p_{i}{ }^{\tau} i
$$

For the estimator to be an unbiased estimator of expression [2], ther ofore, the equality

$$
\sum w_{i} p_{i j} \tau_{i}=\sum \frac{q_{i 0} q_{i 1} p_{i 1}}{q_{i 0}+q_{i 1}}
$$

must hold for all possible $p_{j l}$.

This implies that, for unbiasedness, the $w_{i}$ and $\tau_{i}$, should satisfy the relationship

$$
w_{i} r_{i}-\frac{q_{i 0} q_{i 1}}{q_{i 0}+q_{i 1}} \quad \text { for all } i
$$

Now consider the variance of the estimator wp :

$$
\begin{aligned}
v[w p] & =\sum w_{i}^{2} p_{i 1}{ }^{2} q_{i}-(E[w p])^{2} \\
& =\sum \frac{\left(a_{i 0} a_{i 1}\right)^{2} p_{i 1}{ }^{2}}{\left(a_{i 0}+q_{i l}\right)^{2} \tau_{i}}-E^{2}
\end{aligned}
$$

on using the relationship [3] to remove $w_{i}$ from the expression.

Expression [4] for the variance of the estimator wp would be minimised if we were able to take the $r_{i}$, the probability of selocting commodity $i$, as proportional to

$$
\frac{q_{i 0} q_{i 1} p_{i 1}}{\left(q_{i 0}+q_{i 1}\right)}
$$


We cannot of course achieve this as the $\left\{p_{i 1}\right\}^{\prime}$ 's are unknown in advance. However, if the $\left\{p_{i}\right\}$ 's aro relatively constant, in the sense that they do not vary greatly between different items within the basic heading. then we would expect to achieve an efficient estimator, that is, one with a small sample variance, if we took $r_{i}$ proportional to

$$
\frac{a_{i 0} a_{i 1}}{\left(a_{i 0}+a_{i 1}\right)}
$$

In this case, it is easy to determine what the weights $w_{i}$ should be: Since, from equation [3],

$$
w_{i} r_{i}=\frac{a_{i 0} a_{i 1}}{\left(q_{i 0}+q_{i j}\right)}
$$

the weights must be $w_{i}=1$, for all $i$.

To summarise, the suggested procedure would be,

(a) select commodity at random, with selection probability proportional to

$$
\frac{q_{i 0} a_{i 1}}{\left(a_{i 0}+q_{i 1}\right)}
$$

(b) take as the estimator of the numerator of the expression in equation [1] the observed price of the selected commodity $P_{i}$. Correspondingly, the estimator of the denominator is $\mathrm{P}_{10}$.

The above argument has been devoloped in the simplest case, dealing with a sample of size one. When dealing with larger samples, the expression for the variance of the estimator, [4] above, becomes more complicated and will depend on the particular sampling scheme used, not just on the probabilities ${ }^{i} j$.

But similar principles apply, and this suggests that a reasonable approach when dealing with a sample sizo of $n$ could be as follows.:

(a') select commodities with probabilities proportional to

$$
\frac{a_{i 0} q_{i 1}}{\left(a_{i 0}+q_{i 1}\right)}
$$

$\left(b^{\prime}\right)$ estimate the numerator and denominator of $[1]$ by $\sum p_{j}$ and $\Sigma p_{j o}$ respectively. That is, the estimator of $R_{1}$ based on the sample is

$$
R_{1}-\frac{\Sigma p_{i 1}}{\sum p_{i 0}}
$$


5. This approach cortainly has some intuitive appeal. Both the sample selection stage and the form of the estimator are symmetric between country 0 and col itry 1 , so the desirable property of country reversal is achieved. Moreover, since the sample selection probabilitios are proportional to

$$
\frac{a_{i 0} a_{i l}}{\left(a_{i 0}+a_{i l}\right)}
$$

it can be seen that an item which has high volumes in both countries has a high probability of being selected in the sample; an item which has a low volume in either country has a reduced probability; and a commodity which does not appear in one or other country has zero probability. These features appear emminently. reasonable. However, further consideration suggests that the above approach has the following two basic weaknesses:

(a) the term

$$
\frac{a_{i 0} a_{i 1}}{\left(a_{i 0}+q_{i 1}\right)}
$$

is denominated in the unit in which the quantity of commodity $i$ happens to bo measured. In other words, if commodity i happens to be measured in tons, then the scale of the term is measured in

$$
\frac{\text { tons }^{2}}{\text { tons }}=\text { tons }
$$

If the unit of measurement is then changed, for example to kilos, the value of the above term will change, and hence the probability of selecting commodity i in the sample.

Since, even within a basic heading, there need be no common unit for measuring the quantities of all tho commodities involved, this means that the sampling scheme will vary depending on the arbitrary units for measuring quantities which happen to have been chosen.

(b) The second problem with the approach is that, in selecting a particular sampling scheme to reduce the variance of the estimator. (equation [4]), wo make the assumption that the prices $\left\{p_{i j}\right\}$ did not vary greatly botween different commodities within this basic heading. But prices themselves are a function of the arbitrary unit of volume which is boing used. For example, if we change from expressing the quantity of a given commodity from units of tons to kilos, we will reduce the price per unit of volume by a factor of 1000 . But since the choice of units for measuring the volumes of different commodities is essentially arbitrary, the assumption of relatively constant prices is certainly untenable. It has to be considered therefore, whether the procedure outlined above can be modified to overcome both of these difficulties. 
6. We approach the problem by going back to the basic expression for the solution of the bilatoral Geary Khamis PPPs. and expressing the formula in a more general form. The original formula is

$$
R_{1}=\frac{\sum \frac{a_{i 0} a_{i 1} p_{i 1}}{\left(a_{i 0}+a_{i 1}\right)}}{\sum \frac{q_{i 0} q_{i 1} p_{i 0}}{\left(a_{i 0}+q_{i 1}\right)}}
$$

Suppose that we take a set $k_{j}$ of arbitrary non zero constants; then we can rewrite the expression for $R_{1}$ in the following identically equivalent form, on noting that the $k_{i}$ terms cancel out.

$$
R_{1}=\frac{\sum\left(\frac{\left(k_{i a_{i 0}}\right)\left(k_{i 1} a_{i 1}\right)}{k_{i}\left(a_{i 0}+a_{i 1}\right)} \cdot \frac{p_{i 1}}{k_{i}}\right)}{\sum\left(\frac{\left(k_{i} a_{i 0}\right)\left(k_{i 1} a_{i 1}\right)}{k_{i}\left(a_{i 0}+a_{i 1}\right)} \cdot \frac{p_{i 0}}{k_{i}}\right)}
$$

To overcome problem (5a) above, we want to be able to choose $k_{j}$ in such a way that $k_{i}$ varies inversely with $q_{i}$ and $q_{i 0}$, if the units in which the quantities are expressed are altered. Po overcome problem (5b), we would like the quantities $\left(p_{j} / k_{j}\right)$, and $\left(p_{i o} / k_{j}\right)$ to be relatively stable; and, in particular, to be invariant under changes in the units in which we measure the quantities of goods. Finally, to retain country reversal, we require the definition of $k_{i}$ to be in some sense symmetric between country 0 and country 1 .

One possible way of defining the $k_{i}$ to satisfy these properties would be to take

$$
\begin{array}{r}
k_{i}-1 / 2\left(p_{i 0}+a p_{j 1}\right) \\
\text { whero } \alpha \text { is an arbitrary constant. }
\end{array}
$$

It can readily be checked that the first two properties above are satisfied, as follows.

First of all, if there is a change in the unit in which commodity $i$ is denominated, then there will be a corresponding reciprocal change in the prices $p_{i 0}$ and $p_{j l}$, so that the quantities

$$
1 / 2\left(p_{i 0}+a p_{i 1}\right) q_{i 0}, 1 / 2\left(p_{i 0}+a p_{i 1}\right) q_{i 1}
$$

will be invariant. 
Similarly, the quantities.

$$
\frac{p_{i 1}}{1 / 2\left(p_{i 0}+a p_{i 1}\right)} \text { and } \frac{p_{i 0}}{1 / 2\left(p_{i 0}+a p_{i 1}\right)}
$$

aro invariant under changes in the unit in which the volumes are measured.

We would also expect these latter quantities to be relatively stable: certainly a good deal more stable than the original $\left\{p_{10}\right\}$ 's and $\left\{p_{i 1}\right\}^{\prime}$ 's.

7. An argument analogous to that used in paragraph [4], therefore, applied to equation [1\%], suggests that we might approach the problem of Geary Khamis estimation in the following way:

(a) select a sample of commodities with probabilitios proportional to

$$
\frac{\left(k_{i j} a_{i 0}\right)\left(k_{i} a_{i j}\right)}{k_{i}\left(a_{i 0}+a_{i j}\right)}
$$

where $k_{i}-1 / 2\left(p_{i 0}+a p_{i l}\right)$

and $a$ is a constant, yet to be determined.

(b) take as the estimator of the PPP, the expression

$$
R_{1}=\frac{\sum\left(\frac{p_{i 1}}{1 / 2\left(p_{i 0}+a p_{i 1}\right)}\right)}{\sum\left(\frac{p_{i 0}}{1 / 2\left(p_{i 0}+a p_{i 1}\right)}\right)}
$$

There are however two problems we need to solve before this becomes a practicable procedure. First of all, what value should we choose for the constant $a$ in the definition of the $k_{i}$, in equation [6].

Secondly, the sampling weights depend both on the quantities $a_{j o}$ and $q_{i 1}$ and the unknown $p r i c e s p_{i 0}$ and $p_{i 1}$. How can these weights $b_{e}$ estimated?

The following argument shows how one might be able to solve these problems if there were available an initial estimate of the price relativity between the two currencies; and of commodity level expenditures.

Suppose that a is an initial approximation to the price relativity between country 0 and country 1 for the basic heading being considered; and that to a first approximation 


$$
p_{\text {io }}-a p_{i l}
$$

for each commodity, then,

$$
1 / 2\left(p_{i 0}+a p_{i l}\right) q_{i 0} \div e_{i o}
$$

where $e_{i 0}$ is expenditure on commodity in country 0 , and

$$
1 / 2\left(p_{i 0}+a p_{i l}\right) q_{i 1} \div a e_{i l}
$$

where $e_{i 1}$ is expenditure on commodity i in country 1.

In this case the sampling weights at (a) above aro approximately

$$
\frac{e_{i 0}{ }^{\sigma \theta_{i 1}}}{\left(e_{i 0}+\Delta e_{i 1}\right)}
$$

Equivalently, since the constant a in the numerator does not affect the relative proportions of these weights, we would sample commodities with probability proportional to

$$
\frac{e_{i 0} e_{i 1}}{\left(e_{i 0}+a e_{i l}\right)}
$$

8. We have thus arrived at the following suggested procedure for estimating the Geary Khamis PPP. Suppose we have an initial estimate a of the country 0 to country 1 price relativity, and estimates $e_{j}$ and $e_{i l}$ of the expenditures of the commodities in the two countries. (a) one should select commodities with probabilities proportional to

$$
\frac{e_{i 0^{0}} i l}{\left(e_{i 0}+o e_{i 1}\right)}
$$

(b) the estimate of ${ }_{1} P P_{0}$ should be taken as

$$
R_{1}=\frac{\sum\left(\frac{p_{i 1}}{1 / 2\left(p_{i 0}+a p_{i 1}\right)}\right)}{\sum\left(\frac{p_{i 0}}{1 / 2\left(p_{i 0}+a p_{i 1}\right)}\right)}
$$

As has been seen from the discussion in paragraph [6] above, both the sampling weights and the estimator are invariant under arbitrary changes in the units in which individual items aro measured.

Further, it is readily seen that the above procedure also satisfies the country reversal test, both as regards the determination of sampling weights, and the form of the estimator $R_{g}$. 
9. The procedure outlined in paragraph [7] depends on the availability of initial, but possibly crude, estimates of the price relativity $a$, and of the expenditures on the individual items. In general some initial estimate of a will be available; for want of any more rofined information we could take as an estimate of a the market exchange rate between the two currencies. If, however, some initial information is availablo on prices at item level, then a could be estimated directly from this.

The availability of estimates of expenditures at item level is likely to be much more problematical. However, in many cases, estimates will be available which will bo tantamount to rough estimates of expenditure share. For example, if a classification of items into characteristic and non characteristic items has been attempted, this is likely to be based on some crude assessment of the overall expenditure shares of individual items - even if this only takes the form of an intuitive assessment of whether the expenditure share of individual items falls above or below some particular threshhold. Such crude estimates of broad shares of expenditure, together with the avajlable data on total expenditure at basic heading level, can be converted into rough estimates of item level expenditures, which can then be utilised in the above technique.

Note that the condition in equation [7] means that the price structure within the basic heading has to be approximately multiplicative: (recall that the concept of multiplicativity was defined in chapter 1 , soction 4). Wo have not investigated how efficiently the sampling scheme suggested in this appendix performs when the price structure is very far. from boing multiplicativo: but it is likely that its performance would be robust for moderate departures from multiplicativity. 


\section{References}

1. Geary, R.C. A Noto on Comparisons of Exchange Rates and Purchasing Power Betweon Countries. Journal of the Royal Statistical Socioty, 1958, Sories A 121, pp 87-99.

2. Khamis, S.H. "A New System of Index Numbers for National and International Purposes." Journal of the Royal Statistical Society, 1972 Series A 135, pp 96-121.

3. Fisher, I. "The Making of Index Numbers", 1922, Boston, Houghton Mifflin.

4. Eltetö, O. and Köves, P. On a Problem of Index Number Computation Relating to International Comparison. Statisztikai Szemple, 1964 pp 507-518.

5. Szulc. B. Indices for Multiregional Comparisons, Przeglad Statystyczny, 1964 pp 239-254.

6. Drechsler, L. Regionalisation of the ICP and its consequences, Presented at the Expert Group on ICP Methodology, Luxembourg June 1988.

7. Kravis, Kenessey, Heston and Summers, A System of International Comparisons of Cross Product and Purchasing Power, 1975, Baltimore : The John Hopkins University Press.

8. Kravis, Heston, Summers, World Product and Income, International Comparisons of Real Gross Product, 1982, John Hopkins University Press.

9. Gerardi, G. for example, see "Selected Problems of Inter Country Comparisons on the Basis of the Experience of the EEC, Dec. 1982, Review of Income and Wealth.

10. "Comparison in Real Values of the Aggregates of ESA, 1980" 1983, Eurostat.

11. Hill, P. Multilateral Measurements of Purchasing Power and Real GDP, Office for Official Publications of the European Communities, 1982 . 


\title{
BCONOHICS AND STATISTICS DEPARTMENT \\ VORKING PAPERS
}

\author{
$\star \star$ \\ DEPARTBKIRNT DES AFFAIRES BCONOMIQUBS BT STATISTIQUES \\ DOCUMENTS DE TRAVAIL
}

\begin{abstract}
$\star \star x$
In April 1983, the Economics and Statistics Department initiated a new series of economic studies entitled ESD Working Papers.
\end{abstract}

The following titles have been circulated:

1. Use of Demand Elasticities in Estimating Energy Demand (out of print) Utilisation des Elasticités de la Demande dans l'Estimation de la Demande de l'Energie

Axel Mittelstadt

2. Capital, Energy and Labour Substitution: the supply block in OECD medium-term models

Substitution du Capital, de l'Energie et du Travail : le bloc de l'offre dans les modèls à moyen terme de l'OCDE (épuisé)

Patrick Artus

3. Wage Formation in France: sectoral aspects (out of print)

Formation des Salaires en France : aspects sectoriels

Patrick Artus

4. Service Lives of Fixed Assets (out of print)

Durée de Vie Utile des Actifs Fixes

Derek Blades

5. Resource Prices and Macroeconomic Policies: Lessons from Two 0il Price Shocks

Prix des Ressources Naturelles et Politique Macro-Economique : Les Enseignements de Deux Chocs Pétroliers (épuisé)

John Llewellyn

6. Output Responsiveness and Inflation: An Aggregate Study

Souplesse de la Production et Inflation : Etude Globale

David T, Coe and Gerald Hol tham

7. The Determinants of Exchange Rate Movements (out of print)

Les Déterminants des Mouvements des Taux de Change (épuisé)

Graham Hacche 
8. Simulated Macroeconomic Effects of a Large Fall in 0il Prices (out of print)

Simulation des Effets Macro-économiques d'une Forte Baisse des Prix Pétroliers

Flemming Larsen and John Llewellyn

9. Medium-Term Financial Strategy: The Co-ordination of Fiscal Monetary Policy (out of print)

Stratégie Financière à Moyen Terme : la Coordination des Politiques Monétaire et Budgétaire (épuisé)

Jean-Claude Chouraqui and Robert Price

10. Price Dynamics and Industrial Structure: A Theoretical and Econometric Analysis

Dynamique des Prix et Structure Industrielle : Une analyse théorique économétrique (épuisé)

David Encaoua (with collaboration from Paul Geroski and Riel Miller

11. Evidence on Income Distribution by Governments (out of print)

L'Action Exercée par l'Etat sur la Redistribution du Revenu

Peter Saunders

12. Labour Force Participation: An Analysis vith Projections

Taux d'Activité : Analyse et Projections

James H. Chan-Lee

13. The Demand for Money and Velocity in Major OECD Countries (out of print)

La Demande de Monnaie et la Vitesse de Circulation dans les Grands Pays de l'OCDE

A. Blundell-Wignall, M. Rondoni and H. Ziegelschmidt

14. The Conduct of Monetary Policy in the Current Recovery

La Conduite de la Politique Monétaire dans la Phase Actuelle de Reprise Economique

Paul Atkinson and Jean-Claude Chouraqui

15. Structural Budget Deficits and Fiscal Stance

Déficits Budgétaires Structurels et orientation de la Politique Budgétaire

Patrice Muller and Robert W.R. Price

16. Monetary Policy in the OECD Interlink Model

La Politique Monétaire dans le Modèle Interlink

A. Blundell-Wignall, M. Rondoni, H. Ziegelschmidt and J. Morgan 
17. Real Gross Product in OECD Countries and Associated Purchasing Power Parities (out of print)

Produit Brut Réel et Parités de Pouvoir d'Achat dans les pays de l'OCDE (épuisé)

Peter Hill

18. The OECD Compatible Trade and Production Data Base (out of print) Base de Données Compatibles sur le Commerce et la Production de l'OCDE

Derek. Blades and Wendy Simpson

19. Noxinal Wage Determination in Ten OECD Economies

Détermination des Salaires Nominaux dans Dix Economies de l'OCDE

Darid T. Coe and Francesco Gagliardi

20. Profits and Rates of Return in OECD Countries

Profits et Taux de Rendement dans les Pays Membres de 1'OCDE

James H. Chan-Lee and Helen Sutch

21. Real Interest Rates and the Prospects for Durable Growth

Taux d'Intérêt Réels et Perspectives de Croissance Durable

Paul Atkinson and Jean-Claude Chouraqui

22. Energy Prices: Trends and Prospects

Les Prix de l'Energie : Evolution et Perspectives

Axel Mittelstadt

23. Changes in the Composition of Output and Employment

Changements dans la Composition de la Production et de l'Emploi

Axel Mittelstadt and Françoise Correia

24. Labour Market Flexibility and External Price Shocks

Flexibilité du Marché du Travail et Chocs Extérieurs sur les Prix

F. Rlau and A. Mittelstadt

25. Discrepancies Between Imports and Exports in OECD Foreign Trade Statistics (out of print)

Ecart entre les Importations et les Exportations dans les Statistiques du Commerce Extérieur de l'OCDE

Derek Blades and Marina Ivanov

26. Aggregate Supply in Interlink: Model Specification and Empirical Results

John Helliwell, Peter Sturm, Peter Jarrett and Gérard Salou

27. Commodity Prices in Interlink

Gerry Holtham, Tapio Saavalainen, Paul Saunders and Helen Sutch 
28. Exchange Rates and Real Long-Term. Interest Rate Differentials: Evidence for Eighteen OECD Countries

David T. Coe and Stephen S. Golub

29. Method of Calculating Effective Exchange Rates and Indicators of Competitiveness

Martine Durand

30. Public Debt in a Medium-Term Context and its Implications for Fiscal Policy

Jean-Claude Chouraqui, Brian Jones and Robert Bruce Montador

31. The OECD Compatible Trade and Production Data Base 1970-1983

Anders Brodin and Derek Blades

32. The Formulation of Monetary Policy: A Reassessment in the Light of Recent Experience

Paul Atkinson and Jean-Claude Chouraqui

33. Mécanismes de Transmission et Effets Macro-Economiques de la Politique Monétaire en France : les Principaux Enseignements Econométriques

Marc-0livier Strauss-Kahn

34. Pure Profit Rates and Tobin's $q$ in Nine OECD Countries

James H. Chan-Lee

35. Wealth and Inflation Effects in the Aggregate Consumption Function

G.H. Hol tham and H. Kato

36. The Government Household Transfer Data Base

Rita Varley

37. Internationalisation of Financial Markets: Some Implications for Macroeconomic Policy and for the Allocation of Capital

Mitsuhiro Fukao and Masaharu Hanazaki

38. Tracking the US External Deficit, 1980-1985: Experience with the OECD Interlink Model

Pete Richardson

39. Monetary Policy in the Second Half of the 1980s: How Much Room For Manoeuvre?

Kevin Clinton and Jean-Claude Chouraqui 
40. Tax Reform in OECD Countries: Economic Rationale and Consequences Bob Hagemann, Brian Jones and Bruce Montador

41. A Revised Supply Block for the Major Seven Countries in Interlink Peter Jarrett and Raymond Torres

42. OECD Economic Activity and Non-0il Commodity Prices: Reduced-Form Equations for INTERLINK

Gerald Hol tham and Martine Durand

43. Import and Export Price Equations for Manufactures

Richard Herd

44. Price Determination in the Major Seven Country Models in INTERLINK Ulrich Stiehler

45. International Investment-Income Determination in INTERLINK: Models for 23 OECD Countries and S1x Non-OECD Regions

Darid T. Coe, Richard Herd and Marie-Christine Bonnefous

46. Recent Developments in OECD's International Macroeconomic Model Pete Richardson

47. A Review of the Simulation Properties of OECD's INTERLINK Model Pete Richardson

48. The Medium-Term Macro-Economic Strategy Revisited Jean-Claude Chouraqui, Kevin Clinton and Robert Bruce Montador

49. Are Commodity Prices Leading Indicators of OECD Prices? Martine Durand, Sveinbjörn Blöndal

50. Private Consumption, Inflation and the "Debt Neutrality Hypothesis" The case of Eight OECD Countries

Giuseppe Nicoletti

51. The Effects of Monetary Policy on the Real Sector: An overview of Expirical Evidence for Selected OECD Economies Jean-Claude Chouraqui, Michael Driscoll and Marc Olivier Strauss-Kahn

52. The So-Called "Non-Economic" Objectives of Agricultural Policy L. Alan Winters 
53. Alternative Solution Methods in Applied General Equilibrium Analysis

Richard G. Harris

54. Tests of Total Factor Productivity Measurement

A. Steven Englander

55. Quantifying the Economy-Vide Effects of Agricultural Policies: A General Equilibrium Approach

Jean-Marc Burniaux, François Delorme, Ian Lienert, John P. Martin and Peter Hoeller 